Florida International University FIU Digital Commons

FIU Electronic Theses and Dissertations

University Graduate School

12-7-1999

\title{
Development of rear-end collision avoidance in automobiles
}

Uttamkumar Dravidam

Florida International University

DOI: $10.25148 /$ etd.FI15101226

Follow this and additional works at: https://digitalcommons.fiu.edu/etd

Part of the Computer-Aided Engineering and Design Commons

\section{Recommended Citation}

Dravidam, Uttamkumar, "Development of rear-end collision avoidance in automobiles" (1999). FIU Electronic Theses and Dissertations. 3084.

https://digitalcommons.fiu.edu/etd/3084

This work is brought to you for free and open access by the University Graduate School at FIU Digital Commons. It has been accepted for inclusion in FIU Electronic Theses and Dissertations by an authorized administrator of FIU Digital Commons. For more information, please contact dcc@fiu.edu. 


\section{FLORIDA INTERNATIONAL UNIVERSITY}

Miami, Florida

DEVELOPMENT OF REAR-END COLLISION AVOIDANCE IN AUTOMOBILES

A thesis submitted in partial fulfillment of the

requirements for the degree of

MASTER OF SCIENCE

in

MECHANICAL ENGINEERING

by

Uttamkumar Dravidam 
To: Dean. Gordon R. Hopkins

College of Engineering

This thesis, written by Uttamkumar Dravidam, and entitled Development of Rear-End Collision Avoidance in Automobiles, having been approved in respect to style and intellectual content, is referred to you for judgment.

We have read this thesis and recommend that it be approved.

Diana Rincon

Ibrahim N.Tansel

Sabri Tosunoglu Major Professor

Date of Defense: December 07, 1999

The thesis of Uttamkumar Dravidam is approved.

Dean Gordon R. Hopkins

College of Engineering

Dean Richard L. Campbell Division of Graduate Studies

Florida International University, 1999 


\section{DEDICATION}

I dedicate this thesis to my parents who have been patiently waiting for this piece of work, and who have always been encouraging and supporting me. Without their support, this thesis would not have been written at all. 


\section{ACKNOWLEDGMENTS}

I would like to thank my major professor Sabri Tosunoglu for his advice, support and guidance during my years at FIU. I feel privileged to have earned my two years of degrees under his tutelage. Next, I would like to mention how lucky I feel for having been part of the Robotics and Automation Laboratory. Not only was the research conducted in this lab exciting and challenging, but the members of the lab have made my stay very enjoyable. To all I would like to thank for having to put up with me for so long. To those who were in the lab when I came in: Ray Reyes, Miguel Espina, Pat Batsomboon and Haritha Adumilli. I would like to thank for their guidance and support. I would to thank my friends Samata Chari and Bangalore Guru for their support and guidance in my Java simulation program. I am grateful to my friends Madhusudan Reddy, Prashant Jawalikar, Prachi Jawalikar, Bharath Vembu who have in some way contributed to the success of this work.

At last but not least, I would like to thank my parents for their love and for having believed in me even when I didn't. 


\title{
ABSTRACT OF THE THESIS
}

\section{DEVELOPMENT OF REAR-END COLLISION AVOIDANCE}

\section{IN AUTOMOBILES}

by

\author{
Uttamkumar Dravidam
}

Florida International University, 1999

Miami, Florida

Professor Sabri Tosunoglu, Major Professor

The goal of this work is to develop a Rear-End Collision Avoidance System for automobiles. In order to develop the Rear-end Collision Avoidance System, it is stated that the most important difference from the old practice is the fact that new design approach attempts to completely avoid collision instead of minimizing the damage by over-designing cars. Rear-end collisions are the third highest cause of multiple vehicle fatalities in the U.S. Their cause seems to be a result of poor driver awareness and communication. For example, car brake lights illuminate exactly the same whether the car is slowing, stopping or the driver is simply resting his foot on the pedal. In the development of Rear-End Collision Avoidance System (RECAS), a thorough review of hardware, software, driver/human factors, and current rear-end collision avoidance systems are included. Key sensor technologies are identified and reviewed in an attempt to ease the design effort. The characteristics and capabilites of alternative and emerging sensor technologies are also described and their performance compared. In designing a RECAS, the first component is to monitor the distance and speed of the car ahead. If an unsafe condition is detected a warning is 
issued and the vehicle is decelerated (if necessary). The second component in the design effort utilizes the illumination of independent segments of brake lights corresponding to the stopping condition of the car. This communicates the stopping intensity to the following driver. The RECAS is designed the using the LabVIEW software. The simulation is designed to meet several criteria: System warnings should result in a minimum load on driver attention, and the system should also perform well in a variety of driving conditions.

In order to illustrate and test the proposed RECAS methods, a Java program has been developed. This simulation animates a multi-car, multi-lane highway environment where car speeds are assigned randomly, and the proposed RECAS approaches demonstrate rear-end collision avoidance successfully. The Java simulation is an applet, which is easily accessible through the World Wide Web and also can be tested for different angles of the sensor. 


\section{TABLE OF CONTENTS}

\section{CHAPTER}

1. INTRODUCTION.

1.1 Overview $\ldots$

1.2 General Idea of Collision Avoidance System. ..........................................

1.3 Criteria for Activation of Collision Avoidance System ............................... 4

1.4 Collision Avoidance Maneuvers...................................................... 5

1.5 Types of Collision Avoidance Systems .............................................6

1.5.1 Rear-End Collision Avoidance................................................6 6

1.5.2 Road Departure Collision Avoidance System...................................8

1.5.3 Lane Change/Merge Collision Avoidance System.................................8

1.5.4 Intersection Collision Avoidance System....................................... 7

1.5.5 Vision Enhancement for Crash Avoidance................................... 10

1.5.6 Vision Enhancement Process................................................ 11

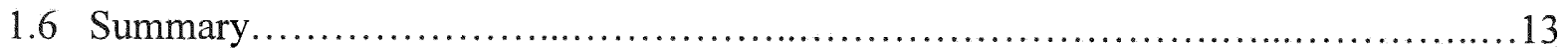

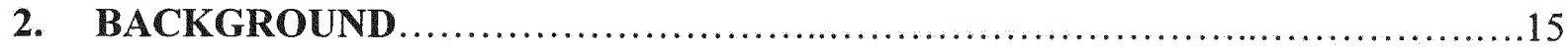

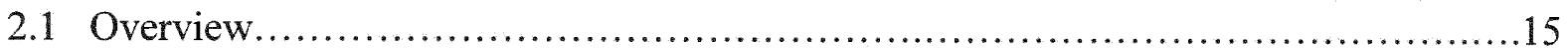

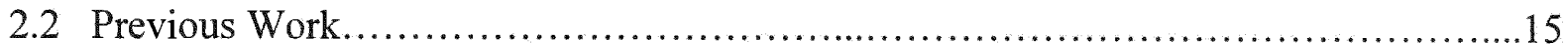

2.3 Rear -End Collision Avoidance System Outline.................................... 16

2.4 A Previous Model of Rear-End Crash Avoidance........................................ 17

2.5 Research on Collision Avoidance System............................................ 19

2.5.1 Delco Electronics......................................................... 19

2.5.1.1 Forewarn Forward Looking System....................................20

2.5.1.2 Forewarn Side Detection System.....................................22

2.5.1.3 Forewarn Back-up Aid System.........................................23

2.5.2 Mazda Motor Corporation................................................26

2.5.3 Mitsubishi, Nissan, Hino................................................. 27

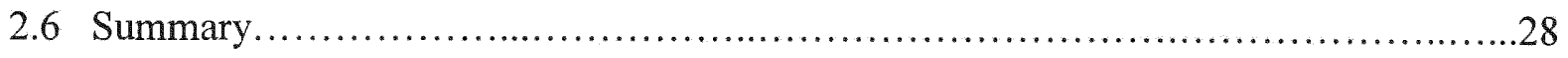

3. ANALYSIS OF REAR-END COLLISION AVOIDANCE SYSTEM..............29

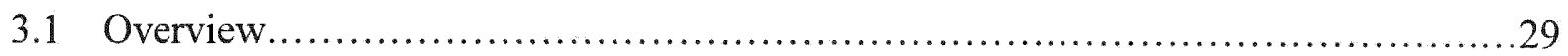

3.2 Types of Rear-End Crashes....................................................... 29

3.3 Behavioral and Perceptual Aspects of Rear-End Crashes.............................. 30

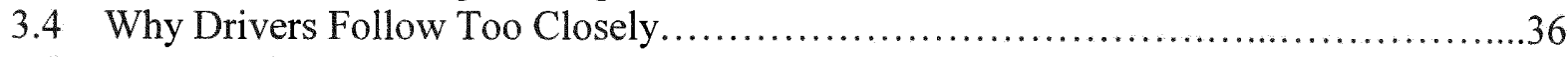

3.5 Perceptual Factors in Rear-End Crashes............................................. 37

3.6 Driver Perception/Decision/Reaction Time....................................... 38

3.7 Relative Velocity Cues........................................................ 41

3.8 Display Factors in Rear-End Crash Systems...................................... 42

3.8.1 False/Nuisance Alarms and Warning Frequency............................42

3.8.2 Likelihood Alarm Displays................................................44

3.8.3 Display Modalities...................................................... 45

3.8.4 Auditory Display Considerations.................................... 45 
3.8.5 Tactile Display Research..............................................48

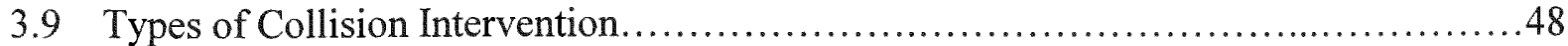

3.9.1 Driver Action Systems........................................................ 49

3.9.2 Headway Maintenance Systems........................................... 49

3.9.3 Manual Operation Subsystem..............................................50

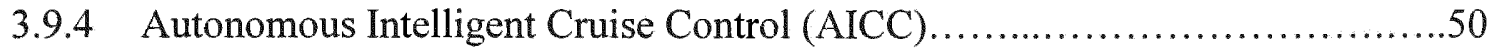

3.9.5 Cooperative Intelligent Cruise Control (CICC) ............................5 50

3.9.6 Automatic Control Systems.............................................. 50

3.10 Candidate Variables for Elimination................................................ 50

3.10.1 System Factors................................................................. 50

3.10 .2 Graded Warning Levels...................................................51

3.10.3 Sensory Modes of Presentation............................................51

3.10 .4 Environmental Factors................................................... 52

3.10 .5 Human and Behavioral Factors.......................................... 54

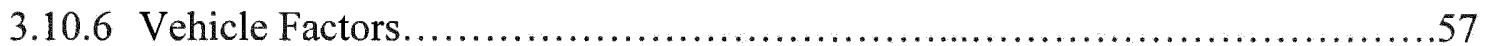

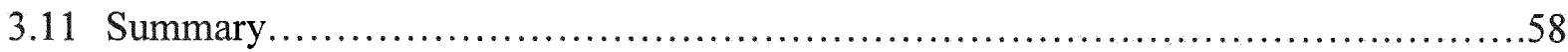

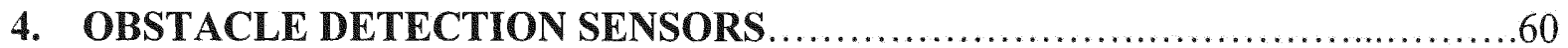

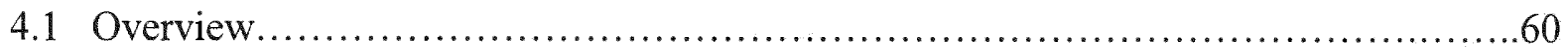

4.2 Sensors Technology in RECAS ..................................................... 60

4.3 Sensor Activation Distance Model..................................................62

4.4 Purpose of Sensor Technology ..................................................63

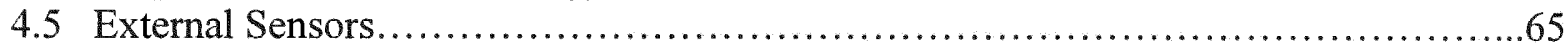

4.5.1 Optical Techniques (Passive Infrared, Laser radar and Vision) .................66

4.5.2 Electromagnetic Techniques (FMCW Radar, Impulse radar and Capacitive) ...........................................................66

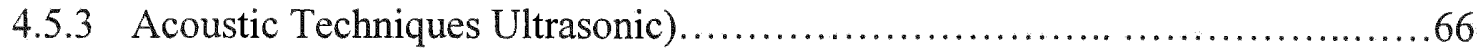

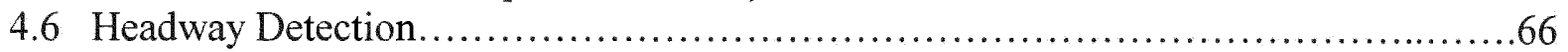

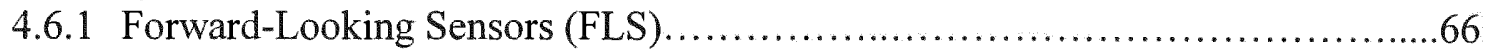

4.6.2 Radar-Based Sensors.....................................................67

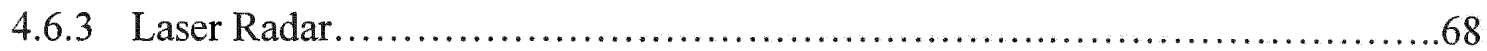

4.6.4 FMCW Radar................................................................ 70

4.6 .5 Impulse Radar............................................................ 71

4.6.6 Vision Based Sensors........................................................ 71

4.6.7 Ultrasonic Distance measuring Sensor..................................... 72

4.6.8 Passive Infrared Sensors...................................................... 73

4.6 .9 Capacitive Sensors.......................................................... 73

4.6.10 Vision System Sensors.................................................... 74

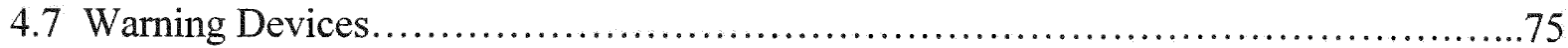

4.7.1 Visual Head-up Displays..................................................... 75

4.7.2 Audio/Voice Signals...................................................... 75

4.7.3 Haptic Devices............................................................. 75

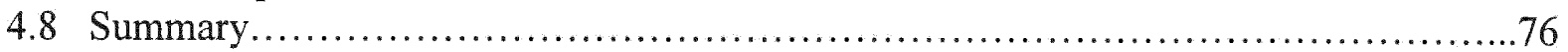


5. DESIGN OF REAR-END COLLISION AVOIDANCE SYSTEM $\ldots \ldots \ldots \ldots \ldots \ldots 78$

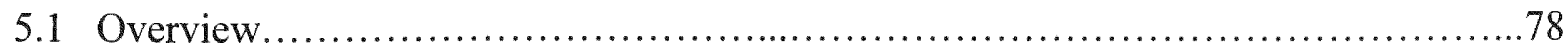

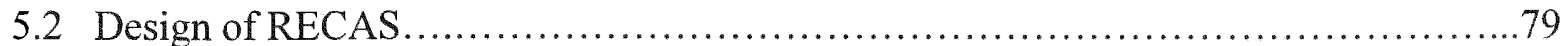

5.2 .1 Data Analysis.................................................................. 80

5.2.2 Determining Brake Pressure .............................................. 82

5.2 .3 Safe Following Distances................................................. 84

5.3 Developed Simulation of Brake Lights Using LabVIEW ............................. 85

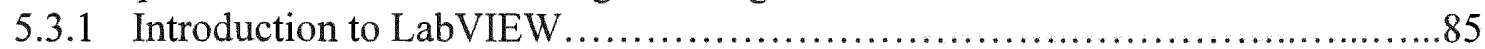

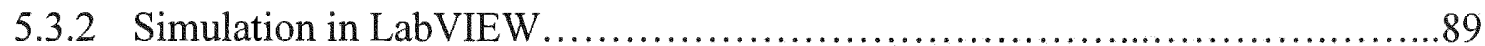

5.4 Simulating Rear-End Collision Concept Using Java...............................93

5.4.1 Design Goals of the Java Programming Language................................93

5.4.2 Simple, Object Oriented, and Familiar Environment............................ 95

5.4 .3 Robust and Secure Platform.................................................. 96

5.4.4 Neutral Architecture and Portable Features.................................... 97

5.4.5 High Performance.............................................................. 97

5.4.6 Interpreted, Threaded, and Dynamic Interpreter................................ 97

5.4.7 The Java Platform: A New Approach to Distributed Computing..................100

5.4 .8 Object Oriented Feature of Java.............................................. 100

5.4 .9 Object Oriented Programming in Java...................................... 100

5.4.10 Programming Using Object Oriented Technology in Java....................101

5.4.11 Java Programming Basics................................................. 103

5.4.11.1 Comments in Java Code............................................ 103

5.4 .11 .2 Defining a Class................................................... 103

5.4.11.3 Main Method.................................................... 104

5.4.11.4 Using Classes and Objects........................................... 104

5.4.11.5 Importing Classes and Packages......................................104

5.4.11.6 Defining an Applet Subclass ..........................................105

5.4.11.7 Implementing Applet Methods.......................................105

5.4 .11 .8 Running an Applet..................................................105

5.5 Development of Simulations.................................................. 107

5.5.1 Java Simulations Program Explanation................................... 108

5.5.2 Brake Lights Segmented Simulation Using JAVA..........................111

5.5.3 Java Simulations Program Explanation...................................114

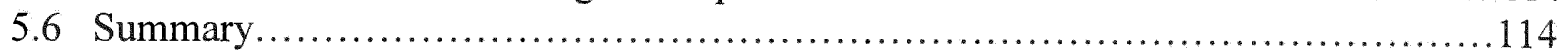

6. CONCLUSIONS, RECOMMENDATIONS, AND FUTURE WORK ...............116

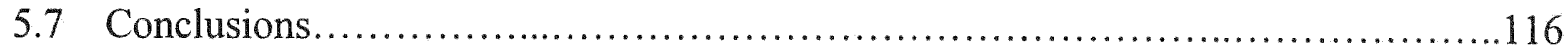

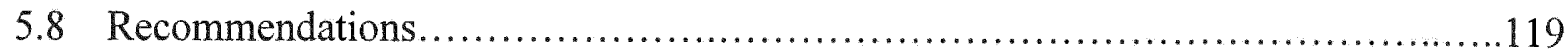

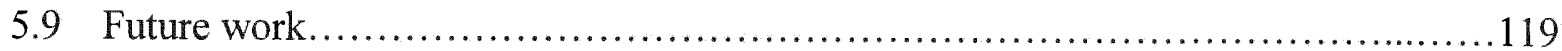

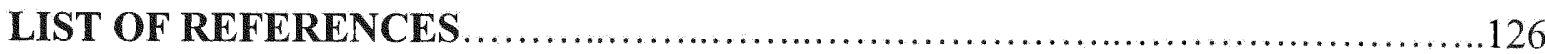

APPENDIX: SIMULATION COMPUTER PROGRAMS IN JAVA ..................138 


\section{LIST OF TABLES}

TABLE

PAGE

Table 1-1. Factors for Intersection Collisions by VAR ..................................

Table 2-1. Different Radars Used on Each car..................................25

Table 2-2. Japanese Commercial CAS Specifications...............................27

Table 3-1. Summary of In-vehicle Glance Times.......................................36

Table 3-2. Trade Study of Display Modalities.................................46

Table 3-3. False Alarm Rates.....................................................55

Table 4-1. Countermeasure Concepts and Applicable Sensor Technologies.............65

Table 4-2. Characteristics and Features of selected Automotive Radar Sensors........67

Table 4-3. Sensor Devices Measures of Performance.............................. 74

Table 5-1. Decelerations for Normal and Extreme Braking.........................81

Table 5-2. Estimated Decelerations for Normal and Extreme Braking................82

Table 5-3. Estimated Brake Pressures Required for Deceleration....................84

Table 5-4. Safe Following Distances.......................................... 85 


\section{LIST OF FIGURES}

FIGURE

PAGE

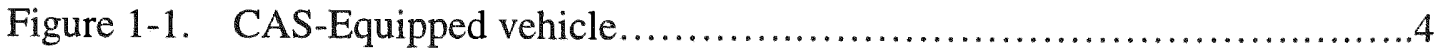

Figure 1-2. Causes of Rear-End Collisions (NHTSA) ..........................

Figure 2-1. Rear-End Collision Avoidance System Block Diagram.................17

Figure 2-2. Forewarn Forward Looking Systems by Delphi Automotive systems..21

Figure 2-3. Forewarn Side Detection System by Delphi Automotive systems.......23

Figure 2-4. Forewarn Back-up Aid System by Delphi Automotive systems........24

Figure 3.1. Model of visual sampling for in-vehicle tasks.....................32

Figure 3-2. Forward View vs. Attention.....................................

Figure 3-3. Glance Length to Forward View as a Function of Traffic type...........35

Figure 3-4. Mean In-Vehicle Glance Length as a Function of Age.................35

Figure 4-1. Stopping Distance Model.........................................66

Figure 4-2. Laser Radar Measurement System..................................69

Figure 4-3. Laser Beam................................................. 70

Figure 4-4. Ultrasonic Distance Sensors.....................................73

Figure 5-1. Speed vs. Time for Normal Deceleration............................80

Figure 5-2. Speed vs. Time for Extreme Deceleration...........................80

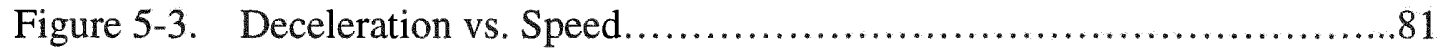

Figure 5-4. Free Body Diagram for Braking Wheel.......................... 82

Figure 5-5. LabVIEW Graphical Programming Language.........................86

Figure 5-6. Blank untitled front panels..................................... 87

Figure 5-7. Blank untitled Block Diagram................................... 88 
Figure 5-8. Front Panel when Deceleration is zero............................ 91

Figure 5-9. Front Panel when Deceleration is at 5.23ft/s2 $2 \ldots \ldots \ldots \ldots \ldots \ldots \ldots . . . \ldots 2$

Figure 5-10. Front Panel when Deceleration is maximum........................92

Figure 5-11. Wiring Diagram for Brake Lights............................. 93

Figure 5-12. A graphical representation of an object........................... 102

Figure 5-13. Simulation for input of Sensor Angle............................. 107

Figure 5-14. Sensor scans the proceeding vehicle..............................109

Figure 5-15. Demonstrates the auto braking system............................110

Figure 5-15. Practical Application Different sensors Mounted on the cars..........110

Figure 5-16. Simulation demonstrates for the Angle $180 \ldots \ldots \ldots \ldots \ldots \ldots \ldots \ldots 11$

Figure 5-17. Simulation of Segmented Brake Lights.........................112

Figure 5-18. Intensity Level of Stopping the Vehicle...........................113

Figure 5-18. When the Preceding Vehicle is Orange and Red sensor Range........114 


\section{ABBREVIATIONS}

$\mathrm{ACC}$

AICC

ASV

AVCS

BUA

CAS

CCD

CICC

FHWA

FLS

FMCW

GES

GPS

IVHS

LAD

LVM

LVS

NHTSA

PFM

PN

PRT

RECAS
Adaptive Cruise Control.

Autonomous Intelligent Cruise Control.

Advanced Safety Vehicle.

Automatic Vehicle Control System.

Back-up Aid Systems.

Collision Avoidance system.

Charged Coupled Device.

Cooperative Intelligent Cruise Control.

Federal Highway Administration.

Forward Looking Systems.

Frequency-modulated Continuous Wave.

General Estimates System.

Global Positioning System.

Intelligent Vehicle Highway Systems.

Likelihood Alarm Display.

Lead-Vehicle Moving.

Lead-Vehicle Stationary.

National Highway Traffic Safety Administration.

Pulsed Frequency Modulation.

Pseudonoise.

Perception Reaction Times.

Rear-End Collision Avoidance System. 
SDS Side Detection System.

TCAS Traffic-Collision Alerting System.

TTC Time-to-Collision.

VAR Veridian Accident Reconstructionists. 


\section{CHAPTER 1}

\section{INTRODUCTION}

\subsection{Overview}

A concern for the need of safety is common among most drivers. This is fueled by the thousands of deaths, millions of injuries and billions of dollars in cost that result from automobile accidents each year. In this chapter, the general idea of collision avoidance systems and the motivation for this research work is introduced. The criteria for activation collision avoidance systems are explained. Three types of collision avoidance maneuvers are reviewed. Literature review of different types of collision avoidance systems including rear-end, road departure, lane change/merge, intersection, vision enhancement for crash avoidance, and vision enhancement technologies is presented.

\subsection{General Idea of Collision Avoidance System}

All drivers are concerned with the need for safety and the need to be aware of what is happening around them. Most drivers hesitate when reacting to unexpected situations on the road. In fact, awareness is one of the most important aspects of driving, and drivers must be ready to take evasive action to avoid collisions. Automobile accidents are the primary cause of death for people between the ages of 5 to 27. During 1995, $3,386,000$ people were injured and 41,798 people were killed as a direct result of 
automobile accidents in the US alone [2]. The cost of these accidents (including hospitalization, property damage, etc.) is estimated to be greater than $\$ 150$ billion per year [5]. However, the fatality statistics have improved since 1985 . This is largely due to increases in the use of safety belts and the recent improvements in safety devices, such as air bags and seat belts. Despite the improvements in death and injury rates between 1985 and 1995 , there is plenty of room for improvement.

The National Highway Traffic Safety Administration (NHTSA) estimates that about $60 \%$ of collisions in the United States are caused by driver inattention or by vehicles following too closely. Overall, rear-end collisions represent about $28 \%$ of all vehicle collisions nationwide $[7,25]$, and $36 \%$ of fatal and injurious collisions in California alone [30]. The development of a Collision Avoidance System (CAS) represents a change of focus in dealing with the consequences of accidents. Traditionally the emphasis has been on injury mitigation for those involved in a collision, for example by providing stronger vehicle frames, seat belts, and airbags, which aim to minimize damage (passive prevention) instead of preventing it (active prevention). Starting with the development of antilock brakes, the focus has now shifted to collision avoidance. Most collision avoidance systems are currently in the experimental stage and before implementation on a wide-scale basis several technical and political questions need to be answered $[23,24,25,29]$.

Driver assistance applications aim to reduce the workload on the driver either by presenting supporting information or by taking over parts of the driving task. In addition, the aim is to reduce driver error by providing information about the task situation. It is 
estimated that 15 to $20 \%$ of the reported accidents involve rear-end collisions. To reduce this relatively high rate, several automotive manufacturers are investigating the feasibility of implementing automatic braking systems. These systems are called Adaptive Cruise Controls, which aid the driver in keeping a safe distance between them and the car in front of them. Thus, it will assist a driver to slow down if the front end of the car is too close to an obstacle while moving forward, and also detect if the car is veering off the road. To assist the driver in braking, it is necessary to calculate different types of brake activation strategies that can stop a vehicle in a safe distance.

Collision warning systems are vehicle-mounted detection devices that continuously scan the front, rear, and blind spots of an automobile for other vehicles or obstacles (as shown in Figure 1-1). These systems issue an audible warning to the driver when they determine that a collision is imminent. Vehicle-mounted transmitters and receivers that bounce radio waves off nearby objects to compute the separation distance perform the scanning function. This information is then correlated with the vehicle's speed and direction to determine whether the separation is adequate. Collision warning systems should provide significant highway safety improvements. Many of the most serious accidents involve head-on collisions that are caused by sleeping or impaired drivers. Audible warnings should significantly reduce these types of accidents. In addition, many accidents occur during lane changes, and collision-warning systems mounted in vehicle blind spots should help to avoid these accidents. Although collision-warning systems leave full control of the vehicle in the driver's hands, they are likely to induce some degree of driver reliance as motorists come to expect warnings when their vehicles get 
dangerously close to other vehicles. Collision avoidance systems are vehicle-mounted, electromechanical devices that detect imminent collisions and then use automatic braking to alert the driver and decrease the probability of an actual collision.

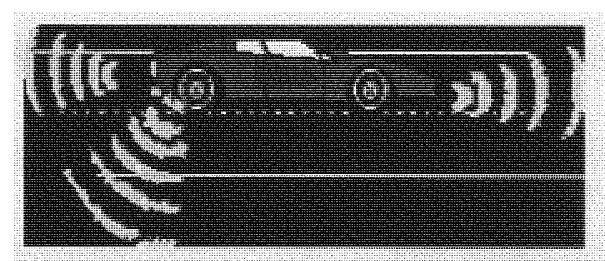

Figure 1-1. CAS-Equipped Vehicle

Advanced collision avoidance systems may also use throttle and steering control to avoid collisions during lane changes. Collision avoidance systems, like collision warning devices, have the potential to reduce accident rates substantially. Collision avoidance systems, however, should outperform collision-warning devices, since the avoidance maneuver may fully prevent the accident without any response by the driver; if not, at least the driver has additional time to evade the accident. The objective of the collision avoidance system is to assist the driver with vehicle longitudinal control and hence to improve driving comforts and traffic safety. As a result, an evaluation of such a support system must also assess criteria based on this aspect and must include the driver, his driving behavior and attitudes in the assessment.

\subsection{Criteria for Activation of Collision Avoidance System}

The time-to-collision criterion: the system determines whether a collision is likely to happen at prevailing speeds and distances, within a certain time interval. In a car- 
following situation, the time-to-collision is the time taken for the two vehicles to collide if they maintain their present speed and heading.

The worst-case criterion: the system assumes that the vehicle preceding the CASequipped vehicle could brake at full braking power at any time. In essence, it operates on a "critical headway distance," that is, the minimum distance necessary for the CASequipped vehicle to come to a stop in the event the leading car suddenly brakes.

\subsection{Collision Avoidance Maneuvers}

The collision avoidance maneuvers are divided into three types

- Headway distance control

- Hazard warning

- Automatic vehicle control

Headway distance control: the system warns the driver whenever his/her car is following the leading car too closely. Some systems include automatic speed control, i.e., the CASequipped car would automatically reduce its speed in order to maintain a safe headway with the leading vehicle.

Hazard warning: the system warns the driver of an object (moving or stationary) within its projected path, so that the driver has sufficient time to avoid a crash.

Automatic vehicle control: the system controls the vehicle's brakes and steering wheel, and applies them automatically when it deems it necessary. In actuality, there are 
currently no systems that use automatic steering to prevent collisions, although the technology has been developed and tested experimentally.

\subsection{Types of Collision Avoidance Systems}

\subsubsection{Rear-End Collision Avoidance}

A rear-end crash occurs when the front of a vehicle strikes the rear of a leading vehicle, both in the same lane. Rear-end collisions were the third highest cause of fatalities in multiple vehicle accidents. The cause seems to be a result of poor driver awareness and ineffective communication during abrupt stopping. In 1994, there were approximately 1.66 million police-reported rear-end crashes. These crashes accounted for over 920,000 injuries and 1,160 fatalities [49]. It is estimated that about 50 percent of these crashes could be avoided by collision avoidance systems that could sense stopped or moving vehicles in the forward lane. By increasing driver awareness and enhancing driver communications, these accidents can be avoided. One cause of rear-end collisions is due to the driver being startled by brake lights illuminating suddenly in front of them, when in actuality, the driver of the automobile in front may be merely resting his foot on the pedal. Conversely, if the driver in front applies his brakes intending to come to a quick stop, the person behind might not realize the intentions until collision avoidance is too late. These situations are examples of poor braking communication. Braking communication between drivers is limited. Brake lights indicate only if a person is braking, not how fast they are braking. 


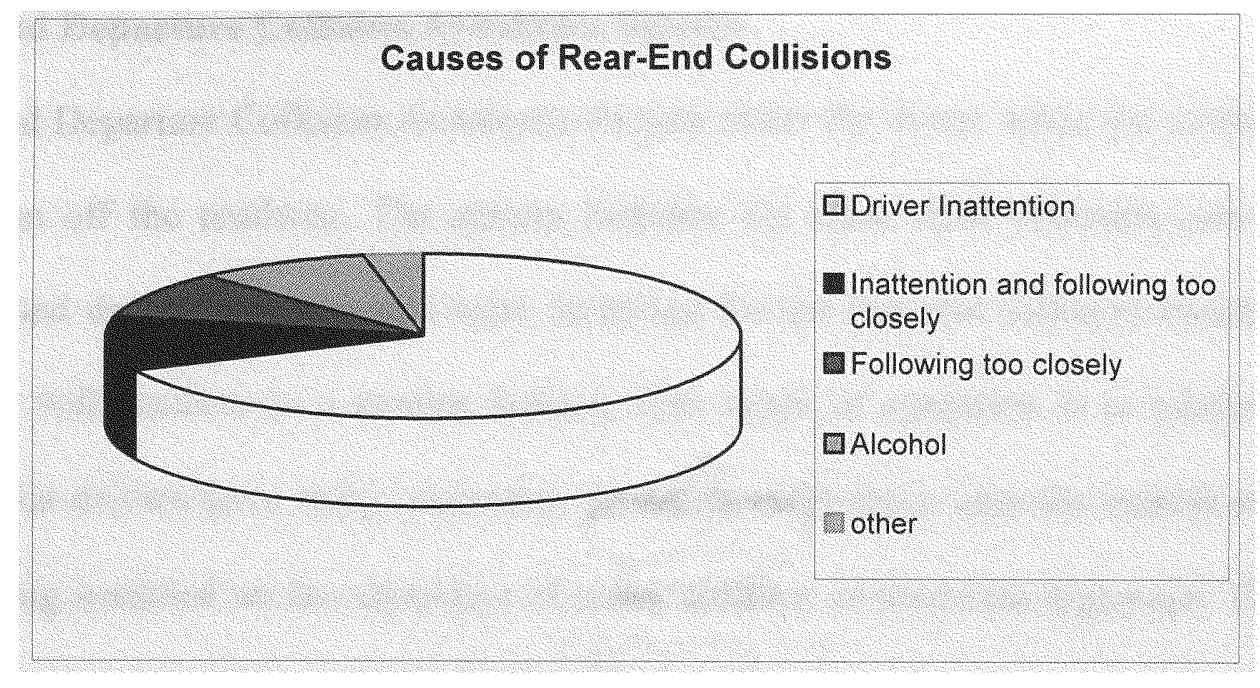

Figure 1-2. Causes of Rear-End Collisions (NHTSA)

Rear-End Collision Avoidance System (RECAS) - alerts driver when a rear-end collision is imminent. These systems will consist of a sensor (such as a radar) that senses the distance and relative speed to vehicles ahead, a computer to process the sensor data and make decisions about the need for a warning to the driver, and a driver interface to present the warning to the driver. The driver interface might include a head-up display and/or an audible message such as a distinct tone or spoken message.

The RECAS concept is to monitor the forward path of the host vehicle, detect other vehicles and objects, and help the driver maintain a safe headway relative to a preceding vehicle or warn the driver if a collision is imminent. At present, the technology to provide effective Rear-End Collision Avoidance Systems is generally believed to be more advanced than systems for some other collision types. 


\subsection{Road Departure Collision Avoidance System}

Road Departure Collision Avoidance System alerts the driver when the vehicle is about to run off the roadway. The system includes the same three elements (sensors, processor, and driver interface) that were described for the rear-end collision avoidance system and will perform in a similar fashion. One mode of operation is to mimic the sensation that drivers have today when they unintentionally drive onto the rumble strips that are being installed on the shoulders of many sections of interstate highways. These systems promise to be especially helpful for rural areas.

\subsubsection{Lane Change/Merge Collision Avoidance System}

This system alerts the driver if it is not safe to change lanes because there is another vehicle in the adjacent lane. It will perform in the same manner as the other collision avoidance systems. While measuring a vehicle's lateral position relative to lane markings on a roadway. The system is capable of tracking white or orange lines, solid or dashed edge lines, while operating in daylight or at night. The tracking system is comprised of two "off-the-shelf" black-white Charge Coupled Device (CCD) video cameras along with commonly available electronic components. The lane-tracking system is capable of outputting real time data at $30 \mathrm{~Hz}$ through an analog output [30]. Using the data from this sensor system it is possible to detect lane changes, determine the magnitude and duration of lane exceedances, and other metrics. 


\subsubsection{Intersection Collision Avoidance System}

Intersections are among the most dangerous locations on U.S. roads. Approximately 1.95 million crashes occurred at intersections in 1994 (30 percent of total crashes), causing over 6,700 fatalities and significant numbers of serious injuries. There are more intersection collisions than any other crash type. However, it is also more technically challenging to prevent this type of crash with detection and warning technology than other crash situations. The system for Intersection Collision Avoidance System should be able to determine if the vehicle is about to violate the right-of-way of another vehicle. If determined that the right-of-way is violated, the system will warn the driver of the imminent danger. The first involves vehicle to infrastructure sensing, processing and control. Veridian Accident Reconstructionists (VAR) is the industry of accident reconstruction and accident investigation, investigated over 200 intersection collisions to determine their cause. This analysis resulted in the following distribution of causal factors.

Table 1-1. Factors for Intersection Collisions by VAR [23]

\begin{tabular}{|c|c|}
\hline Casual Factors & Percentage \\
\hline \hline Attempt to Beat Other Vehicle & $5.08 \%$ \\
\hline \hline Attempt to Beat Traffic Control & $0.90 \%$ \\
\hline Deliberate Violation of Signal & $9.01 \%$ \\
\hline Deliberate Violation of Sign & $3.38 \%$ \\
\hline
\end{tabular}


Table 1-1 (Contd.). Factors for intersection Collisions by VAR [23]

\begin{tabular}{|l|c|}
\hline Casual Factors & Percentage \\
\hline \hline Driver Inattention & $28.66 \%$ \\
\hline Driving Under the Influence & $4.57 \%$ \\
\hline \hline Faulty Perception & $33.88 \%$ \\
\hline \hline Hit and Run & $0.31 \%$ \\
\hline \hline Vehicle Defect & $2.09 \%$ \\
\hline \hline Vision Impaired/Obstructed & $11.13 \%$ \\
\hline
\end{tabular}

\subsubsection{Vision Enhancement for Crash Avoidance}

The goal of Vision Enhancement for Collision Avoidance is to reduce the number and severity of collisions that occur during impaired visibility such as nighttime or foggy conditions. 43 percent of all accidents and 31 percent of all fatal accidents in 1991 occurred during these conditions. This high percentage shows that there is a definite use for this user service. If vision enhancement can improve the ability of the driver to notice obstructions on and along the roadway during impaired conditions, the user service will be successful in helping to prevent collisions with other vehicles and objects that would normally be hard to see. Vision Enhancement will have an indirect cost to transportationdependent industries that is accomplished by reducing the losses that are related to crashes and productivity. The goals that are associated with Vision Enhancement relate directly to the goals of improvement of safety and reduction in total number of accidents, which are part of the goals for the overall implementation of ITS technologies [28]. 


\subsubsection{Vision Enhancement Process}

In order for vision enhancement, along with the other user services in the Automatic Vehicle Control System (AVCS) bundle to be successful, they must follow the three P's: These are Perceive, Process, and Present. The user services must:

- Perceive critical information about an obstacle in the surrounding environment that can cause unsafe driving conditions.

- Process the information that it is observed and transform it into an acceptable form that the driver can understand.

- Present the information in a method so that the driver can understand what must be done to avoid the unsafe driving condition and that prevents the driver from being unsafe while receiving the message.

When the user services in this bundle can successfully complete the three P's, they should then be implemented into vehicles. If they fail, the technologies are only going to put the driver at more risk.

One of the problems with the idea of vision enhancement is that the public will believe it is going to prevent accidents. The public must be educated that this technology, along with other technologies from the Advanced Vehicle Control and Safety Systems, will help to avoid accidents, but it is up to the driver to operate his vehicle in a safe manner to prevent accidents. Vision enhancement cannot prevent decision error, inattention, excessive speeding, or brake failure. It can help to make the driver aware of 
what is ahead of his vehicle in the surrounding environment that can cause an unsafe driving condition.

The vision enhancement technologies can be implemented in a variety of ways. The most popular is in-vehicle sensors that display images of the roadway ahead. An example of this is a heads-up display that overlays the image on the out-the-windshield view. This can be done through two types of technologies; either active or passive. These technologies need to have the capability of detecting the different objects that would be a hazard to the driver and produce them on a display, which the driver can observe.

Passive systems detect energy radiated by all objects without any systemgenerated illumination. The systems include infrared technologies that can form images of the roadway and its surroundings by detecting differences in thermal energy intensity. There is no external lighting needed for these systems to work. Active systems, on the other hand, scan the environment with radar and lasers to develop images. The images are formed based on the reflection of the emitted energy from obstacles. The problem with active systems is that they need to illuminate the environment in order to produce the images.

The most promising of the technologies is the infrared systems. The reason is that it is a passive system; therefore, no external light source is necessary. This means the driver can obtain an infrared image of the line of travel ahead without the need for headlights or street illumination. This system will not replace headlights, which are a necessity for impaired vision travel. Vision Enhancement will augment headlights in helping to identify what is on the road ahead of the vehicle. Most of the infrared images 
gather information on the varying energy levels in the surrounding environment and develop them into a form that can be visually displayed. The earlier systems that were developed used an Electro-optical multiplexer which reformatted the data and sent it to a monitor by using light-emitting diodes.

More up-to-date technology includes the use of sensitive infrared systems that were developed by the military. A system that was modeled in an actual motor vehicle showed that the technology can increase a drivers night time visibility of objects and lane markings in the line of travel up to three times as much compared to headlights alone. Passive systems that have been examined are not as far along in development as the active systems. The main reason is the need for external lighting. Active systems can operate in darkness so much money is being put into their development. A system developed that senses microwave energy has been shown to improve some aspects of impaired vision. The sensors produce a radiometric image that is very accurate in even the most visually impaired situations. The systems that have been developed have been installed on aircraft and are very successful in assisting the plane in landing.

\subsection{Summary}

This chapter presented the complete CAS review of literature and different types of CAS approaches has been reviewed which includes rear-end, road departure, lane change/merge, intersection, vision enhancement for crash avoidance, and vision enhancement process vision enhancement technologies. From the above literature survey 
it has been found that rear-end collisions are the third highest cause of multiple vehicle fatalities from the NHTSA statistics. Their cause seems to be a result of poor driver awareness and communication. For example, a car's brake lights illuminate exactly the same whether the car is slowing, stopping or the driver is simply resting his foot on the pedal. A preliminary research in CAS is included as a foundation for the future research, and as a framework for supporting the development of a rear-end collision intervention system. Further research is carried out on the RECAS and the on going research projects conducted by the organizations like NHTSA, Delco, Mitsubishi, Nissan, and Hino, has been is presented in the next chapter. 


\section{CHAPTER 2}

\section{BACKGROUND}

\subsection{Overview}

In this chapter the rear-end collision avoidance system has been defined and a summary of current and past collision intervention systems is presented. Although many existing system descriptions concentrate on sensor technologies and not the driver interface, an attempt was made to isolate driver interfaces of each system. The international approach to this rear-end problem has been discussed. This includes the Delco Electronics' forewarn forward-looking system, forewarn side selection system, and forewarn back-up aid system, as well as Mitsubishi, Nissan, Hino, Mazda Motor Corporations approach to the RECAS are reviewed.

\subsection{Previous Work}

Rear-End Collision Avoidance System (RECAS) has been developed as a system of ASV (Advanced Safety Vehicle). ASV project has started in 1991 and aims to improve vehicle safety by electronic technology [53]. RECAS has been developed as a system corresponding to the accident avoidance system of ASV. It is a driver-assist system to avoid rear-end collision. It informs the driver of distance headway and warns the driver when there is a collision potential hazard. It activates the automatic brake to 
avoid the collision when the driver does not avoid the hazard in spite of warning, or in case of emergency. It warns the trailing vehicle by blinking the high-mount stop lamp when the trailing vehicle comes too close.

\subsection{Rear-End Collision Avoidance System Outline}

Rear-End Collision Avoidance System (RECAS) is composed of five blocks:

- The driving situation recognition system

- Vehicle sensors

- Collision potential lead evaluation system

- Warning system and

- Brake control system

Figure 2-1 shows the block diagrams. Driving situation recognition system is classified into the forward monitoring system and the rearward monitoring system.

The forward monitoring system employs a single-type CCD camera and scanning laser radar. The forward CCD camera detects the candidates of the preceding vehicle and the road lane by image processing. The laser radar also detects the candidates of the preceding vehicle from the pieces of distance and angle information, and calculates the relative velocity and the relative acceleration to each vehicle. A preceding vehicle is recognized from these candidates by a network-type fusion method [53]. 
Driving Situation Recognition System

Laser Radar

Forward CCD Camera

Rearward CCD Camera

Vehicle Sensors

Wheel Speed Sensor Acceleration

Stop Lamp Switch etc.
Warning System

Buzzer

Head-Display

Hight-Mount Stop Lamp

Potential Hazard

Evaluation System

Brake Control System

Laser Radar

Forward CCD Camera

Rearward CCD Camera

Figure. 2-1. RECAS Block Diagram [53]

\subsection{A Previous Model of Rear-End Crash Avoidance}

In an attempt to model potential theoretical collision avoidance system effectiveness, Knipling [52] developed a model of rear-end collision countermeasure action. This model is valuable because it factors in the kinematics of the vehicle deceleration problem and the time required for a driver to initiate a countermeasure action. The output of the model is a prediction of the distance required to bring a vehicle to a complete stop given its initial velocity and a driver/vehicle response delay. It is also recognized that variance in the normal driving population made it unfeasible to use a single set value when determining brake reaction times. Several different perceptionreaction times (PRTs) and vehicle response scenarios were analyzed to define optimistic and pessimistic values for the distance required to stop for the following vehicle. The following equation defined by Knipling provides the headway distance required to assure that a collision will not occur in a lead vehicle in a stationary collision scenario: 


$$
\mathrm{D}_{\mathrm{HD}}=\mathrm{T}_{\mathrm{D}} \mathrm{V}_{\mathrm{O}}-0.13 \mathrm{~V}_{0}+\mathrm{V}_{0}^{2} / 2 \mathrm{~A}
$$

Where $\mathrm{D}_{\mathrm{HD}}$ is Total distance in feet needed by the headway detection system to prevent a lead-vehicle stationary collision.

$T_{D}$ is Time response delay of driver/vehicle system (sec).

$\mathrm{V}_{\mathrm{O}}$ is Initial velocity of the following vehicle $(\mathrm{ft} / \mathrm{sec})$.

A is Rate of braking deceleration during maximum braking efficiency $\left(\mathrm{ft} / \mathrm{sec}^{2}\right)$.

Knipling also discussed the implications of designing a system based on both optimistic and less-than-optimistic reaction times and braking performances. Several relationships were developed to show the effects of different driver and vehicle capabilities. The optimistic driver/vehicle reaction curve used a driver reaction time value that was two standard deviations below normal reaction time and a vehicle deceleration value that was two standard deviations above normal braking abilities. Conversely, the less-than-optimistic driver/vehicle reaction curves were generated using values for driver reaction and vehicle reaction that were two standard deviations above and below the respective mean values.

All the systems mentioned previously involve some form of detection and warning system and some even involve vehicle control. Specifically, different technologies are appropriate for different situations. The longitudinal collision avoidance technologies include an array of tasks such as monitoring separation distance and closing rate between vehicles traveling in the same lane, providing information on unsafe conditions, advising driver on immediate action to avoid danger, and automatic vehicle 
control. The tasks involve technology that is included in one of the following technology categories.

- Surveillance: infrared sensors, microwave and radar sensors

- Data/Voice Communication (vehicle-to-vehicle): microwave, voice output, visual display and heads-up display

Currently, there are a few commercial radar-based headway detection systems on the market. These sensors are primarily used for rear-end collision avoidance. The major problems with these systems have been their high false alarm rate. This is a result of signal returns from objects adjacent to the lane of travel, which pose no collision threat.

\subsection{Research on Rear-End Collision Avoidance System}

\subsubsection{Delco Electronics}

Delco Electronics developed the FOREWARN system. This system warns the driver of an impending collision, but does not automatically take control of the vehicle. The integrated warning system incorporates four basic steps:

- Road object sensing

- Collection of vehicle data

- Data processing

- Threat assessment, and driver warning execution 
To fulfill these tasks, vehicles are equipped with two front sensors (laser radar and microwave radar), a rear sensor, and driver warning devices (head-up display, audio, and a brake pulse).

The radar sensors measure and report the position and relative velocity of road objects in the spaces ahead and behind the vehicle. This information is combined with data from sensors on the vehicle itself (vehicle speed, steering angle, brake status and gear position, among others) to determine which of the detected objects are in the vehicle's path. An algorithm is used to prioritize collision threats. The range and time to collision are calculated as a function of relative speed and heading, and are compared to typical driver behavior (average following headway, projected braking distance and time). If the driver of the CAS-equipped vehicle fails to brake or steer, then the appropriate warnings are enabled. Warning thresholds can be adjusted in real-time, depending upon the external environmental conditions (windshield wiper status), the vehicle's state (tire pressure), or estimated driver level of attention (if the audio controls are being adjusted, it is assumed that the driver is not paying full attention to the roadway) [32].

Delphi Delco developed a family of forward-, rear- and side-detection collision warning systems to detect objects and warn drivers of potential accidents.

\subsubsection{Forewarn Forward Looking System}

Forewarn Forward Looking Systems (FLS) increase the driver's awareness of objects in the vehicle's forward path. Adaptive Cruise Control (ACC) is the first FLS 
product. The ACC system utilizes a radar sensor mounted at the front of the vehicle to detect objects in the vehicle's path, as well as range and rate of those objects shown in Figure 2-2. Then, utilizing throttle control and limited braking, it adjusts the speed of the vehicle to improve the performance of cruise control. Additional products under development in the FLS area include Collision Warning, Collision Intervention, and Collision Avoidance Systems.

\section{Product Features}

- Multiple target tracking (even through curves)

- $76 \mathrm{GHz}$ operation

- All-weather performance

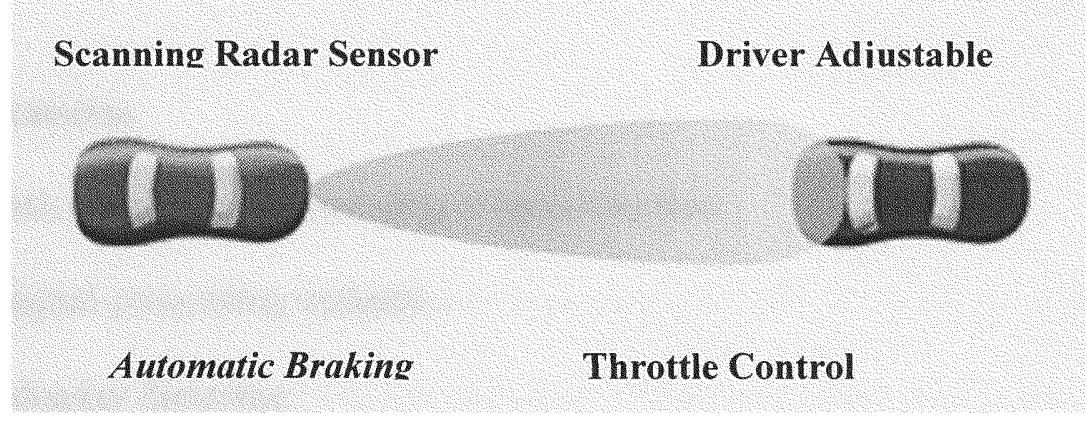

Figure 2-2. Forewarn Forward Looking Systems by Delphi Automotive Systems [54]

\section{Consumer Benefits}

- Identifies and tracks objects in the forward path of the vehicle

- Functions in all weather conditions

- Functions in daylight and darkness 
- Automatically maintains distance between vehicles at highway speeds

- Alerts driver when to avoid collision and corrective action is needed.

\subsubsection{Forewarn Side Detection System (SDS)}

Forewarn Side Detection Systems (SDS) help drivers "see" areas that are actually out of sight. SDS detects and alerts drivers of objects in the detection zones to the side of the vehicle that are difficult to see or are not visible known as blind spots using the side or rear view mirrors as shown in Figure 2-3. The Forewarn SDS is mounted in the rear quarter panel area of the vehicle. The system's radar sensor is designed to detect objects out to the adjacent lane on either side of the vehicle and complements the existing mirrors to enhance driver safety.

\section{Product Features}

- Automatic stationary and moving object detection

- Radar signal processing updates

- Driver display dimming

- Automatic rear disable

\section{Consumer Benefits}

- Gives a visual indication to driver to warn of objects in driver's path before changing lanes

- Reports targets and not ground, minimizing unnecessary warnings

- Provides full time day/night use 
- Disables system while backing up

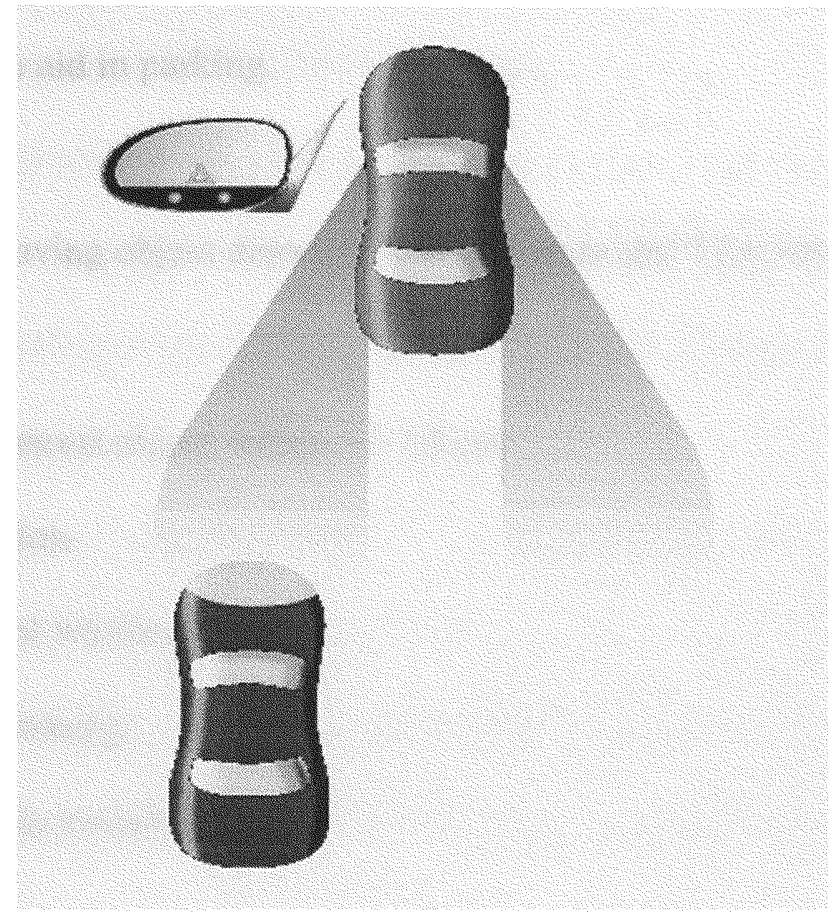

Figure 2-3. Forewarn Side Detection System by Delphi Automotive systems [54]

\subsubsection{Forewarn Back-up Aid System (BUA)}

Delphi Automotive Systems Forewarn family of products includes Forward Looking Systems, Rear Detection Systems, Side Detection Systems, and Collision Avoidance Systems. Back-up Aid Systems (BUA) help drivers "see" areas that are actually out of sight. BUA is designed to detect and alert drivers of objects, such as other vehicles, tricycles or bicycles that are in the system's detection zone and help reduce the chance of backing into them. The Forewarn BUA system is mounted in the rear bumper area on passenger vehicles. The system's radar sensor is designed to detect moving and 
stationary objects directly behind the vehicle out to 6 meters. Ultrasonic sensors provide near field coverage to aid in parking.

\section{Product Features}

- Stationary and moving object detection with distance and Time-to-Collision based warnings

- Distance to the nearest object within $+/-10 \mathrm{~cm}$

- Automatic operation

- Audible and visual warning

- Driver display dimming

- Momentary disable switch

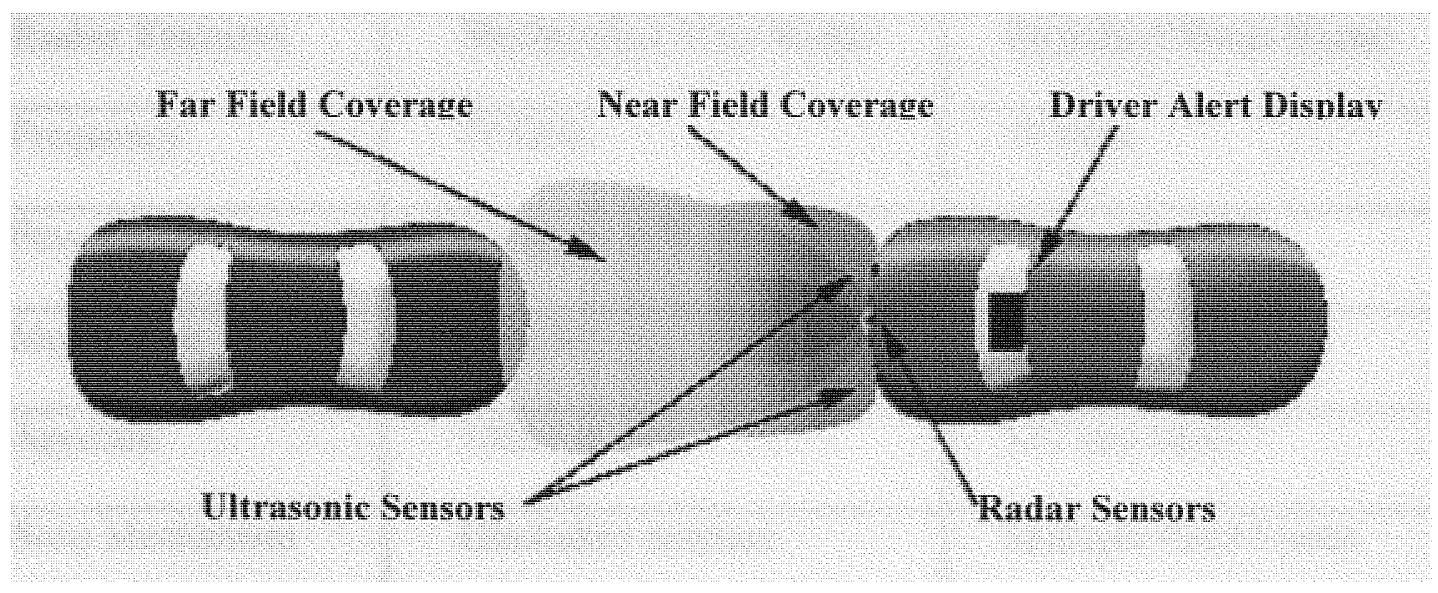

Figure 2-4. Forewarn Back-up Aid System by Delphi Automotive systems [54] 


\section{Consumer Benefits}

- Warns driver of unseen objects in detection zones

- Enhances ability to park close to known objects

- Gives audible and visual warnings while in reverse gear

- Gives audible warning to quickly alert driver of potential object; visual alert complements audio alert

- Provides full time day/night use

- Allows for compatibility with towing

Two vehicles were equipped with the FOREWARN system: a Cadillac Seville, and a Lexus LS 400. Different radars were used on each car, as detailed in Table 2-1.

Table 2-1. Different Radars Used on Each Car [32]

\begin{tabular}{|l|l|l|}
\hline Radar Features & Mechanical Scan Radar & Switched Beam Radar \\
\hline Frequency & $77 \mathrm{GHz}$ & $77 \mathrm{GHz}$ \\
\hline Power & Under $10 \mathrm{~mW}$ & Under $10 \mathrm{~mW}$ \\
\hline Modulation & FMCW & FMCW \\
\hline Aperture & $102 \times 178 \mathrm{~mm}$ & $127 \mathrm{~mm}$ (dia) \\
\hline Scan Mechanism & Gimballed antenna & Multiple fixed beams \\
\hline Scan Time & $100 \mathrm{msec}$ & $100 \mathrm{msec}$ \\
\hline Field of View & $16 \mathrm{deg}$ & 22 deg \\
\hline Range & Over $100 \mathrm{~m}$ & Over $100 \mathrm{~m}$ \\
\hline
\end{tabular}




\subsubsection{Mazda Motor Corporation}

Mazda Motor Corporation has developed a system, which uses automatic emergency braking to avoid collision with pedestrians and preceding vehicles. The RECAS works both on straight and on curved roads, under the critical headway criterion. It operates according to the basics of RECAS operation: it does not intervene during normal driving conditions, an alarm warns of potential danger for longitudinal collision, and if the driver does not decelerate after warning, the system applies an automatic emergency brake to avoid collision. The system includes four elements detailed below:

Headway distance measurement: Scanning laser radar is used to detect the distance and direction of obstacles, a camera is used to detect the lane marks, and a road surface sensor is used to predict the road surface friction. The scanning laser radar can detect a pedestrian within $35 \mathrm{~m}$ to $60 \mathrm{~m}$, depending on clothing color and material. This detection range is sufficient as long as the vehicle's velocity is less than $50 \mathrm{~km} / \mathrm{h}$. The radar is a narrow, fanned laser beam, which is thin in azimuth and fanned in elevation, and it scans rapidly over a broad area.

Path estimation algorithm: This algorithm uses the lane marks, or in their absence the steering angle and yaw rate of the vehicle, to estimate the road curvature radius. This in turn is used to project the vehicle's path. It is sufficiently accurate for a $120 \mathrm{~m}$ detection rate, given a minimum road curvature radius of $300 \mathrm{~m}$ and a maximum velocity of 100 $\mathrm{km} / \mathrm{h}$. 
Collision prediction: This is based on a critical headway criterion. It is expected that the vehicle should avoid a collision by decelerating at $6 \mathrm{~m} / \mathrm{s}^{2}$, when the preceding vehicle decelerates at a maximum rate of $8 \mathrm{~m} / \mathrm{s}^{2}$ [32].

Longitudinal automatic brake control: A warning signal is activated at a certain time before the measured headway distance is shorter than the calculated critical headway distance. When the headway is less than the critical headway, the brakes are automatically activated, and released only when the headway is longer than the critical headway. The driver can regain control by applying the brakes stronger than the automatic system. The automatic brake actuator is installed as part of the ABS system and performs longitudinal acceleration feedback control using high-speed solenoid valves [32].

\subsubsection{Mitsubishi, Nissan and Hino}

Collision warning systems for trucks have already been marketed in Japan independently by Mitsubishi, Nissan, and Hino. These systems use laser radars with sufficient accuracy (plus or minus two to four meters) for vehicle-to-vehicle distances of $40 \mathrm{~m}$ to $50 \mathrm{~m}$ their main weaknesses lie in the poor performance of the laser radar in severe external environmental conditions (rain, fog, snow, etc.), and the relatively long computation time and low accuracy caused by differentiation of distance data [32]. 
Table 2-2. Japanese Commercial CAS Specifications

\begin{tabular}{|c|l|l|l|}
\hline Name: & Distance Warning & Traffic Eye & Safety Eye \\
\hline Manufacturer & Mitsubishi Motor & Nissan Diesel & Hino \\
\hline Type of Vehicle & Passenger car & Large truck & Large truck \\
\hline Available since & October 1992 & December 1989 & May 1992 \\
\hline Size (WxHxD) & $194 \times 87 \times 120 \mathrm{~mm}$ & $200 \times 75 \times 115 \mathrm{~mm}$ & $200 \times 52 \times 140 \mathrm{~mm}$ \\
\hline Peak Power & 15 watts & 14 watts & 25 watts \\
\hline Range/Accuracy & $99 \mathrm{~m} / 4 \mathrm{~m}$ & $100 \mathrm{~m} / 4 \mathrm{~m}$ & $99 \mathrm{~m} / 2 \mathrm{~m}$ \\
\hline
\end{tabular}

\subsection{Summary}

This chapter reviewed the past and present research on rear-end collision avoidance systems carried out by different organizations. This includes the Delco Electronics' forewarn forward-looking system, forewarn side selection system, and forewarn back-up aid system, as well as Mitsubishi, Nissan, Hino, and Mazda Motor Corporations approach to the RECAS. The goal of this review is to identify the existing research on RECAS and to develop a performance specification for future rear-end collision intervention systems. Included in this specification, presented in the next chapter, a thorough review of hardware, software, driver/human factors and current rear-end collision intervention systems. 


\section{CHAPTER 3}

\section{DRIVER BEHAVIORAL FACTORS}

\subsection{Overview}

This chapter reviews and examines the applicable literature on the driver/human factors issues that contribute to rear-end crashes. In addition to a review of the literature, a detailed rear-end crash scenario decomposition is discussed. A preliminary model is included as a foundation for the conduct of needed future research, and as a framework for supporting the development of a rear-end collision intervention system performance specification. By understanding the complex driver/human factors of the rear-end crash and how these factors affect the timeline of an impending crash, more effective crash avoidance systems can be designed. The purpose of this review is to build a framework for evaluating and describing all driver/human factors issues involved in rear-end collisions. In order to make recommendations for system specifications, all issues relating to rear-end crashes must be understood.

\subsection{Types of Rear-End Crashes}

Rear-end crashes can be classified into two major categories that vary with respect to causal circumstances: Lead-Vehicle Stationary (LVS) and Lead-Vehicle Moving (LVM). These conditions vary greatly with respect to pre-crash dynamics (e.g., closing speeds and distances) as well as a number of parameters relating to driver perception and 
performance. A general comparison shows that in 1990-96, LVS crashes accounted for $69.7 \%$ of rear-end crashes [47]. In another LVS and LVM crash study which analyzed 77 rear-end crashes [47], nearly $75 \%$ of crashes involved LVS vehicles. Knipling [52] also found that most (54.2\%) of LVM crashes occurred at non-junctions, while only $35.4 \%$ of LVS crashes occurred at non-junctions. About $54.9 \%$ of all rear-end crashes were intersection, intersection-related, or driveway/alley access-related LVS crashes. Also, about $57.3 \%$ of LVM crashes occurred on non-divided highways, while $67.1 \%$ of LVS crashes occurred on non-divided highways. When the roadway speed limits were known and the crashes analyzed, $28.6 \%$ of LVM crashes and $13.4 \%$ of LVS crashes occurred on high speed limit $(55 \mathrm{mph}+$ ) roadways. Mortimer [49] also found that of the moving vehicles struck, $28 \%$ were traveling at $20 \mathrm{mph}$ or less.

\subsection{Behavioral and Perceptual Aspects of Rear-End Crashes}

\subsubsection{Driver Attention}

Driver inattention accounts for the largest of rear-end crash causal factors. In one sampling by the NASS CDS (1991) [47], 63\% of rear-end crashes were caused by driver inattention. Although it is possible for a driver to "look but not see," attention in driving is generally directly related to where a driver is looking at any given time. The driver is constantly scanning the environment - looking out the forward windshield, side windows, scanning mirrors, and attending to stimuli in the vehicle. Since the human visual attention operates for all practical purposes as a single channel processor, drivers experience periods of time when no information is being processed from the forward roadway. 
Operating in-vehicle controls, navigating to a destination, and carrying on conversations require drivers to take their eyes off of the roadway and "attend" to other stimuli. Often, drivers return their point of gaze repeatedly "head down" or off the forward roadway. It is these repeated non-forward-looking glances that create the potential for a rear-end crash.

Visual sampling both in and out of the vehicle has been modeled previously [57]. As illustrated Figure 3.1 for this normative, deterministic model. The model starts when the driver begins to perform an in-vehicle task by glancing to an appropriate location. Information extraction begins as time elapses. If the information can be chunked at about one second or less, the driver will comfortably return to the forward scene. However, when experiencing time pressure, the driver will take up to 1.5 seconds to glance and retrieve information. If the information cannot be obtained (or chunked) in less than 1.5 seconds, the driver will return the glance to the forward scene and try again later. The driver continues to extract other information in the same way, until all required visual information is obtained.

Wierwille states that manual tasks requiring in-vehicle glances can be separated into five categories based largely on the needed driver resources. Some tasks are learned quickly after only a few glances, and are quickly and manually mapped out by the driver. Light switches, turn signals, and other simple controls are often performed automatically by the driver. A subset of this control mapping (manually only) occurs when a driver looks at a control to obtain position or status information, then adjusts the control without looking for example, when checking to see where the climate control system is set and 
then manipulating the controls without looking at them. Wierwille classifies this type of action as manual primarily.

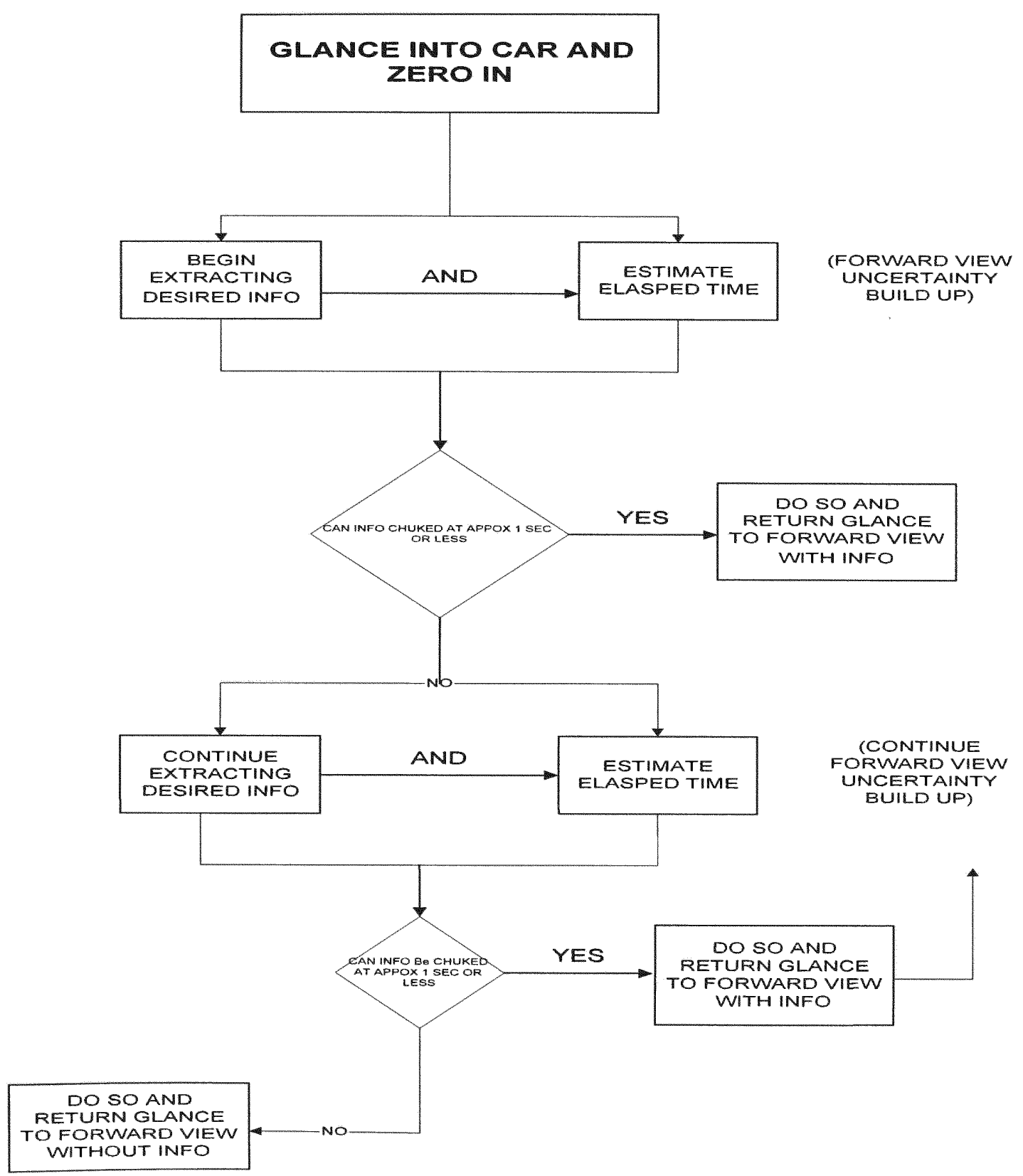

Figure 3.1 Model of Visual Sampling for in-Vehicle Tasks [47] 
Visual only are tasks that require no manual input and are information gathering in nature. These types of tasks include the speedometer, checking the radio station frequency and time of day. Wierwille [49] categorizes tasks that rely heavily on vision, but require a degree of manual input as visual primarily. An example of this type of task is determining the radio station frequency when the initial display reads like a clock.

The last classification that Wierwille describes is that of visual-manual. This type of task is related to interactive activities inside the vehicle, such as repeated input and visual attention. This input includes manually tuning a radio to a specific frequency, operating a cellular phone, and adjusting an outside rear-view mirror. In-vehicle most glances require more than 1.2 seconds as shown in the Table $3-1[67,56]$. This relatively long glance-duration time is one of the key factors contributing to driver loss of situation awareness to the forward vehicle. Scanning behavior resulting in the "head-down" factor in normal driving lead to reduce out the window glance times.

Wierwille, Hulse, Fischer and Dingus [57], have calculated probabilities of a driver's eyes being on the forward roadway under varying degrees of attentional demand as illustrated in the Figure 3-2.

They found that as the driver's subjective rating of attention demand increases, so does the probability that the driver's eyes will be on the forward view. Wierwille et al., surmise that drivers undergoing increased visual loading, due primarily to the task of driving, adapt their visual sampling strategy. They are under great pressure to return their glance to the forward view sooner and maintain it for a great proportion of the total time. 


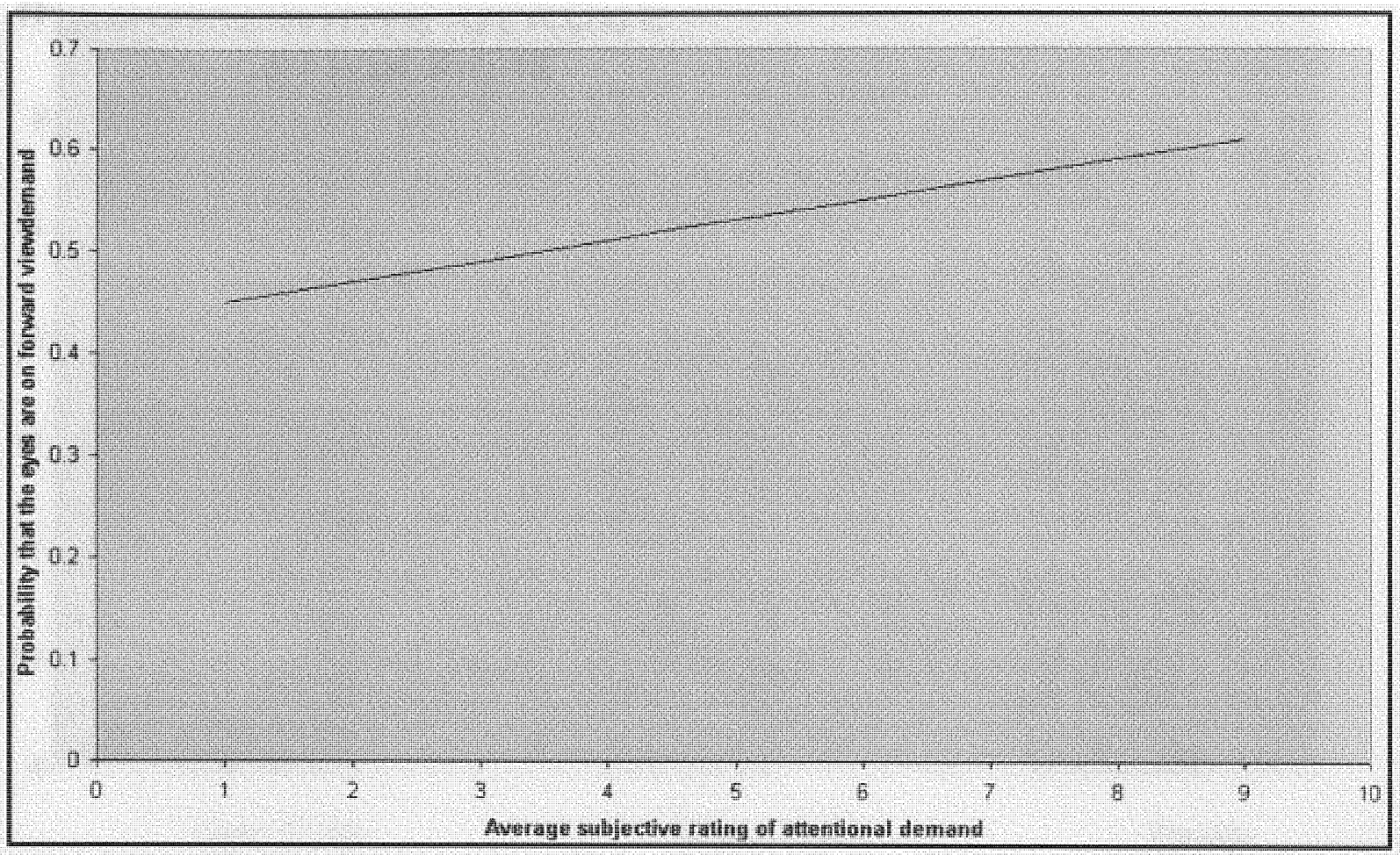

Figure 3-2. Forward View vs Attention Demand [49]

Wierwille and his colleagues also found that traffic density increases the driver's glance length of the forward view. As the traffic view increases, so does the glance length increase of the forward view as shown in Figure 3-3. Driver age also has a bearing on how long glance-duration takes place. Hayes [61] found that middle aged and older drivers had significantly longer in-vehicle glance times than those of younger drivers. These age effects are generally due to deterioration of vision and slowing of cognitive processes as illustrated in Figure 3-4. This effect is critically important to consider when designing in-vehicle controls and displays. 


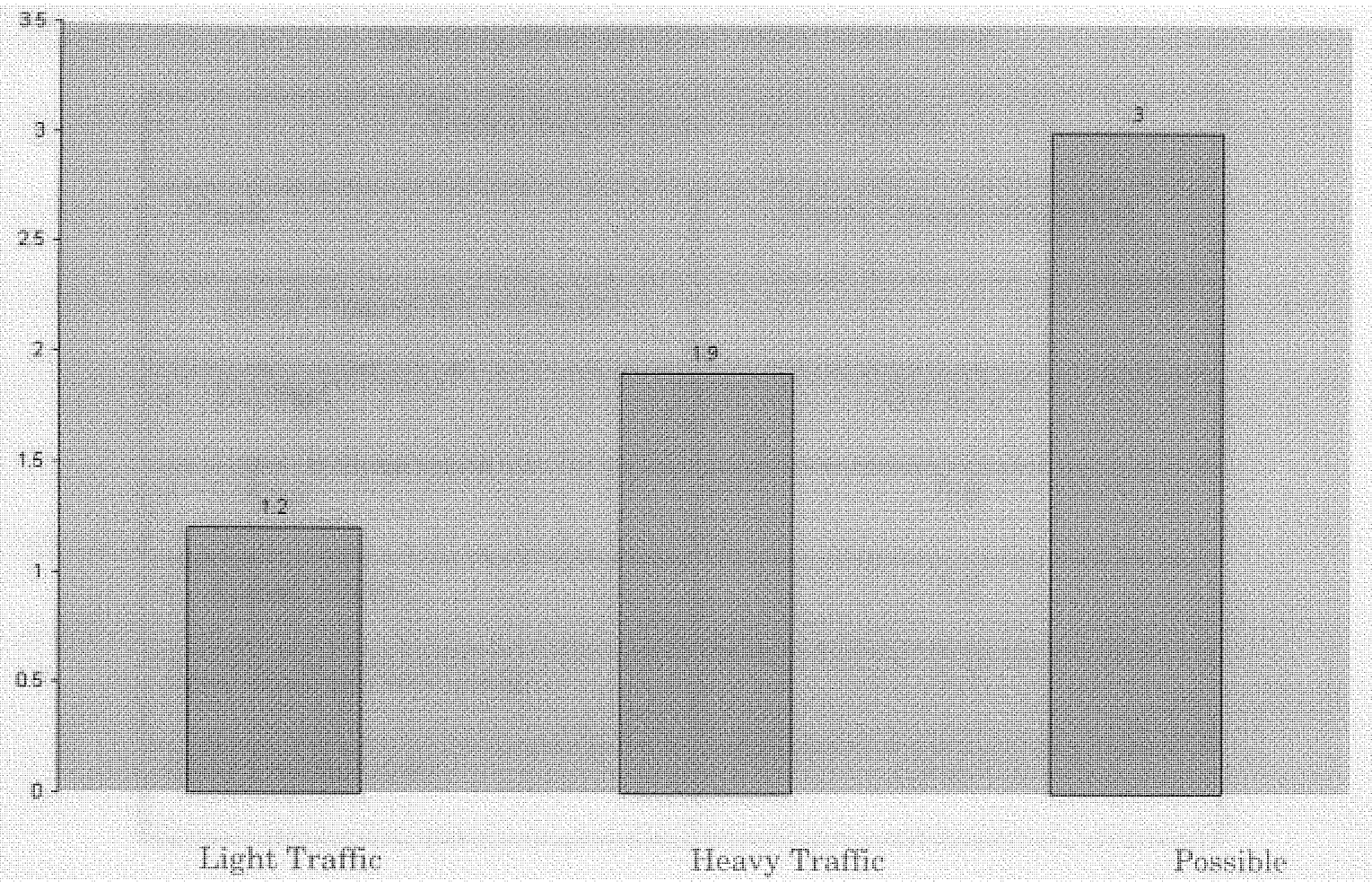

Ineident

Figure 3-3. Glance Length to Forward view as a Function of Traffic Type [49]

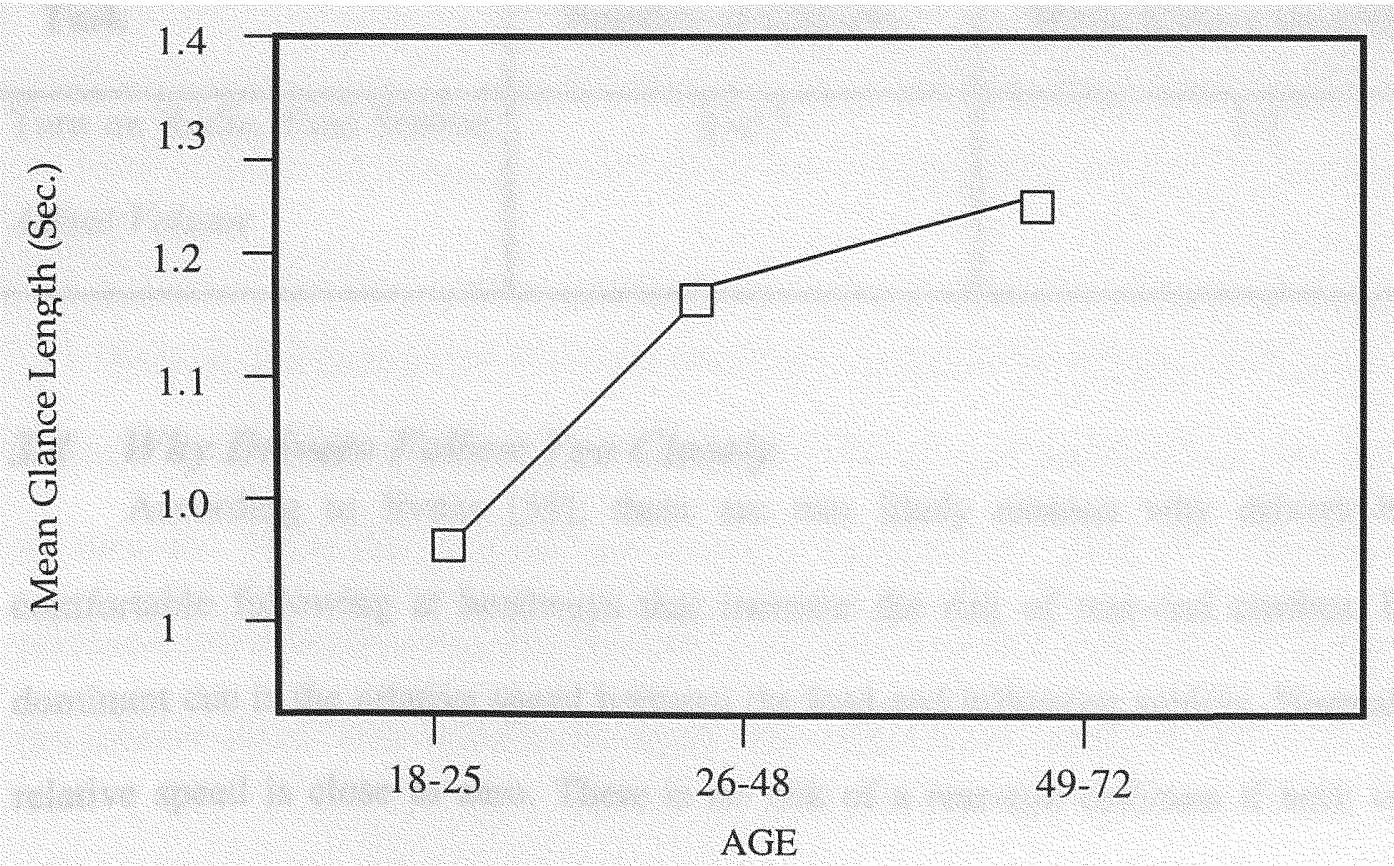

Figure 3-4. Mean In-vehicle Glance Length as a Function of Age [49] 
Table 3-1a. Summary of In-Vehicle Glance Times

\begin{tabular}{|c|c|}
\hline \multicolumn{2}{|c|}{ Tasks Requiring a Single Glance } \\
\hline \hline Task & Mean Glance duration \\
\hline \hline Read Analog Speedometer & \\
\hline \hline Normal & 0.4 to 0.7 \\
\hline \hline Check & 0.8 \\
\hline Exact Value & 1.2 \\
\hline \hline Read Analog Fuel Gauge & 1.3 \\
\hline \hline Read Digital clock & 1.0 to 1.2 \\
\hline
\end{tabular}

Table 3-1b. Summary of In-Vehicle Glance Times

\begin{tabular}{|c|c|c||}
\hline \multicolumn{2}{|c|}{ Tasks Requiring Several Glances } \\
\hline \hline Task & Number of Glances & Mean Glance Duration \\
\hline Turn on Radio, Find Station & 2 to 7 & 1.1 \\
Adjust Volume & & \\
\hline
\end{tabular}

\subsection{Why Drivers Follow Too Closely}

According to Evans [58], there are two likely reasons why drivers become comfortable following at headways that increase the risk of rear-end crashes. First, a dominant cue is the relative speed between the lead and following vehicle. Normally, the relative speed is close to zero. There is no risk of a rear-end collision if both vehicles 
maintain identical speeds, regardless of the speed. Evans believed that the largely static visual impression in vehicle following tends to lower awareness and concern regarding speed. If the speed of the vehicle in front changes suddenly, then the ensuing dynamic behavior of both vehicles is strongly speed dependent. The second reason Evans believes drivers become comfortable when following too closely, is that they have learned, from repeated experience without adverse consequences, that it is safe to do so. Evans also indicated that experience teaches drivers that the vehicle in front does not suddenly slow down.

\subsection{Perceptual Factors in Rear-End Crashes}

Considerable evidence suggests rear-end crashes occur because the driver of the striking vehicle does not see the vehicle ahead, or because of complex perceptual factors [60], Several perceptual factors determine distance and rate of closure information for following vehicles. When making judgments regarding depth, pictorial cues (such as relative size) are the strongest depth cues [63]. To make this judgment, the observer does not have to know anything about the actual size of objects; it is necessary only to assume that they are identical.

Ittelson and Kilpatrick [71] illustrated this point by presenting subjects with two balloons at the same distance from the subjects. The sizes of the balloons were controlled by bellows. When the balloons were viewed monocularly under dim illumination (to eliminate other depth cues), the distances assigned to them by the subjects depended on the relative sizes. Two balloons of equal size were viewed equal distances away, but a 
larger balloon was always thought to be closer. This example can be directly applied to how we view vehicles ahead. When a vehicle is far ahead, it looks smaller than it does when it is close. As a result, the visual angle is small when the vehicle is far away, and when the vehicle is up close, the visual angle is larger.

Several other studies have been performed that are related to this perceptual phenomenon. One study by Baker and Steedman [61] indicated that when an aluminous object was viewed in a stimulus-free environment, motion could be inferred toward the observer when the visual angle subtended by the object had increased by about 0.02 degree. In another study conducted by Braunstein and Laughery [34], it was found that by using vehicles decelerating at 0.8 to $1.48 \mathrm{ft} / \mathrm{sec}^{2}$, Weber fractions (principle that the justnoticeable difference is a constant fraction of the intensity of the comparison stimulus) of $0.09-0.12$ for headway change detection were obtained. In another driving study [60], the sensitivity of drivers' changes in headway was measured from initial headways at 70 mph of 120 feet and 320 feet, and at $35 \mathrm{mph}$ of 40 feet and 120 feet. The Weber fraction (principle that the just noticeable difference is a constant fraction of the intensity of the comparison stimulus) for headway change detection was 0.12 degree of visual angle, which was similar to Braunstein and Laughery. This indicates that drivers similarly view leading vehicle change in size and relative velocity.

\subsection{Driver Perception/Decision/Reaction Time}

The next stage of the collision avoidance process when considering the perceptual factors relating to the visual angle of rear-end crash is driver reaction time. The usual 
driver reaction to a potential collision is sudden braking and/or steering. As a major consequence, a factor in determining whether a collision will be avoided is the driver's perception-reaction time (PRT). PRT has long been the object of study; however, large sample studies which look at reaction time as it relates to in-vehicle braking is rather sparse. More research on perception-reaction times to relevant lead vehicle deceleration is needed. Past research has generally concentrated on reaction to traffic signals and objects in the road [81]. These studies also informed drivers that they should expect rapid slow downs. Driver reaction time estimates vary from 0.9 seconds for unexpected events (with athletes as drivers [85]) to 1.6 seconds for 95 th percentile drivers with unexpected events using a more representative population [82].

Lister [83], in a laboratory study, investigated PRT in which a subject was expected to press a pedal when a lamp was lit. Lister split the total brake PRT into perception time (time from the presentation of stimulus until the foot starts to move) and movement time (time from the start of the movement until the foot reaches the brake pedal). The mean overall brake reaction time obtained under these conditions was found to vary between .45 and .60 seconds. Lister's study measured only the reaction time to the light itself, no other stimulus was tested. This accounts for the fast reaction times obtained in the study relative to other field tests.

In an experiment conducted by Olson and Sivak [81], it was found that the 95thpercentile PRT interval for a population of ordinary drivers confronted with an unexpected roadway obstacle was 1.1 seconds, with a range ( 2 to 98 percentile) of 0.81 to 1.76 seconds. Note that PRT may be shorter for more intimidating test conditions. Taoka 
[66] suggested that brake reaction times of unalerted drivers could be represented by a $\log$ normal distribution. He surmised that the log normal distribution for brake reaction time is more realistic than a standard normal distribution because of the skewness of the $\log$ normal distribution. Most studies have shown that the distribution mean is greater than the median PRT because there are more large reaction times at the high end of the distribution than the normal distribution would indicate. More large reaction times are realistic since they describe more of the population (age and impairment effect) and take into consideration day-to-day driver inattention problems. Furthermore, detection times might vary depending on the type of signal presented (e.g., auditory or visual). In perhaps one of the most ecologically valid studies on brake perception-reaction time, Lerner [57] instrumented over 116 individuals personal vehicles to conduct "roadway quality" drives in older and younger drivers. At the end of about an hour of evaluating roadways, the drivers were directed onto a new section of deserted freeway. After driving 0.7 mile on the new freeway section, a bright yellow barrel was launched from behind a bridge abutment. Reaction times in the form of braking and/or steering were recorded. Lerner found that $87 \%$ of the 116 drivers made some overt vehicle maneuver. Of these, about $43 \%$ both braked and steered, $36 \%$ steered only, and $8 \%$ braked only. Mean PRT for all subjects was 1.5 seconds with a standard deviation of 0.4 second. After reviewing studies on PRT, a wide range of values was found.

The Davis [84] study commented that PRT in certain situations might be a simple or complex reaction according to test procedures. They found that perception-reaction time increased with following distance. Increased attention drivers had towards the lead 
vehicle explained this effect of short PRTs for short headways. In most studies, which involved car following or obstacles in the road, it was found that mean brake reaction times were well over one second. In studies where brake reaction times were found by braking according to a light or sound stimulus, mean brake reaction times were well under one second.

In car following and obstacles in the road studies, where most subjects are not expecting to brake, complex reactions occurred. In most studies where subjects are often expecting to brake due to light or sound stimuli, less complex reactions occur. The study by Johannson and Rumar [75] suggested that when braking is anticipated, a correction factor of 1.35 seconds must be used to find the correct PRT.

\subsection{Relative Velocity Cues}

Based on the available literature, drivers are apparently able to judge accurately whether a gap between them and another vehicle is opening or closing [59]. However, it also appears (as mentioned in the previous section) that drivers base their closure rates heavily on changes in visual angle. Mortimer [60] found that drivers are able to derive little information on the velocity and relative velocity of their own vehicle as well as the vehicle ahead of them. Drivers are able to make accurate estimates on the distance to the car ahead of them (within approximately 20\%) and are reasonably sensitive in determining a change in the headway between their vehicle and one ahead of them (within an approximately $12 \%$ change). 
A study by Hoffman [59] found that in many situations, drivers do not have the opportunity to estimate relative velocity because the threshold for human perception of that factor is often not exceeded. He also determined in another study [59] that the threshold for angular velocity is approximately $3.5 \times 10-3 \mathrm{rad} / \mathrm{sec}$. However, the same study showed that in a car-following simulator, drivers made little use of relative velocity information. Drivers were able to more effectively scale the absolute speed of the car being followed.

It was concluded that unless the relative velocity between two vehicles becomes quite high, drivers use changes in their headway, or the change in angular size of the vehicle ahead, to determine their speed. Even in high relative velocity situations, drivers cannot scale relative velocity into more than three or four categories. As a result, Hoffman suggested that rear-end collisions could be reduced if drivers were aided by a display which indicated the relative velocity of the car being followed.

\subsection{Display Factors in Rear-End Crash Systems}

\subsubsection{False/Nuisance Alarms and Warning Frequency}

False alarms and warning frequency are two of the most important issues that must be considered in the design of collision warning devices. A false alarm is an alarm activation in which a device does not function as designed (e.g., an electronic sensor interprets ambient noise as a signal and activates the alarm).

Nuisance alarms are similar to false alarms. They occur when a system functions as designed when the situation does not constitute a true crash threat (e.g., sensor signal 
reflects off of a guardrail while rounding a corner). These types of alarms occurred with the design of the first generation TCAS-I, the Traffic-Collision Alerting System for commercial aircraft. TCAS-I had such a high nuisance and false alarm rate in congested traffic areas that pilots no longer believed the system was producing a valid alert. This type of situation is directly transferable to the automotive collision intervention domain. Historically, warning systems have used discrete on/off criteria. Such discrete systems present several design parameters that must be estimated. If false alarm rates are too high, the user loses faith in the system and deems it useless. Since it is estimated that a driver is involved in a car crash an average of every five years [85], and that rear-end crashes represent about $1 / 5$ of all collisions, a driver may only be involved in a rear-end crash every 25 years. This indicates that theoretically, collision interventions should rarely occur if the false/nuisance alarm rates are in line with the actual hazards.

Horowitz and Dingus [56] discussed the potential for warnings to add to the attention and information-processing load of drivers. Warning displays, if not properly designed, could divert attention to the wrong place at the wrong time. In addition, frequent warnings may be ignored, because the driver may perceive it as false and useless, therefore redundant information. To overcome potential negative aspects, four concepts were suggested:

- A graded sequence of warnings

- A parallel change in modality

- Individualization of warnings

- A head-way only display 
These recommendations are intended to optimize warning displays to their fullest. In the scope of warning signal design, it is imperative to reduce the false alarm rates as much as possible without missing any real hazards.

\subsubsection{Likelihood Alarm Displays}

In a Likelihood Alarm Display (LAD), information about event likelihood is computed by an automated monitoring system and encoded into an alerting signal for the human operator. Sorkin, Kantowitz and Kantowitz [74] evaluated operator performance within a dual-task paradigm with two LADS: a color-coded visual alarm and a linguistically coded synthetic speech alarm. The results indicated that LADs can improve the allocation of attention among tasks and improve information integrated into operator decisions LADs do not necessarily add to the operator's attentional load.

This type of display, and the recommendations brought forth by Horowitz and Dingus is similar in nature. The idea that warnings or information in general be graded, such that the driver does not react to a discrete on/off signal or warning, may have a positive effect on the design of warning systems. If an alarm demands a high mental workload and operator performance decreases, the alarm may not be useful. This cannot be emphasized enough. It is crucial that the system be intelligent enough to recognize critical and non-critical situations. 


\subsubsection{Display Modalities}

Alerting through several sensory modalities is possible for incorporation into collision intervention systems. The goal of any display modality is to display information to the driver such that a rear-end collision can be overted. A correlated goal of these information displays is to orient the attention of the driver to the collision threat. The primary modality for most of the current systems available is a visual display paired (generally a discrete on/off LED) with an audio tone. The advantages and disadvantages of several display modalities are described in Table 3-2.

\subsubsection{Auditory Display Considerations}

An alternative medium to visual displays is auditory information including voicebased systems. Several collision intervention systems utilize auditory displays of one kind or another [45]. Many studies have been published discussing the use of auditory channels in advanced automotive technologies. Most however, have been related to the use of automotive navigation systems. During some of the first prototype synthesized voice studies, Turnage and Hawthorne found that drivers did not respond as well to synthesized speech as to natural speech.

Thomas [56] found that the processing of synthetic speech could produce increased demands on the short-term memory as compared to human speech. They noted that the observed performance decrements were attributed to memory capacity and not to mis-perception of synthetic speech. In contrast, later work indicates that synthetic speech has become more of an asset and that intelligibility has improved over the years. 
Table 3-2. Trade Study of Display Modalities

\begin{tabular}{|c|c|c|}
\hline DISPLAY MODALITY & ADVANTAGES & DISADVANTAGES \\
\hline Quantitative & 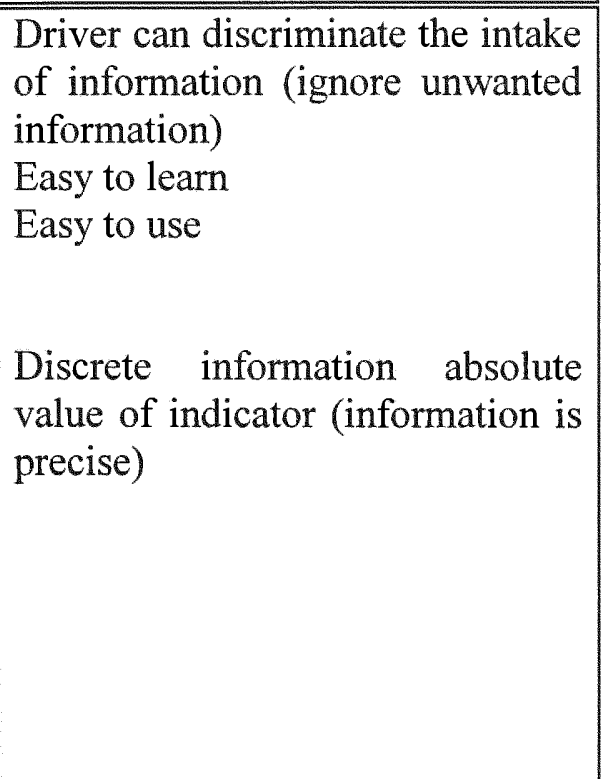 & $\begin{array}{l}\text { May be difficult to initially alert } \\
\text { visual attention of driver } \\
\text { Must be looking at display to } \\
\text { gather info increase visual } \\
\text { attention workload clutter of } \\
\text { dashboard } \\
\text { May be distracting. } \\
\text { Must be looking at display to } \\
\text { gather info discrete on/off } \\
\text { display may increase false } \\
\text { Alarm preconceptions attention } \\
\text { Increase visual al and } \\
\text { workload digital information } \\
\text { not specific to meaning draws } \\
\text { point of regard away from } \\
\text { collision. }\end{array}$ \\
\hline $\begin{array}{l}\text { AUDITORY } \\
\text { Voice }\end{array}$ & $\begin{array}{l}\text { Does not require focus of } \\
\text { attention provides varying } \\
\text { information messages of danger. } \\
\text { Alerts driver without overloading } \\
\text { visual attention. } \\
\text { Parallel processing. } \\
\text { Personalized effect for alerting } \\
\text { driver most likely to orient driver } \\
\text { attention to the forward vehicle } \\
\text { Alerts driver without visual } \\
\text { overloading } \\
\text { Most likely to orient driver } \\
\text { attention to the forward vehicle } \\
\text { does not require visual attention. }\end{array}$ & $\begin{array}{l}\text { Not applicable for hearing } \\
\text { impaired auditory message may } \\
\text { confuse driver and cause } \\
\text { disruption of focused attention } \\
\text { Continuous tones will be } \\
\text { annoying driver may adapt to } \\
\text { continuous tones } \\
\text { Not applicable for hearing } \\
\text { impaired intensity can startle } \\
\text { driver. }\end{array}$ \\
\hline
\end{tabular}


Table 3.2 (cont). Trade Study of Display Modalities

\begin{tabular}{|c|c|c|}
\hline DISPLAY MODALITY & ADVANTAGES & DISADVANTAGES \\
\hline $\begin{array}{l}\text { HAPTIC } \\
\text { Steering Wheel } \\
\text { Vibration }\end{array}$ & $\begin{array}{l}\text { Alert driver without visual } \\
\text { overload } \\
\text { Don't need to be paying visual } \\
\text { attention } \\
\text { May orient the point of regard to } \\
\text { the forward vehicle }\end{array}$ & $\begin{array}{l}\text { Response conflict: steering to } \\
\text { avoid collision, vibration } \\
\text { May interfere at fast speeds, car } \\
\text { (wheel) may already vibrate } \\
\text { Signal misinterpreted on rough } \\
\text { road (gravel) } \\
\text { May provide ambiguous cue }\end{array}$ \\
\hline $\begin{array}{l}\text { Shoulder Belt } \\
\text { Tightening }\end{array}$ & $\begin{array}{l}\text { Alert driver without causing a } \\
\text { jerky reaction }\end{array}$ & $\begin{array}{l}\text { Use of shoulder belt may not be } \\
\text { universal it may provide } \\
\text { ambiguous cue }\end{array}$ \\
\hline Seat Vibration & $\begin{array}{l}\text { Alert driver without visual } \\
\text { overload } \\
\text { May orient the point of regard to } \\
\text { the forward vehicle }\end{array}$ & $\begin{array}{l}\text { Seat may vibrate when car is } \\
\text { traveling at fast speed signal } \\
\text { Misinterpreted on rough road } \\
\text { (gravel) } \\
\text { May misdirect attention }\end{array}$ \\
\hline
\end{tabular}

Despite the apparent advantages of voice systems over visual displays for invehicle applications, Dingus and Hulse [56] pointed out that aural information may not be a panacea for attention and workload concerns. The workload required to process auditory messages increases as the intelligibility of these messages decreases. For collision warning applications (relative to automotive navigation displays) where very short words or commands are displayed, this may be an advantage. Dingus and Hulse point out that low-cost voice synthesizers have poor quality output, whereas digitized voice is very realistic.

Even though numerous research studies have been conducted testing various forms of synthesized speech, the state-of-the-art knowledge is not yet to the point where 
intelligibility/comprehensibility can be predicted in all situations or environments. However, it is known that a number of factors influence intelligibility, including speech rate, message length, message content, message complexity, background noise, pitch, and loudness [49]. The goal of any collision intervention system should be to focus the attention of the driver on the leading vehicle. The visual displays ultimately serve as status information, while providing increased situation awareness. It is crucial that visual displays do not detract the driver's point of gaze away from a lead vehicle-braking hazard.

\subsubsection{Tactile Display Research}

There are methods of information presentation that can be used to bypass visual and auditory information. Janssen and Nilsson [70] compared a buzzer, light and a "smart gas pedal" (an accelerator pedal that would pulsate when headway was reduced) in three simulator collision-warning systems. The use of lights or buzzers increased potentially negative behavior. Negative behavior was defined as an increase in driving speed, increase in acceleration and deceleration levels, and an increase in left lane driving (passing behavior). The smart gas pedal had none of these negative side effects and reduced following distance.

\subsection{Types of Collision Intervention}

Rear-End Collision Avoidance Systems have been divided into three broad categories which are

- Driver Action Systems 
- Headway Maintenance Systems

- Automatic Control Systems

Each of these system categories has unique driver interface issues, which must be assessed before driver behavior, and the resulting system performance, can be understood.

\subsubsection{Driver Action Systems}

A driver action system, generally referred to as a "collision warning system," indicates to the driver the actions required to avoid an impending collision. For example, this system would warn the driver of an unsafe rate of closure and inform the driver to brake to avoid an impending collision. This system will not automatically take control of the vehicle to avoid a crash.

\subsubsection{Headway Maintenance Systems}

Headway maintenance systems provide collision threat information to the driver, but do not instruct the driver on specific actions or take total control of the vehicle. Headway maintenance systems can be broadly categorized into one of three types:

\subsubsection{Manual Operation Subsystem}

The manual operation subsystem displays vehicle distance to the vehicle in front, information that enables the driver to maintain a constant headway. This type of system would not provide a warning, nor would it instruct the driver as to specific actions required to avoid an accident. 


\subsubsection{Autonomous Intelligent Cruise Control (AICC)}

The Autonomous Intelligent Cruise Control (AICC) allows the driver to select a cruise control feature that, in addition to maintaining a pre-set vehicle speed, tracks a forward vehicle (when present) and automatically maintains a safe headway. Such a device may include an alarm feature, which would activate when unsafe closing speeds are detected.

\subsubsection{Cooperative Intelligent Cruise Control (CICC)}

The Cooperative Intelligent Cruise Control (CICC) subsystem is an extension of AICC in which the leading vehicle uses a rearward transponder or other vehicle dynamics to transmit information to a following vehicle.

\subsubsection{Automatic Control Systems}

Automatic control systems, generally referred to as a "collision avoidance system," are those systems that have the ability to take partial or full control of the vehicle in the event that the driver is not responding properly to an unsafe situation. They may include systems that only brake or brake and steer the vehicle to avoid a crash.

\subsection{Candidate Variables for Elimination}

\subsubsection{System Factors}

Many different system design parameters may be used as variables in a model to describe a potential rear-end collision scenario. In an effort to keep this model valid and usable, the following variables will be assigned a constant value based on the results of previous research efforts. 


\subsubsection{Graded Warning Levels}

A report defining guidelines for collision avoidance devices [33], suggested that two distinct levels of warning information need to be provided to the driver: imminent crash and cautionary crash avoidance warnings. The imminent crash avoidance warning should be presented in situations where immediate corrective actions are required. This warning should be displayed in the most salient method available.

The cautionary crash avoidance warning should be used in situations that require immediate attention and corrective action. This warning should be presented in a method that will capture the driver's attention, but will not be as annoying or disturbing as the immediate crash warning. The cautionary warning will be triggered more often in false and nuisance alarm situations. These two warning levels allow a less annoying alarm to be used for the cautionary message, by providing a more salient message when immediate action is required.

\subsubsection{Sensory Modes of Presentation}

Imminent crash avoidance warnings need at least two sensory modes [33]. One of the sensory modes should be visual, and the other either auditory or tactile. The auditory method is the most desired mode of presentation when it is necessary to command the driver's attention. The haptic sensory mode also holds promise, but requires additional research in the context of collision warning. Using the visual mode of presentation in combination with the auditory mode provides the ability to efficiently get the driver's attention and convey situation-specific information. 
Cautionary crash avoidance warnings are generally less urgent than imminent warnings and can be displayed more often. In order to minimize the driver distraction and annoyance that might be created by an abundance of auditory cues, the COMSIS report [33] recommends that the visual mode of presentation be used alone for cautionary information.

Some research has been performed on the use of haptic cues for conveying collision avoidance information to the driver. To date, there is no clear understanding of the effectiveness of these types of displays. The use of this type of display requires more research before a determination about its effectiveness can be made. For purposes of this analysis, it is assumed that the COMSIS recommendations for display modality are correct, but future display modality research will include haptic displays.

\subsubsection{Environmental Factors}

Environmental factors can affect the system and driver's ability to detect an imminent collision situation and how the vehicle will react when countermeasures to avoid the collision situation are applied. As defined in a previous section of this report, there is an abundance of environmental factors that can be included in a model to predict the outcome of a potential rear-end collision situation. In a review of the 1990 NASS General Estimates System (GES) crash statistics database, it was found that at least one environmental variable was a factor in approximately half of all LVS rear-end collisions.

While all environmental variables combined have a substantial effect on the rear-end collision scenario, several individual variables contribute to such a low percentage (less than 10\%) of collisions that their elimination from a prediction model 
would not affect its validity in most cases, particularly if those cases are not considered as model inputs.

\subsubsection{Roadway Curvature and Elevation Changes}

The 1990 GES crash statistics show that less than 10 percent of all rear-end collisions occurred on curved roadways. Even fewer (less than 3\%) of all rear-end collisions were reported to have occurred in the vicinity of a hillcrest. The effects of a hillcrest or change in roadway curvature are technically challenging circumstances that will result in increased probability of system errors. Due to the relatively low involvement of these variables, and the inability of current, low-cost technologies to provide error-free data, they will not be considered in the development of a rear-end collision prediction model for this project.

\subsubsection{Weather}

The significant variable associated with weather appears to be its effect on the vehicle's ability to brake effectively, rather than any effects it may have on the driver's ability to perceive a potential collision situation. According to 1990 GES statistics, 72 percent of rear-end collisions occurred on dry pavement and around 25 percent occurred on wet pavement. Snow and ice were listed as a contributing factor in less than four percent of rear-end collisions, while fog was listed as a factor in less than one percent of all rear-end collisions. The low percentages for visibility-impairing weather indicate that it is the weather's effect on roadway friction that contributes most to rear-end collision situations, rather than decrements to visibility, Because of the low percentages, fog and 
snow will not be considered in the development of the rear-end collision prediction model.

\subsubsection{Ambient illumination}

Less than six percent of all rear-end collisions occurred due to a lack of ambient illumination. All other collisions occurred in conditions of artificial street lighting or daylight. This is not surprising, since it is easier for a driver to detect the brake lights of a slow moving vehicle in high-contrast, darker background conditions. These results suggest that a lack of ambient illumination is not a significant factor in the rearend collision scenario and should not be considered in the development of a near-term model.

\subsubsection{Human and Behavioral Factors}

\subsubsection{Driver Impairment}

Driver impairment, due to the use of alcohol, contributed to less than three percent of rear-end collisions according to the 1990 GES crash database and less than nine percent according to the Indiana Tri-Level Crash statistics [29]. While alcoholinduced driver impairment is a significant problem in overall driving safety, it appears to be a less-significant factor in rear-end collision scenarios. Because of the relatively low impact of driver alcohol impairment on the rear-end collision scenario, and the resources required to assess affected model parameters initially, it will not be considered in the Rear-End Collision prediction model developed for this project. Drivers must accept RECA systems. In general, this means that the system must be useful to the driver and must not interfere with normal driving habits. This has several interpretations. 
First warnings given by the system should result in a minimum load on driver attention. An increase in warning frequency produces a tradeoff between two harmful driver responses. Frequent warnings may desensitize the driver and cause future warnings to be ignored. Rare war can distract the driver during critical situations. Therefore, the method of warning the driver and the frequency at which warnings are given must be chosen carefully. One potential solution is to give constant visual feedback to the driver. Unlike random warnings, constant visual feedback in the form of graduated light displays or relative distance displays may not be obtrusive to the driver. Therefore, the type of warning may not desensitize the driver. This type of warning should actually cause the driver to become accustomed to the RECAS so that they should not be startled when a critical warning is given.

\subsubsection{Criteria of Activation}

These tests vary the parameters of the time-to-collision or worst-case scenario criteria. In one case [52], the test consisted of simulating the approach to a slower vehicle ahead. Three different warning activation times were employed (three, four, and five seconds time-to-collision), and subjects were instructed to brake at the last moment to avoid a collision. The main finding of this study was that subjects tend to brake earlier when presented with earlier warning. However, it is not necessarily the case that an early warning results in earlier breaking action. A study by Janssen and Thomas found that a CAS, which employs a three-second time-to-collision plus a one-second headway criterion, performed worse (that is, lead to later braking action and more collisions) than a CAS, which does not use the additional one-second headway. 
The time-to-collision (TTC) criteria needs to be traded-off against the likelihood of false alarms: for example, a four-second TTC criterion generates more false alarm than a three-second TTC criterion, and consequently may lead to higher levels of driver annoyance, and perhaps even to disregard for the warning signals. A study by Lerner [34] in fact confirmed, under normal driving conditions, that annoyance levels tend to increase with the frequency of inappropriate alarms. For each driver in the study, the CAS generated three real alarms (at random times) during the first eight hours of driving on a given week. False alarms were generated at different rates, as shown in Table 3-3.

Table 3-3. False Alarm Rates.

\begin{tabular}{|c|c|c|c|}
\hline Driver & Alarm Rate & Duration & Signal Type \\
\hline \hline 1 & $\begin{array}{c}\text { 4 alarms per hour of } \\
\text { driving }\end{array}$ & 1 week & Tone \\
\hline \hline 2 & 1 per hour & 1 & Tone \\
\hline \hline 3 & 1 per hour & 1 & Voice \\
\hline \hline 4 & 1 per 4 hours & 2 & Tone \\
\hline \hline 5 & 1 per 8 hours & 3 & Tone \\
\hline
\end{tabular}

Findings indicated that the largest jump in annoyance ratings occurred between the conditions of four false alarms/hour and one false alarm/hour. It was also noticed that the voice stimulus device resulted in an average annoyance rating comparable to that of a tone device with a false alarm rate four times as large. Not much influence was seen between condition 4 and 5 from the table 3-3, which suggests that drivers may accept warning systems even if nuisance alarm are not extremely rare. A simulation study [34] 
based on the Federal Highway Administration (FHWA) data and plausible braking and driver reaction time assumptions reported approximately 1100 false alarms per crash with an algorithm based on a minimum following distance criterion. If a rear-end crash occurs once every 50 years, this false alarm rate averages less than two false messages per month for each driver (the average western driver is involved in a rear-end collision about once every 25 to 30 years).

\subsubsection{Gender}

There is no evidence to support that gender has any effect on the Rear-End collision scenario. For both LVS and LVM scenarios, the percentages of male and female drivers involved in rear-end collisions is equal. There is also no clear evidence that indicates that gender affects other aspects of driving behavior such as following distances or reaction times. Therefore, gender will not be used in developing a collision model.

\subsubsection{Vehicle Factors}

According to the Indiana Tri-Level Crash statistics [29], vehicular factors were reported to have contributed to 11 percent of LVS crashes and 17 percent of LVM crashes. With the exception that most crashes were related to the brake system, details were not available. Even though vehicular factors contributed to a relatively high percentage of rear-end collisions, they will not be included as a variable in future modeling efforts beyond the definition of the normal braking characteristics of the vehicle. While brake system failures have a very high potential to create a rear-end collision, a rear-end collision avoidance system could do very little to resolve this problem. In the case of poorly operating brake systems, the collision avoidance system 
could notify the driver of the condition. However, since this condition is rare on a day operations basis, further consideration in future rear-ends collision-modeling efforts would have limited utility.

\subsection{Summary}

This chapter reviewed and examined the applicable literature on the driver/human factors issues that contribute to rear-end crashes. In addition to a review of the literature, a detailed rear-end crash scenario decomposition is discussed. A preliminary model is included as a foundation for the conduct of needed future research, and as a framework for supporting the development of a rear-end collision intervention system performance specification. By understanding the complex driver/human factors of the rear-end crash and how these factors affect the timeline of an impending crash, more effective crash avoidance systems can be designed.

NHTSA has categorized collision intervention systems into three categories:

- Driver Action systems

- Headway Maintenance Systems

- Automatic Control Systems

These systems have been defined and a summary of current and past collision intervention systems is presented. Rear-end crashes can be classified into two major categories that vary with respect to causal circumstances: lead-vehicle stationary (LVS) and lead-vehicle moving (LVM). These conditions vary greatly with respect to pre-crash dynamics (e.g., closing speeds and distances) as well as a number of parameters relating 
to driver perception and performance. The demand on a driver's attention is discussed in detail, as well as a behavioral analysis on why drivers follow too closely. Perceptual factors are presented in relation to driver perception-reaction time and interpretation of relative velocity cues. Display factors are an important consideration in the design of rear-end collision intervention systems (e.g. likelihood alarm displays and warning frequency). Visual, auditory, and tactile displays are discussed in relation to Intelligent Vehicle Highway Systems (IVHS). 


\section{CHAPTER 4}

\section{OBSTACLE DETECTION SENSORS}

\subsection{Overview}

Sensor technologies of RECAS are identified based on a literature survey search about available products, prototypes, and experimental systems. The characteristics and capabilites of alternative sensor technologies are described based on published literature. Rear-end collision avoidance sensor technologies encompass microwave, millimeterwave and near-infrared radars; ultrasonic, passive infrared detectors; millimeter-wave imaging radar; and near-infrared communications. Vision at night and during inclement weather conditions will be enhanced by systems that sense images that the driver does not normally perceive and converts them into visible forms for detection by the driver. Overall, these products sense objects in the near-field around the vehicle, process information with the aid of artificial intelligence, communicate with other vehicles and roadside devices, and deliver assistance to the driver through visual, audio, and tactile presentations, and through supplementary control.

\subsection{Sensors Technology in RECAS}

The rear-end collision avoidance capabilities of motor vehicles can be significantly improved by applying advanced technologies to assist drivers in avoiding crashes. Recent 
advances in electronics, communications, processors, and control systems now allow for the design of collision avoidance systems with increased sophistication, reduced cost, and high reliability. One of the challenging aspects is the vehicle speed sensor. It needs a sensor, which does not only detect a vehicle, but also its speed. There are a few principles on which this sensor will operate. Optical sensors are too sensitive for dirt on the road. Microwave radar measurement is too expensive and power consuming. Measuring the change in inductance of an integrated on-chip coil, however, seems a very promising one. Combining the results of two slightly offset sensors can be used to measure speed, but this is rather sensitive to noise because the distance between the two sensors is small. The accuracy of this measurement can be enhanced by intelligent digital signal processing, which finds the correlation peak of the two signals. The digital signal processing may also be required to distinguish the signals of the vehicles in the various lanes. As indicated before, the single-chip speed sensor seems a tough but interesting topic. In any case, it is possible to make a simpler sensor, which only detects the vehicle. In this case the speed can be determined by combining the data of two units (spaced some $12 \mathrm{~m}$ apart). The main disadvantage of this simple approach is that it is more difficult to distinguish vehicles if the units are spaced apart more than the distance of the vehicles. Furthermore, the spacing between the units must be known exactly, which makes installation on the road more difficult. 


\subsection{Sensor Activation Distance Model}

The distance at which the sensor should be activated is calculated the analyses using UMTRI's Phase IV vehicle simulation program [45], a computerized model for simulating the braking and steering dynamics of cars, articulated vehicles and tractor/trailer combinations. This Fortran-based model allows the user to modify many vehicle parameters to determine the effects of these parametric changes on the performance of the vehicle. Phase IV was used to predict stopping performance, calculate sensor activation distances, impact speeds, and determine lateral stability. The stopping distance model used is shown in Figure 4-1 below.

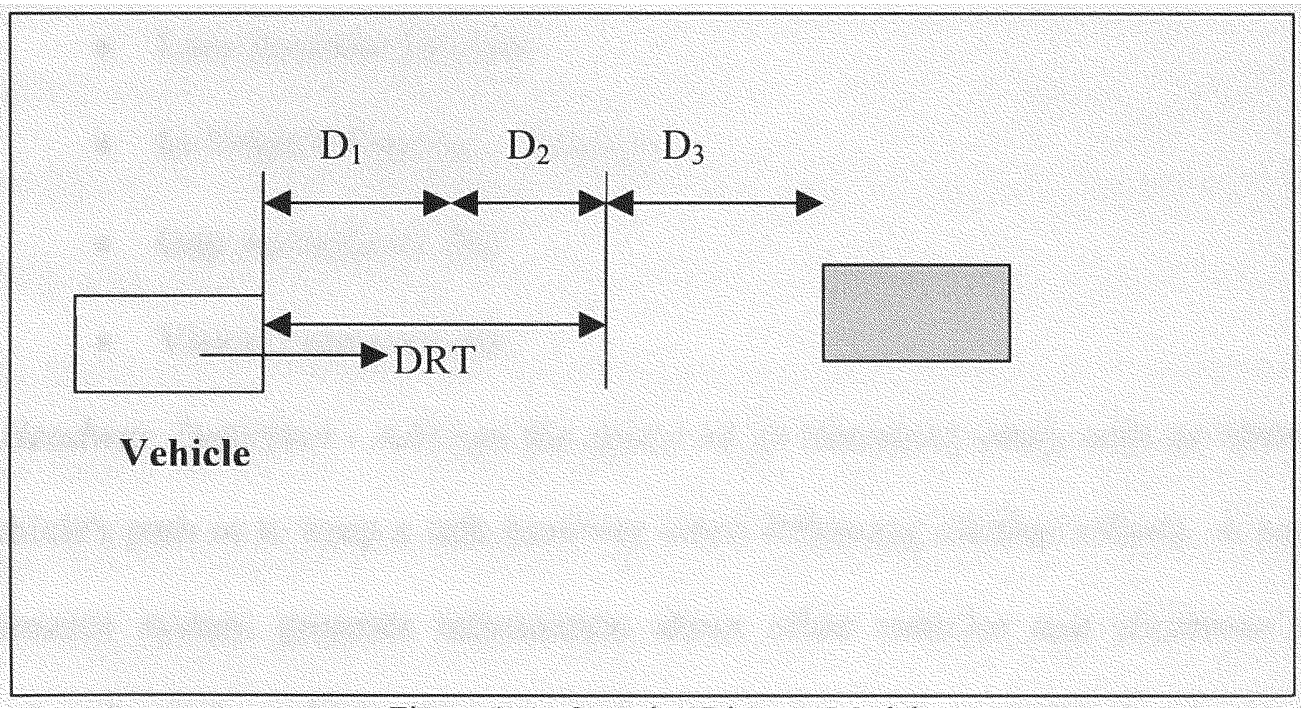

Figure 4- 1. Stopping Distance Model

where

In Figure 4-1, D1 is the distance traveled during the cognizance time, the time it takes the driver to recognize a situation that needs a braking reaction. 
D2 is the distance traveled during the reaction time, the time it takes the driver to react to the condition that exists and apply the brakes.

DRT is the driver Reaction Time

D3 is the distance traveled during the braking time, the time it takes the system to react to the brake pedal input and decelerate the vehicle to a stop.

\subsection{Purpose of Sensor Technology}

The sensor technology is divided mainly into six types

- Headway Detection

- Proximity Detection

- Lane Position Monitor

- In-Vehicle Signing - Conveys

- Gap Acceptance Aid

- Vision Enhancement

-Headway Detection - Advises the driver of an imminent crash with an obstacle in the vehicle's path or to keep a safe headway when following another vehicle. A headway maintenance system presents information about other vehicles and situations in the forward path of the vehicle. The external sensors are used to fulfill the headway and obstacle detection tasks.

-Proximity Detection - Provides the driver with information about vehicles in adjacent lanes or obstacles in the vehicle's path while backing up. 
-Lane Position Monitor - Advises the driver if vehicle is drifting out of its travel lane.

-In-Vehicle Signing - Conveys to the driver posted or dynamic information provided by the traffic control infrastructure.

-Gap Acceptance Aid- vises the driver to safely cross or turn at intersections.

-Vision Enhancement -Presents the driver with a clear image of the environment ahead during reduced visibility conditions (e.g., night/inclement weather).

The application of enabling technologies to motor vehicles, as building blocks for collision avoidance products, must meet stringent requirements in performance, cost, reliability, fault tolerance, and environmental hardening'. In addition to low cost, automotive product applications approach those of military electronics, including 5- to 10-year life, over 1,000 thermal cycles from $-40 \mathrm{C}$ to $+150 \mathrm{C}, 150 \mathrm{~g}$ mechanical shocks, and $50-\mathrm{g}$ sine wave vibrations. Moreover, automotive electronics must be immune to vehicle fluids and electromagnetic interference. Sensor technologies, in particular, must operate under additional conditions such as dust, dirt, snow, ice, fog, and adverse weather. The technologies of collision avoidance systems were previously reviewed with regard to their three main functional elements: sensor, decision-making capability, and driver/system interface. Below presents a brief description of the principles of operation of different types of sensors, and their main advantages and disadvantages. Sensors should be able to determine the headway distance, the relative speed between the preceding vehicle or obstacle and the equipped vehicle, or both. How well this is achieved can measure with the following indicators: 
- Sensing range: the maximum range over which the technique can be used.

- Resolution: the relative change in distance that can be measured.

- Directionality: the width of the beam over which the sensor is sensitive.

- Response time: how quickly the sensor can respond to a change in distance.

Table 4-1. Countermeasure concepts and Applicable Sensor technologies

\begin{tabular}{|c|c|c|}
\hline Types & Sensors & Target Crashes \\
\hline Headway Detection & Radar, laser, \& video & Rear-end \\
\hline Proximity & Radar \& ultrasonic & $\begin{array}{l}\text { Backing and lane } \\
\text { change/merge }\end{array}$ \\
\hline Lane Position Monitor & Laser and video & $\begin{array}{l}\text { Road departure and opposite } \\
\text { direction. }\end{array}$ \\
\hline In-vehicle signing & $\begin{array}{l}\text { Video, IR* comm., \& } \mu \text {-wave } \\
\text { transponder }\end{array}$ & $\begin{array}{l}\text { Road departure, opposite } \\
\text { direction and intersection } \\
\text { path } \\
\end{array}$ \\
\hline Gap Acceptance Aid & Video & Intersection/crossing path \\
\hline Vision Enhancement & Radar, passive FIR* ${ }^{*} \&$ CCD* & Reduced visibility \\
\hline
\end{tabular}

*Forward Infrared Sensors (FIR), charge-coupled device (CCC), Infrared (IR).

\subsection{External Sensors}

These sensors fulfill the tasks of headway control and obstacle detection, which are the basis of CAS Sensing techniques can be classified in three main groups, according to Stobart and Upton, [67].

\subsubsection{Optical Techniques (Passive Infrared, Laser radar and Vision)}

They all suffer from the disadvantage of being sensitive to external environmental conditions. Passive infrared and vision cannot provide a direct measurement of distance 
to an object. Laser radar appears as the most useful of these techniques, despite its high cost.

\subsubsection{Electromagnetic Techniques (FMCW Radar, Impulse radar and Capacitive)}

Unlike the optical techniques, they perform well under adverse environmental conditions. Despite its relatively high cost, $\mathrm{FMCW}$ radar seems to be the best technique for long-range distance measurement. It could also be used at short and medium range, rendering a quite flexible technique.

\subsubsection{Acoustic Techniques (Ultrasonics)}

Well suited in applications where only short-term relative distance measurements are required, because they are able to provide high resolution for a relatively low cost. Researchers are considering combinations of several of these technologies (sensor fusion), to overcome some of the disadvantages. Sensor performance may also be improved by using cooperative techniques, i.e. having vehicles equipped with front sensors and rear passive transponders [82]. As this requires wide system implementation, it is unlikely to happen in the near future.

\subsection{Headway Detection}

\subsubsection{Forward-Looking Sensors (FLS)}

These are used in headway detection systems to gather information about targets ahead of the vehicle, in both active and passive modes. Active sensors employ the principle of radar measurements to determine range, relative speed, angular position, and profile of targets. These sensors operate in a wide range of the frequency spectrum, either 
in microwave ( $\mu$-wave) (1-30 GHz), millimeter-wave (mm-wave) (30-300 GHz), or Near-Infrared (NIR) $(0.75-3 \mu \mathrm{m})$ regions. Passive sensors rely on charge-coupled device (CCD) cameras to acquire images of targets ahead and measure distances based on video image processing.

\subsubsection{Radar-Based Sensors}

Table 2 provides the characteristics and distinct features of some selected radar sensor prototypes and products. Automotive radar-based FLSs operate in various modes of transmission including pulse, pulse Doppler, frequency-modulated continuous-wave (FMCW), binary phase modulation using maximal-length pseudonoise (PN) code sequences, and pulsed frequency modulation (PFM). Cooperative radar systems using passive transponders on the rear of vehicles these systems posses some advantages, including no interfere due to masking, blinding, or crosswalk, no false alarms due to nonhazardous targets, and similar radar cross section for all tagged vehicles. However, one major drawback of such systems is that damaged tags and non-equipped obstacles cannot be detected. Measurements of distance, relative speed, and relative angle to a $17.5 \mathrm{GHz}$ transponder" mounted on the rear of a lead vehicle were accomplished at a maximum range of $150 \mathrm{~m}$.

Table 4-2. Characteristics and Features of selected Automotive Radar Sensors

\begin{tabular}{|c||c|}
\hline \multicolumn{1}{|c|}{ Characteristics* } & \multicolumn{1}{|c|}{ Distinct Features } \\
\hline \hline $35 \mathrm{G} \mathrm{Hz}$, pulse, 10-200m, 12.5m & $\begin{array}{l}\text { Beam is electronically scanned at } 2 \mathrm{H} / \mathrm{ms} \text { with } \\
\text { angular sweep of }+16 \text { and steered by stepping } \\
\text { frequency from } 34.3 \mathrm{GHz} @ 16 .\end{array}$ \\
\hline
\end{tabular}


Table 4-2 (Contd.). Characteristics and Features of selected Automotive Radar Sensors

\begin{tabular}{||l|l||}
\hline \multicolumn{1}{|c|}{ Characteristics* } & \multicolumn{1}{|c|}{ Distinct Features } \\
\hline \hline $50 \mathrm{GHz}, \mathrm{FM}-\mathrm{CW}, 2 \times 2,100 \mathrm{~m}, 2 \mathrm{~m}$ & $\begin{array}{l}\text { Fixed and single Mill's cross transmit and receive } \\
\text { antennas at right angles at each other and polarized } \\
\text { to avoid in coming radars, Side lobes are below } \\
27 \mathrm{db} .\end{array}$ \\
\hline \hline $60 \mathrm{GHz}$, Pulse, $1.5 * 1.5,15-100 \mathrm{~m}$ & $\begin{array}{l}\text { Quasi-optical design is used for heterodyne } \\
\text { detection where a gunn diode acts as transmitter } \\
\text { and local oscillator using modulated bias pulse } \\
\text { shapes. Active antenna is integrated with mixed } \\
\text { anode }\end{array}$ \\
\hline $77 \mathrm{GHz}$, & $\begin{array}{l}\text { Antenna is built with a 4-element micro strip patch } \\
\text { array using folded optic design. A micro strip PIN } \\
\text { switch matrix selects 3 scanned beams. Random is } \\
\text { self-tested for any precipitation. Diameter } \\
=145 \mathrm{~mm} .3 \text { beams are processed sequentially } \\
\text { within 1ms. }\end{array}$ \\
\hline \hline $78 \mathrm{GHz}$ & $\begin{array}{l}\text { Antenna is mechanically scanned over 30 based on } \\
\text { diffraction electronics, which is achieved by a } \\
\text { rotating drum. }\end{array}$ \\
\hline \hline *Characteristics: frequency, modulation, beam width, range and range resolution. \\
\hline \hline
\end{tabular}

\subsubsection{Laser Radar}

Two techniques exist: one uses a high power pulsed beam of infrared light, while in the other the amplitude of the light is modulated with a sine wave. The pulsed technique offers long range, high directionality and fast response time. Its limitations are its high cost sensibility to external conditions (mud, poor visibility), and the need to keep the laser power within safe levels.

Laser radar is one of the most attractive and stable systems. As a means to measure a dangerous front distance, it is embodied in automobiles. The conventional laser radar system even if it can cover several areas and vehicles in front of our vehicle; it 
monitors only one front vehicle i.e., monitors the distance and the relative speed and announces the safety situation. Here we consider strategies to monitor the entire full situation of our vehicle more comprehensively by full use of the functions of the conventional laser radar.

\subsubsection{Laser Radar System and Problem Description}

Figure 4-1 shows the laser radar system. A short laser pulse is generated from the system set at the front of the automobile and receives the reflected pulse from the reflectors of the front moving vehicles. By multiplying the speed of light by the time interval taking by the light pulse to traverse the distance between our automobile and the front vehicle, the relative distance is obtained.

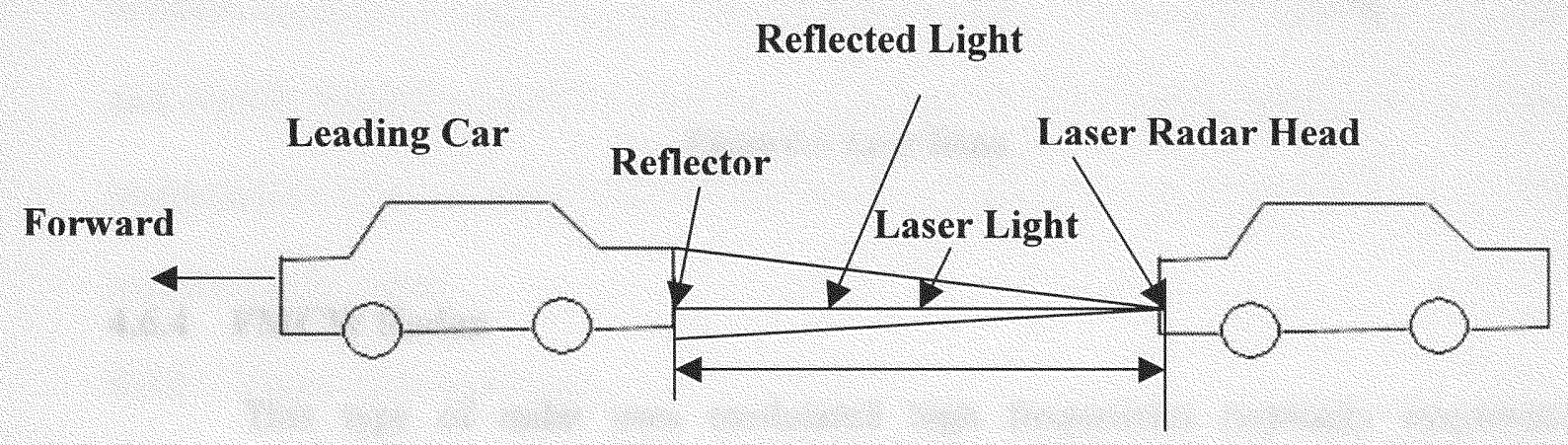

The Distance Between Cars

Figure 4-2. Laser Radar Measurement Systems

The laser radar monitors three discrete directions as shown in Figure 4- 2 the laser beam has some width and each beams has some over lapping. By a simple signal processing, the direction can be divides into 5 discrete areas. Thus the system can covers 
five areas as shown in Figure 4-2. The maximum front direction and the resolution is determined by the strength of the beams and the accuracy of the receiver and the processing speed.

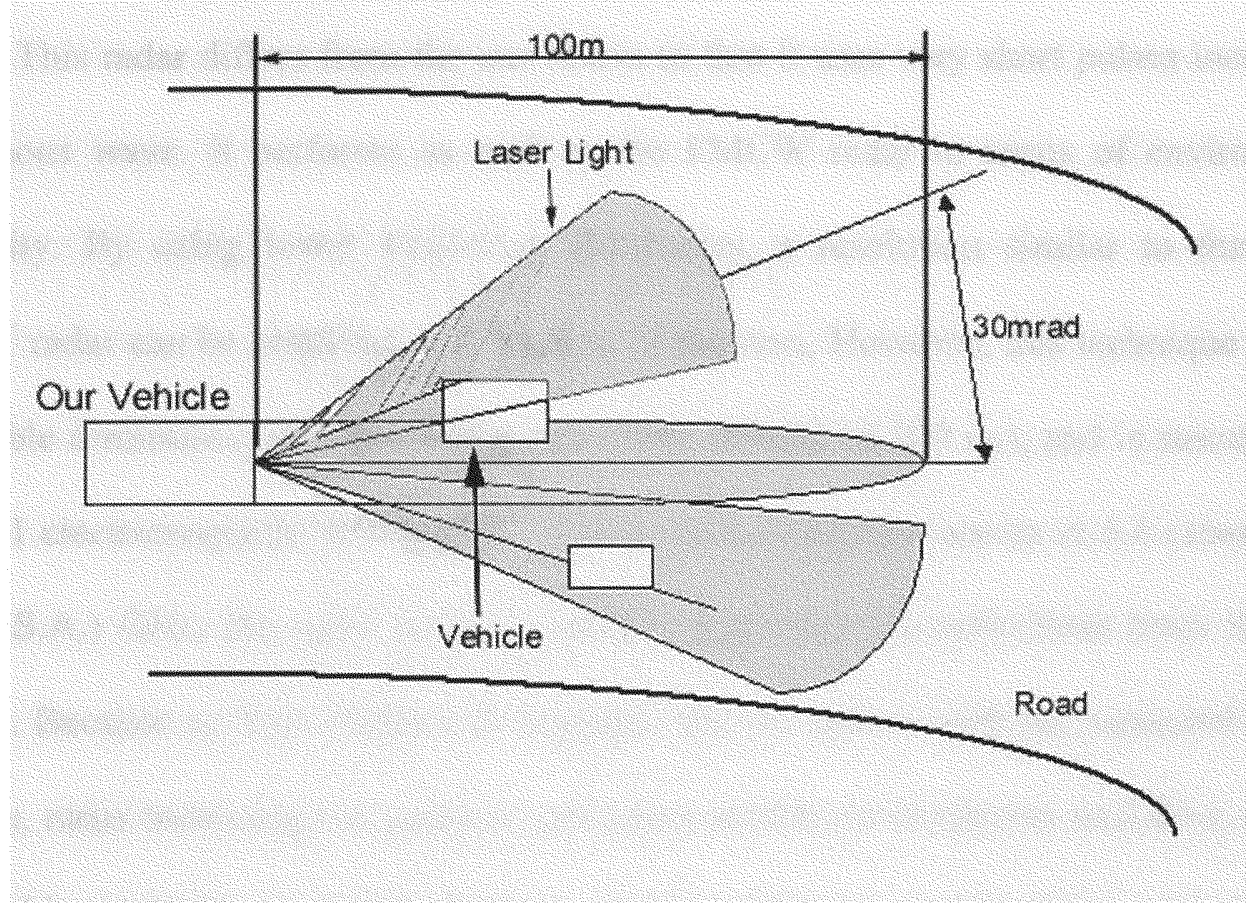

Figure 4-3. Laser Beam

\subsubsection{FMCW Radar}

This type of radar uses modulated high frequencies (typically microwave frequencies), so that the frequency difference between the reflected and the transmitted signal is proportional to the distance to the object ahead. In addition, the Doppler shift on the reflected signal can be used to determine the relative speed between the vehicle and the object ahead. Despite its high cost, this technique offers the advantages of being 
insensitive to mud and poor visibility conditions, and to allow the beam width to be modified depending on the particular application.

\subsubsection{Impulse Radar}

This radar differs from the one above in that it uses very short pulses instead of a continuous wave. It performs as well as the FMCW radar in terms of environmental immunity. By using lower frequency electronics, a resolution similar to that of the FMCW radar can be obtained, at a fraction of the cost. However, this technique presents a sensible diminution in maximum range $(50 \mathrm{~m}$. instead of $200 \mathrm{~m}$.), and is susceptible to external electromagnetic interference. Using electromagnetic waves at 5.8 (standard) or 6.2 (U.S.A.) GHz, the radar product captures and times the reflections from the target surface. Because no host medium is required, and no contact with the measured material is made, radar technology is suited to extremely hostile environments including vacuums and highly corrosive materials. Impulse radar can be to monitor blind spot, but these technologies lack of flexibility of integration, reliability, and affordable to become commercially viable.

\subsubsection{Vision Based Sensors}

Vision-based FLSs were developed for vehicle following and obstacle detection and ranging applications using one and two $\mathrm{CCD}$ cameras, respectively. In intelligent cruise control where the driver sets the headway to a lead vehicle, one camera measures only the changes in the gap between the two vehicles. The lead vehicle is identified and marked using features such as tire spacing and external shape. Once the size of the target's image is stored for a set headway, the following vehicle maintains this headway 
based on the image size, which is inversely proportional to the inter-vehicle gap. Measurements are achieved in $80 \mathrm{~ms}$ and are reliable for up to $50 \mathrm{~m}$. To determine the absolute distance to a lead vehicle, two cameras are utilized to measure the distance based on differences between right and left camera images. A significant problem with this stereovision system is image correspondence between the right and left cameras, which is alleviated by using a third camera. An experimental 3-camera vision system has been tested which measures distances to objects ahead every $100 \mathrm{~ms}$. This system consists of a custom digital processor and off-the-shelf CCD cameras to perform image acquisition, feature extraction, stereo matching, and post filtering. To further improve the cost/performance of such a system, two VLSI chips are being developed: an image acquisition chip with a wide intensity dynamic range to cover various weather and lighting conditions, and a hybrid analog/digital array processor for edge detection and stereo matching. Finally, a camera Chip is being developed to provide a high dynamic range of $100 \mathrm{dBs}$. This dynamic range is necessary both for imaging of high-contrast scenes with brightness changes of $100,000: 1$ from frame to frame and to avoid severe saturation caused by reflections of bright sources such as the sun. Further advantages of this camera chip include short access time, good ambient temperature range, and low power consumption.

\subsubsection{Ultrasonic Distance measuring Sensor}

These sensors work by measuring the time-to-flight of a short burst of sound energy. The headway distance is obtained by measuring the time between transmitting a pulse and receiving a reflection. Their main advantage is their relative low cost and small 
size; however certain target are likely to go undetected because of their poor reflection. These sensors are also very sensitive to variations in temperature and the detection range $80 \ldots 5000 \mathrm{~mm}$. These sensors have series of UP $500 \ldots$ UP 5000 . Ultrasonic senor is illustrated shown in Figure 4-3. Which has resolution $+-1.5 \ldots+-3 \mathrm{~mm}$ (acc. to model), analogue voltage and current outputs, and switching rate $2 \ldots 30 \mathrm{~Hz}$.

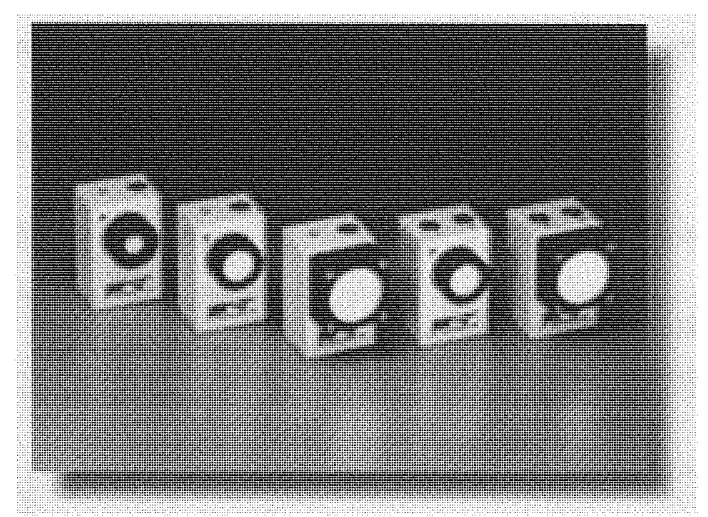

Figure 4-4. Ultrasonic Distance Sensors

\subsubsection{Passive Infrared Sensors}

These sensors measure the thermal energy emitted by objects in the vicinity of the sensor. Their main advantage is their low cost and small size, but they are unable to determine precisely the distance to any detected object, and they have a slow response time.

\subsubsection{Capacitive Sensors}

Capacitive sensors are able to detect close objects (within $2 \mathrm{~m}$.), using the capacitance variations between electrodes excited at low frequencies, typically $5 \mathrm{kHz}$. Despite their limited range, they are low in cost, and robust to external environmental 
effects. They may be useful in slow-speed collision warning, such as for obstacle detection during backing-up maneuvers.

\subsubsection{Vision System Sensors}

These techniques are based on the use of a video camera and image processing software. Their high cost and high sensitivity to external environmental effects makes their use unlikely in most vehicle applications. Another problem is the large amount of power needed to process the image.

Table 4-3. Measures of Performance for Sensor Devices

\begin{tabular}{|c|c|c|c|c|c|c|}
\hline Sensor & $\begin{array}{l}\text { Sensing } \\
\text { Range } \\
\end{array}$ & Resolution & Directionality & $\begin{array}{c}\text { Response } \\
\text { Time }\end{array}$ & Cost & Size \\
\hline Ultrasonics & $\begin{array}{r}10 \mathrm{~m} . \\
(\max .)\end{array}$ & $10 \mathrm{~mm}$. & $30 \mathrm{deg} .(\mathrm{min})$ & $\begin{array}{c}\text { Speed of } \\
\text { sound }\end{array}$ & $\$ 15$ & $\begin{array}{l}30 \mathrm{~mm} \text {. } \\
\text { diameter }\end{array}$ \\
\hline $\begin{array}{l}\text { Passive } \\
\text { Infrared }\end{array}$ & $\begin{array}{l}10 \mathrm{~m} . \\
(\max )\end{array}$ & Poor & $90 \mathrm{deg}$. & $1 \mathrm{sec}$. & $\begin{array}{l}\text { Under } \\
\$ 10\end{array}$ & $\begin{array}{l}20 \mathrm{~mm} . \\
\text { square }\end{array}$ \\
\hline $\begin{array}{l}\text { Laser } \\
\text { Radar }\end{array}$ & $\begin{array}{l}100 \mathrm{~m} . \\
(\max .) \\
0.5 \mathrm{~m} . \\
(\min )\end{array}$ & $\begin{array}{l}1 \mathrm{~mm} . \\
(\mathrm{min})\end{array}$ & $1 \mathrm{deg}$. & $\begin{array}{l}\text { Fast (10 } \\
\text { msec.) }\end{array}$ & $\begin{array}{l}\text { Over } \\
\$ 50\end{array}$ & $\begin{array}{c}50 \mathrm{~mm} . \\
\times 100 \\
\mathrm{~mm} .\end{array}$ \\
\hline $\begin{array}{l}\text { FMCW } \\
\text { Radar }\end{array}$ & $150 \mathrm{~m}$. & $10 \mathrm{~mm}$. & $\begin{array}{l}2 \text { deg. or } \\
\text { wider }\end{array}$ & $\begin{array}{l}\text { Fast (1 } \\
\text { msec) }\end{array}$ & $\begin{array}{l}\text { Over } \\
\$ 200\end{array}$ & $\begin{array}{c}250 \mathrm{~mm} . \\
\times 150 \\
\mathrm{~mm} .\end{array}$ \\
\hline $\begin{array}{l}\text { Impulse } \\
\text { Radar }\end{array}$ & $\begin{array}{r}50 \mathrm{~m} . \\
(\max .)\end{array}$ & $10 \mathrm{~mm}$. & $25 \mathrm{deg}$. & $\begin{array}{l}\text { Fast (1 } \\
\text { msec) }\end{array}$ & $\begin{array}{l}\text { Over } \\
\$ 100\end{array}$ & $\begin{array}{c}250 \mathrm{~mm} . \\
\times 100 \\
\mathrm{~mm} .\end{array}$ \\
\hline Capacitive & $\begin{array}{c}2 \mathrm{~m} . \\
(\max )\end{array}$ & $10 \mathrm{~mm}$. & $\begin{array}{l}90 \text { deg. or } \\
\text { wider }\end{array}$ & $\begin{array}{l}\text { Fast (1 } \\
\mathrm{msec})\end{array}$ & $\$ 1$ & Small \\
\hline $\begin{array}{l}\text { Vision } \\
\text { Systems }\end{array}$ & $100 \mathrm{~m}$. & Poor & Good & $\begin{array}{c}100 \\
\text { msec. }\end{array}$ & $\begin{array}{l}\text { Over } \\
\$ 200\end{array}$ & $\begin{array}{c}40 \mathrm{~mm} . \\
\times 100\end{array}$ \\
\hline
\end{tabular}




\subsection{Warning Devices}

The RECAS utilizes warning displays to alert the driver of hazardous circumstances. However, they did not provide automatic braking or release of the accelerator pedal. Warning devices in RECAS are divided into mainly three types

- Visual head-up displays

- Audio/Voice signals

- Haptic devices

\subsubsection{Visual Head-up Displays}

Warnings are displayed on the windshield in the driver's field of view, so that their content can be assimilated in conjunction with the driving scene ahead. These displays are intended to minimize distraction from driving tasks, in addition to ensuring that the warning does not go undetected.

\subsubsection{Audio/Voice signals}

In comparison to visual signals, auditory signals appear to be less intrusive on driving tasks. They are also insensitive to external conditions such as poor light, bad weather, or a dirty windshield. Two different auditory warnings have been developed: speech (synthesized voice) or non-speech (buzzer) displays.

\subsubsection{Haptic devices}

A good CAS design should provide redundant information via alternative sensory modalities, given that the primary visual or auditory channel may be degraded or 
overburdened. Research suggests that one possibility is to increase the force needed to push the gas pedal [80].

\subsection{Summary}

In this chapter, Sensor technologies of Rear-End Collision Avoidance Systems are identified based on a literature search about the available products, prototypes, and experimental systems. These sensors contribute the front-end functional element of potential countermeasure systems to rear-end, backing, lane change, roadway departure, opposite direction, intersection, and reduced visibility crashes. The characteristics and the capabilities of alternative sensor technologies are described based on published literature. Rear-End Collision Avoidance sensor technologies encompass microwave, mille meterwave and near-infrared radars; Ultrasonic transducers, charge-coupled device cameras operating in near-infrared and visible bands; passive infrared detectors; millimeter-wave imaging radar; and near-infrared communications. Vision at night and during inclement weather conditions will be enhanced by systems that sense images that the driver does not normally perceive and converts them into visible forms for detection by the driver. Overall, these products will sense objects in the near-field around the vehicle, process information with the aid of artificial intelligence, communicate with other vehicles and roadside devices, and deliver assistance to the driver through visual, audio, and tactile presentations, and through supplementary control. When a crash does occur, emergency help can be summoned to the site of the crash through a (manual or automated) collision notification transmission. Systems that incorporate collision detectors, Global Positioning 
System (GPS) position location receivers, and communications systems that provide increased safety. 


\section{CHAPTER 5}

\section{DESIGN OF REAR-END COLLISION AVOIDANCE}

\section{SYSTEM}

\subsection{Overview}

The intention of this research is to design a complete RECAS, which will have two components enhancing driver communication and awareness. The first component monitors the distance and speed of the car ahead. If an unsafe change is detected, a warning is issued and the brake pressure required to activate the auto braking system of the vehicle is computed for different speeds. The second component illuminates independent segments of the brake lights corresponding to the stopping condition of the car. This communicates the stopping intention to the driver of the following car. In order to illustrate this system, a Java program was developed to simulate the response of the proposed RECAS in a multi-lane, multi-car highway environment. The Java simulation is an applet, which is easily accessed through the World Wide Web.

\subsection{Design of RECAS}

In designing the RECAS, the first and foremost step is to determine the brake pressure required to stop the vehicle for different speeds. This involves designing a system, which computes the relative acceleration between two cars based on the change 
in distance between them. Using this distance and acceleration data, a determination is made whether danger is impending. The system compares the distance and acceleration data with experimentally determined safety values. When one of these values is exceeded, a warning is issued or the controller actuates the automatic braking mechanism. While designing the auto braking system, the required brake pressure at each speed is to be calculated; furthermore, automatic control brakes should not interfere with normal driving operations. A driver who is attempting an avoidance maneuver, such as steering, may be startled and possibly lose vehicle control if the system automatically applies brakes.

\subsubsection{Data Analysis}

The data used in the analysis were acquired experimentally on a 1991 Toyota Corolla. This vehicle was accelerated to a constant velocity of $30 \mathrm{mph}(44.0 \mathrm{ft} / \mathrm{s}), 40$ $\mathrm{mph}(58.7 \mathrm{ft} / \mathrm{s})$ and $50 \mathrm{mph}(78.3 \mathrm{ft} / \mathrm{s})$. At each of these velocities two types of braking were initiated. The first was termed "normal braking" and was meant to simulate braking as experienced when approaching a red light. The second was termed "extreme braking" and was meant to simulate braking in a dangerous situation (such as near collisions). Figure 5-1 shows the vehicle speed as a function of time during normal braking. Figure 5-2 shows the vehicle speed as a function of time during extreme braking deceleration of $8.2 \mathrm{ft} / \mathrm{s}^{2}\left(2.5 \mathrm{~m} / \mathrm{s}^{2}\right)$, which is between the deceleration calculations for normal and extreme braking. By fitting a linear curve to this data and taking the first derivative of its function the decelerations for each initial velocity were determined. Table 5-1 shows the trial velocities and the deceleration calculated for both normal and extreme braking. 


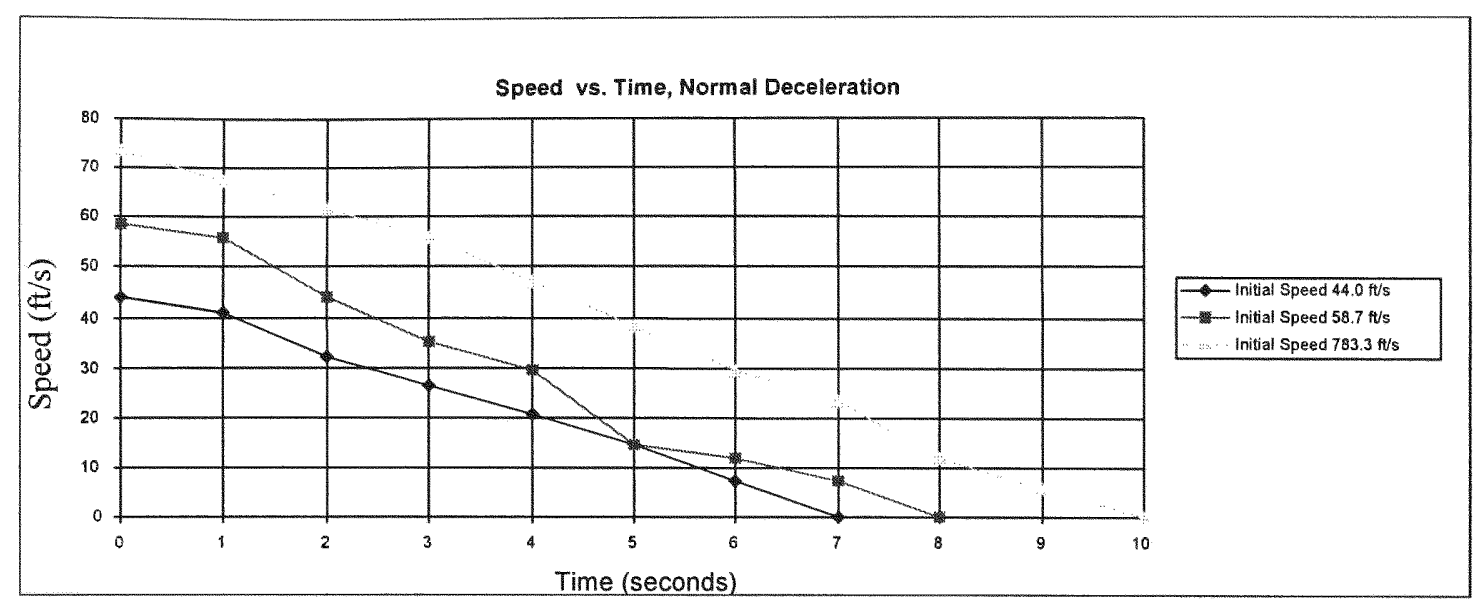

Figure 5-1. Speed vs. Time for Normal Deceleration

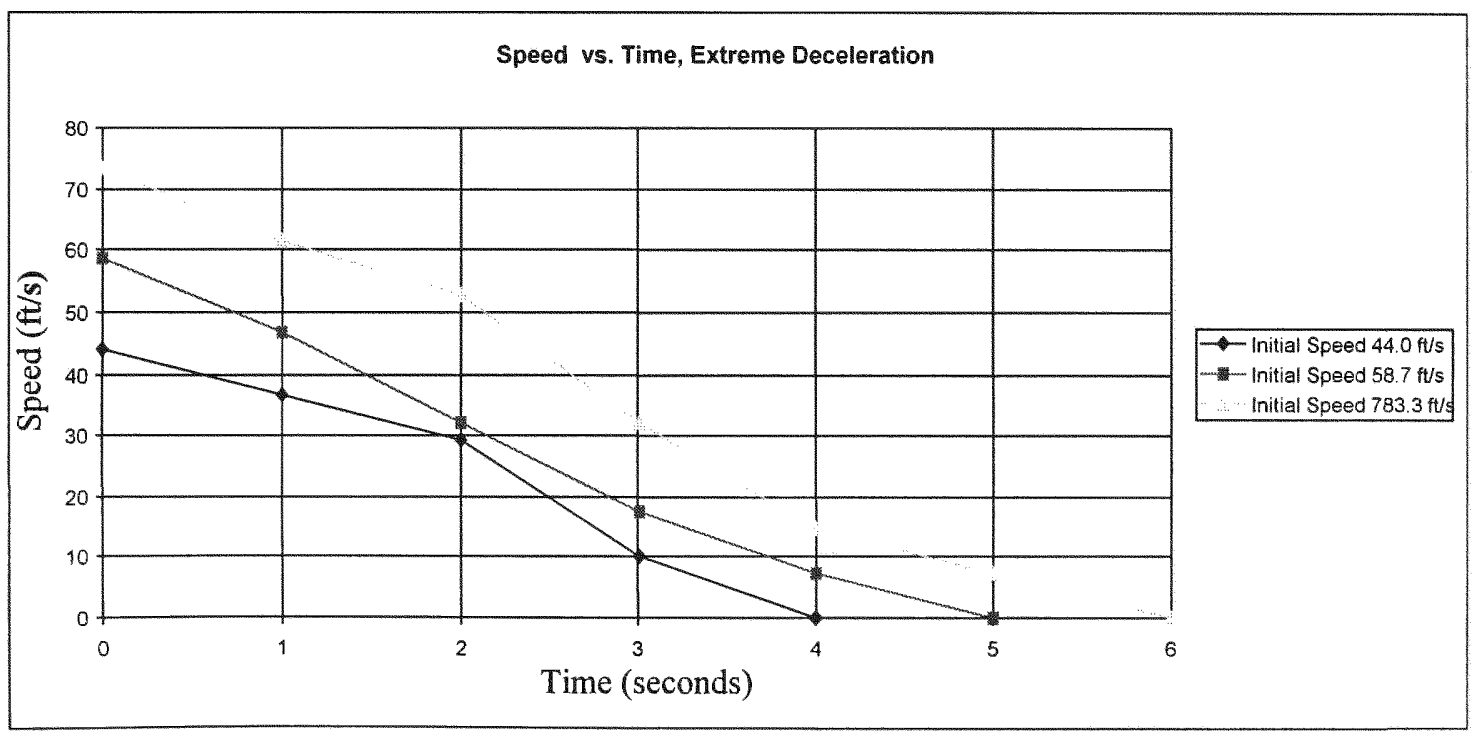

Figure 5-2. Speed vs. Time for Extreme Deceleration 
Table 5-1. Decelerations for Normal and Extreme Braking

\begin{tabular}{|c|c|c|}
\hline Initial Speed (mph) & $\begin{array}{c}\text { Deceleration for Normal } \\
\text { Braking }\left(\mathbf{f t} / \mathbf{s}^{\mathbf{2}}\right)\end{array}$ & $\begin{array}{c}\text { Deceleration for Extreme } \\
\text { Braking }\left(\mathbf{f t} / \mathbf{s}^{\mathbf{2}}\right)\end{array}$ \\
\hline \hline 30 & -6.330 & -11.075 \\
\hline 40 & -7.338 & -11.740 \\
\hline \hline 50 & -7.830 & -13.050 \\
\hline
\end{tabular}

Using the calculated decelerations for 30,40 and $50 \mathrm{mph}$, decelerations are estimated for 60,70 and $80 \mathrm{mph}$ (actual test data were not obtained at these speeds since these are not regarded as safe operating speeds). To estimate these decelerations, experimental decelerations were plotted as a function of speed. A linear trend line was then fit to that data and the decelerations at 60,70 and $80 \mathrm{mph}$ were determined using the equation of that of a line. Figure 5-3 shows the graph of the estimated deceleration as a function of time. Table 5-2 shows the estimated decelerations at 30 to $80 \mathrm{mph}$.

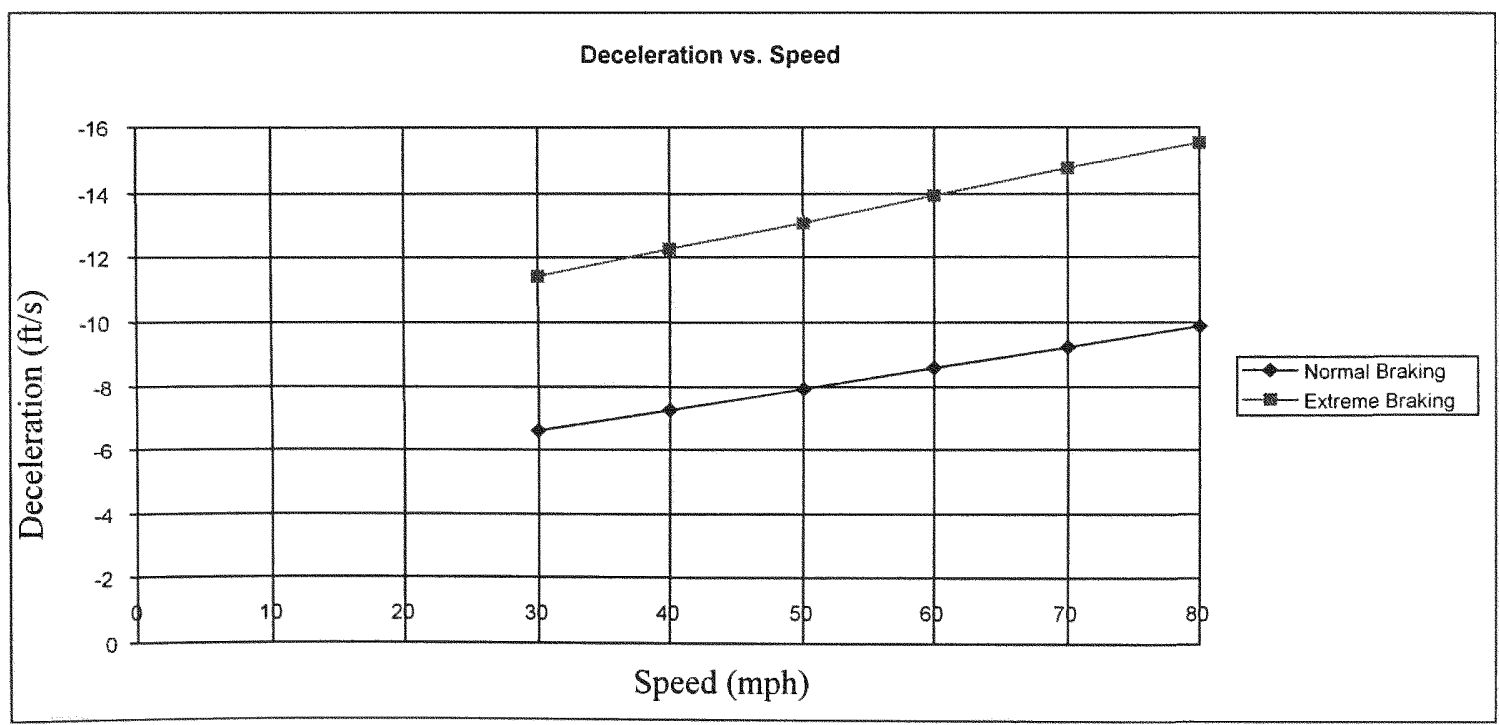

Figure 5-3. Deceleration vs. Speed 
Table 5-2. Estimated Decelerations for Normal and Extreme Braking

\begin{tabular}{|c||c|c|}
\hline Initial Speed (mph) & $\begin{array}{c}\text { Deceleration for Normal } \\
\text { Braking }\left(\mathbf{f t} / \mathbf{s}^{\mathbf{2}}\right)\end{array}$ & $\begin{array}{c}\text { Deceleration for Extreme } \\
\text { Braking }\left(\mathbf{f t} / \mathbf{s}^{\mathbf{2}}\right)\end{array}$ \\
\hline \hline 30 & -6.615 & -11.417 \\
\hline 40 & -7.269 & -12.245 \\
\hline 50 & -7.923 & -13.073 \\
\hline 60 & -8.577 & -13.901 \\
\hline 70 & -9.231 & -14.729 \\
\hline 80 & -9.885 & -15.557 \\
\hline
\end{tabular}

Once the required decelerations are determined, they need to be converted into a useful output to decelerate the car. By mathematically modeling the system of a braking wheel the brake pressure required for each deceleration can be determined. Figure 5-4 shows a sketch of the free-body diagram used to model a wheel. The equations are derived from this model and these equations are used to determine the brake pressures. Table 5-3 shows the brake pressure required for each of the decelerations above.

\subsubsection{Determining Brake Pressure}

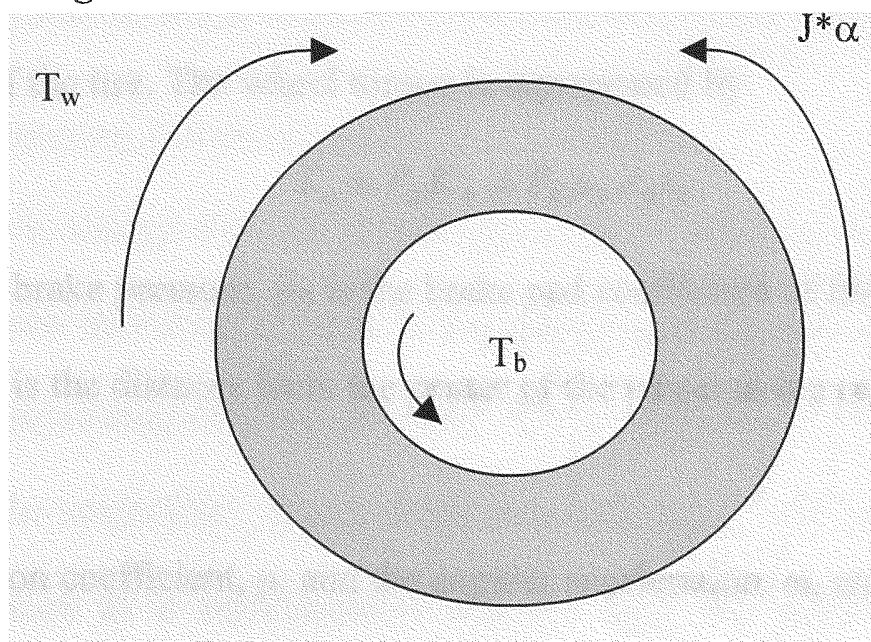

Figure 5-4. Free Body Diagram for Braking Wheel 
The equation of motion of this wheel is

$$
J^{*} \alpha+T_{b}-T_{w}=0
$$

where

$\mathrm{J}$ is the moment of inertia,

$\alpha$ is the angular acceleration of the wheel,

$T_{b}$ is the torque applied by the brake, and

$T_{\mathrm{W}}$ is the wheel torque.

This equation is rewritten to solve for the brake torque

$$
T_{b}=T_{w}-J^{*} \alpha
$$

This equation is further simplified by substituting the equations for brake torque and wheel torque. The brake torque is expressed as

$$
T_{b}=\mu N r
$$

where $\mu$ is the brake coefficient of friction [6], $\mathrm{N}$ is the weight of the vehicle per tire, and $r$ is the radius of the tire. The wheel torque is represented by

$$
T_{w}=P_{B} K_{B}=P_{B} \mu_{B} A_{B} r_{B}
$$

where $P_{B}$ is the brake pressure, $\mu_{B}$ is the brake pad coefficient of friction, $A_{B}$ is the brake pad area and $\mathrm{r}_{\mathrm{B}}$ is the distance from the center of the wheel to the centroid of the brake pad.

The brake friction coefficient, $\mu$, and the angular acceleration, $\omega$, are determined from the following relationships: 


$$
\mu=-\frac{a_{v}}{g}
$$

where $a_{v}$ is the acceleration of the vehicle and $g$ is the acceleration of gravity

$$
\alpha=\frac{a_{v}}{r}
$$

By computing these values the required brake pressure at each wheel is determined for each desired deceleration.

Table 5-3 presents the estimated brake pressures for decelerations calculated using the above equations.

Table 5-3. Estimated Brake Pressures Required for Deceleration

\begin{tabular}{|c|c|c|}
\hline Initial Speed (mph) & $\begin{array}{c}\text { Required Brake Pressure } \\
\text { for Normal Braking (psi) }\end{array}$ & $\begin{array}{c}\text { Required Brake Pressure } \\
\text { for Extreme Braking (psi) }\end{array}$ \\
\hline \hline 30 & 894.5 & 1543.8 \\
\hline 40 & 982.9 & 1655.8 \\
\hline 50 & 1071.4 & 1767.7 \\
\hline 60 & 1159.8 & 1879.7 \\
\hline \hline 70 & 1248.3 & 1991.7 \\
\hline \hline 80 & 1336.7 & 2103.6 \\
\hline
\end{tabular}

\subsubsection{Safe Following Distances}

In order to design RECAS effectively, a safe following distance range has to be defined. The safe following distance is the minimum distance a car can follow another and not hit the preceding car when braking. These distances rely on the reaction time of the driver or the controller. Since driver reaction times vary greatly, in this work 1 second is selected as a representative reaction time for an average driver. Kipling introduced the following assumptions to find the safe following distance [62]: The safe 
following distances at 1 second were chosen as the upper limit for the warning device (where the warnings would initiate) and the safe following distances at 0.02 second were chosen as the lower limit for the warning device (where automatic braking is actuated).

Table 5-4 presents the upper and lower limits for safe following distances for the warning device at speeds varying between 30 to $80 \mathrm{mph}$.

Table 5-4. Safe Following Distances

\begin{tabular}{|c|c|c|}
\hline Initial Speed (mph) & $\begin{array}{c}\text { Upper Limit, Warning } \\
\text { Initiated (ft) }\end{array}$ & $\begin{array}{c}\text { Lower Limit, Braking } \\
\text { Initiated (ft) }\end{array}$ \\
\hline \hline 30 & 15 & 0.3 \\
\hline 40 & 20 & 0.4 \\
\hline 50 & 25 & 0.5 \\
\hline 60 & 30 & 0.6 \\
\hline \hline 70 & 35 & 0.7 \\
\hline \hline 80 & 40 & 0.8 \\
\hline
\end{tabular}

\subsection{Simulation of Segmented Brake Lights Using LabVIEW}

\subsubsection{Introduction to LabVIEW}

LabVIEW is a program development application, much like various commercial C or BASIC development systems, or National Instrument's Lab Windows. However, LabVIEW is different from those applications in one important respect. Other programming systems use text-based languages to create lines of code, while LabVIEW uses a graphical programming language, $\mathrm{G}$, to create programs in block diagram form as shown in Figure 5-5. LabVIEW has extensive libraries of functions and subroutines for most programming tasks. For PC, Macintosh, and Unix based systems, LabVIEW contains application-specific libraries for data acquisition and VXI instrument control. 
LabVIEW also contains application-specific libraries for GPIB and serial instrument control, data analysis, data presentation, and data storage. LabVIEW includes conventional program development tools, so one can set breakpoints, animate program execution to see how data passes through the program, and single-step through the program to make debugging and program development easier.

LabVIEW includes libraries of functions and development tools designed specifically for instrument control. For PC, Macintosh, and Unix based systems, LabVIEW also contains libraries of functions and development tools for data acquisition. LabVIEW programs are called virtual instruments (VIs) because their appearance and operation imitate actual instruments. However, they are analogous to functions of conventional language programs. VIs have both an interactive user interface and a source code equivalent, and accept parameters from higher-level VIs. The important VI features are described below.

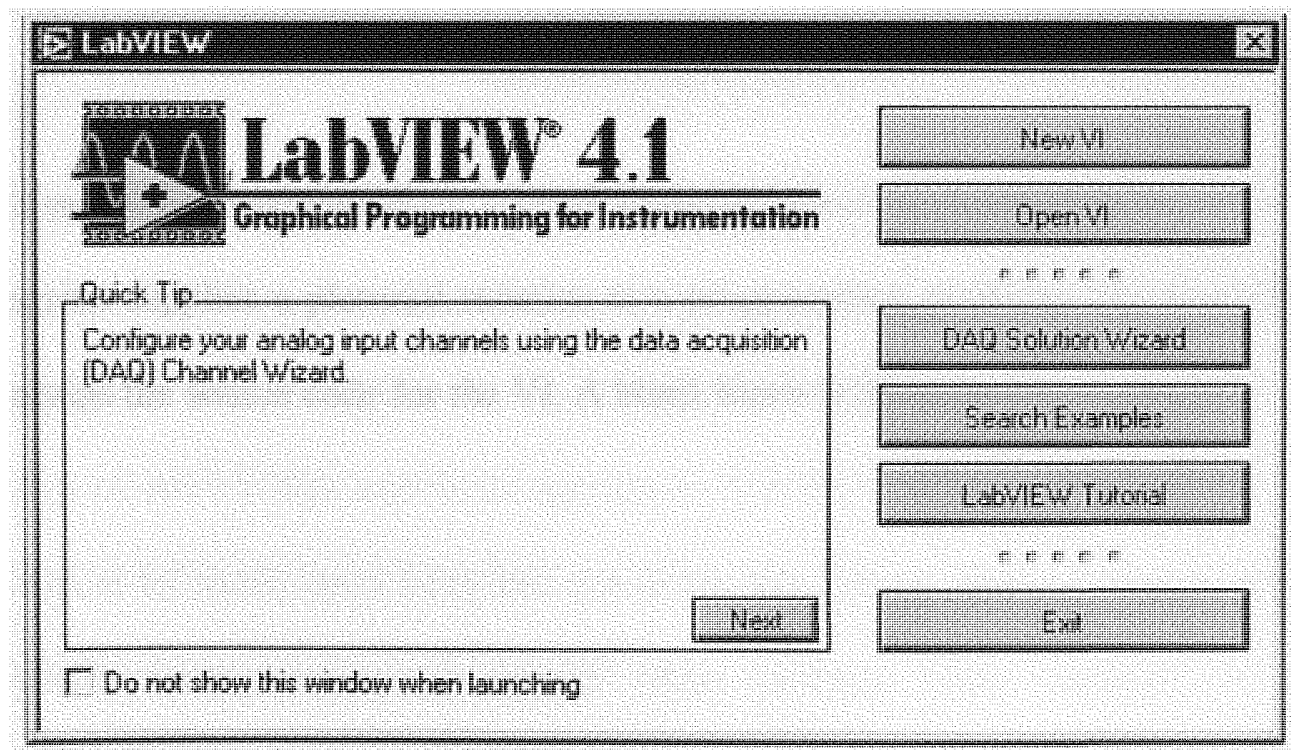

Figure 5-5. LabVIEW Graphical Programming Language 
- VIs contain an interactive user interface, which is called the front panel, because it simulates the panel of a physical instrument. The front panel can contain knobs, push buttons, graphs, and other controls and indicators. The user can input data using a keyboard and mouse, and then view the results on the computer screen as shown in Figure 5-6.

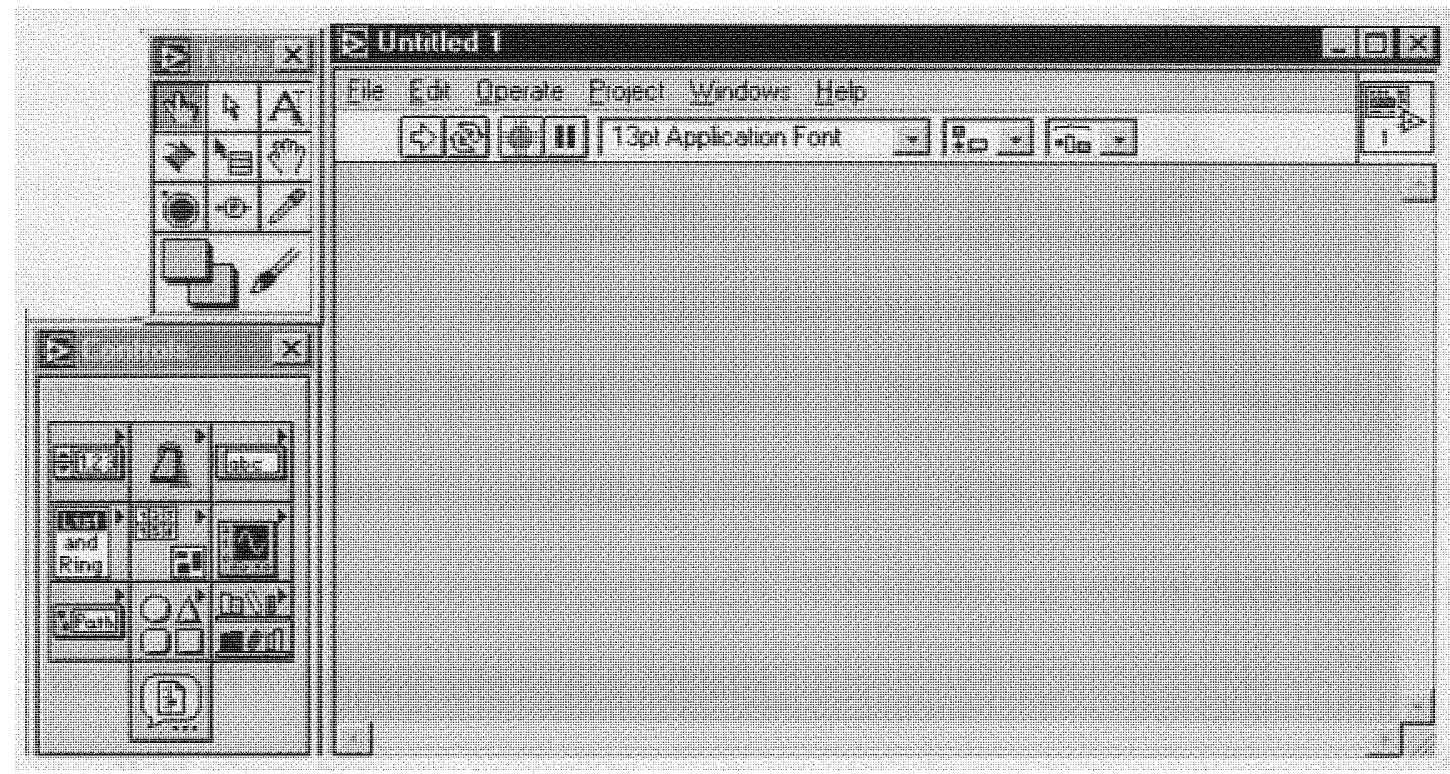

Figure 5-6. Blank Untitled Front Panel

- VIs receive instructions from a block diagram, which is constructed in G. The block diagram supplies a pictorial solution to a programming problem. The block diagram contains the source code for the VI. A blank block is illustrated in Figure 5-7. 


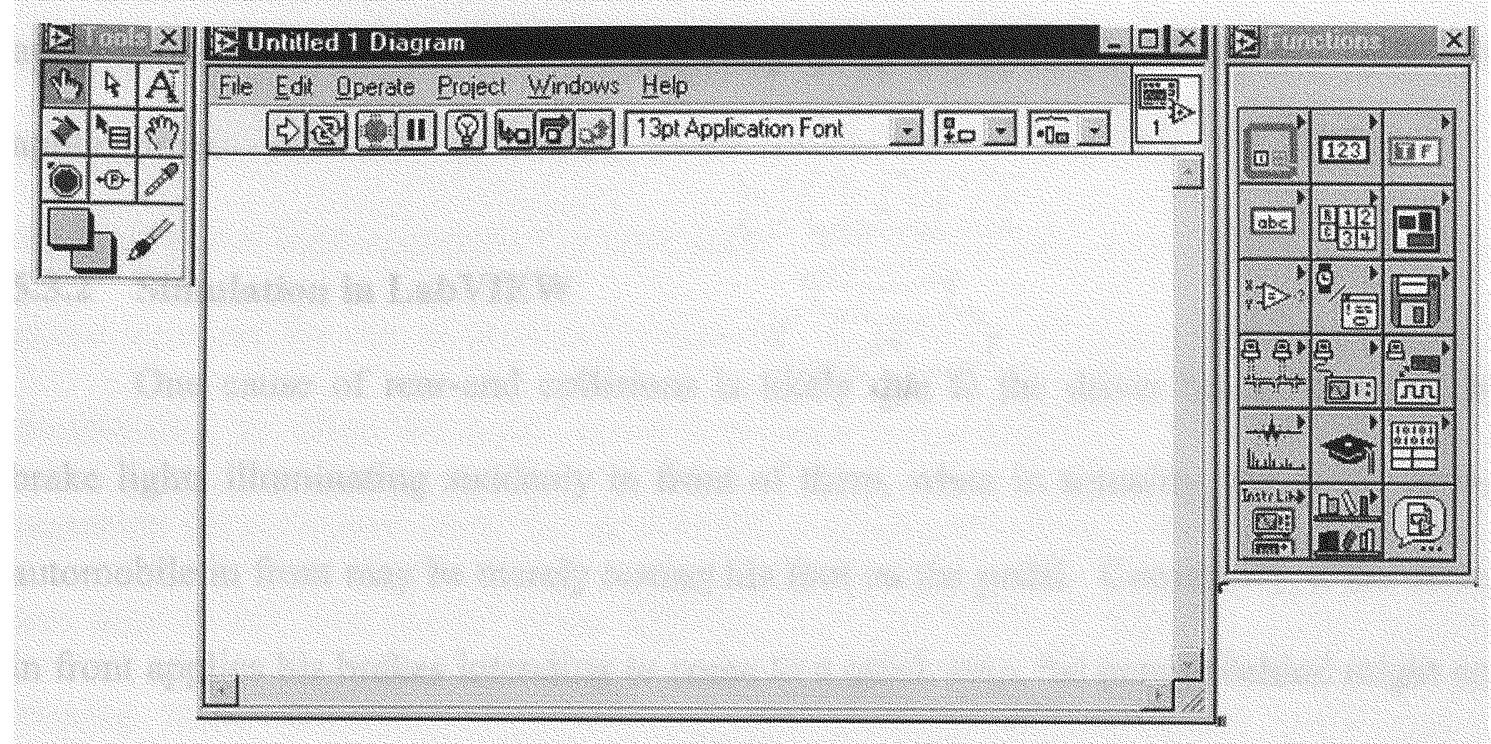

Figure 5-7. Blank Untitled Block Diagram

- VIs use a hierarchical and modular structure. It is used as top-level programs, or as subprograms within other programs or subprograms. A VI within another VI is called a subVI. The icon and connector pane of a VI work like a graphical parameter list so that other Vls can pass data to it as a subVI.

With these features, LabVIEW promotes and adheres to the concept of modular programming. The user divides an application into a series of tasks, which the user can divide again until a complicated application becomes a series of simple subtasks. The user can build a VI to accomplish each subtask and then combine those VIs on another block diagram to accomplish the larger task. Finally, the top-level VI contains a collection of subVIs that represents application functions. Because the user can execute each subVIs by itself, apart from the rest of the application, debugging is much easier. Furthermore, many low-level subVIs often perform tasks common to several 
applications, so that the user can develop a specialized set of subVIs suited to applications.

\subsubsection{Simulation in LabVIEW}

One cause of rear-end collisions is likely due to the driver being "startled" by brake lights illuminating suddenly in front of them, when in actuality, the driver of the automobile in front may be merely resting his foot on the pedal. Conversely, if the driver in front applies his brakes intending to come to a quick stop, the person behind might not realize the intentions until collision avoidance is too late. These situations are examples of poor braking communication. To design the RECAS, communication between the two cars should be increased. This communication is accomplished through the use of segmented brake lights.

The car in the front (designated as Car A) has the collision avoidance system. The stopping condition of Car A determines the number of segments illuminated, i.e., one segment for slowing, two segments for regular stopping and three segments for sudden stopping. The stopping condition of Car $\mathrm{A}$ is determined by monitoring the change in speed over time of Car A. When the deceleration of Car A passes experimentallydetermined deceleration values, the brake light segment corresponding to that deceleration is illuminated. This system utilizes the voltage input to the speedometer of Car A to determine its decelerations (for cars with mechanical speedometers a wheel mounted accelerometer can be used instead).

This design is purely a communications tool rather than intervening on behalf of the driver. It is designed to warn following drivers of the stopping intensity of the 
preceding car. By monitoring the change in speed of the car over time the brake light segments are activated when certain levels of safety are passed. The design uses three separate brake light segments for each light. The first (inner most) segment and third brake light on the car is activated when the acceleration of Car A is less than zero decelerating or when the brake pedal is pressed (even slightly). The other two light segments are activated using the decelerations calculated above. When acceleration is less than $-6 \mathrm{ft} / \mathrm{s}^{2}$ the second brake light is illuminated (this is regarded as the comfort braking zone) and when acceleration is less than $-11 \mathrm{ft} / \mathrm{s}^{2}$ the third brake light is illuminated (this is regarded as the extreme braking zone). This will help inform the driver of the car following Car A of its stopping conditions so that appropriate actions can be taken. The segmentation can also be represented as

$$
\mathrm{a}=\left\{\begin{array}{l}
<0 \text {; segment } 1 \text { on } \\
<-6 \mathrm{ft} / \mathrm{s}^{2} ; \text { segment } 1 \text { and } 2 \text { on } \\
<-11 \mathrm{ft} / \mathrm{s}^{2} \text {; segments } 1,2 \text { and } 3 \text { on }
\end{array}\right.
$$

Note that the negative sign is used to indicate deceleration.

The system is designed so that the deceleration is proportional to the intensity of the braking lights. In Figure 5-8 the controller is shown in which the deceleration is zero. 


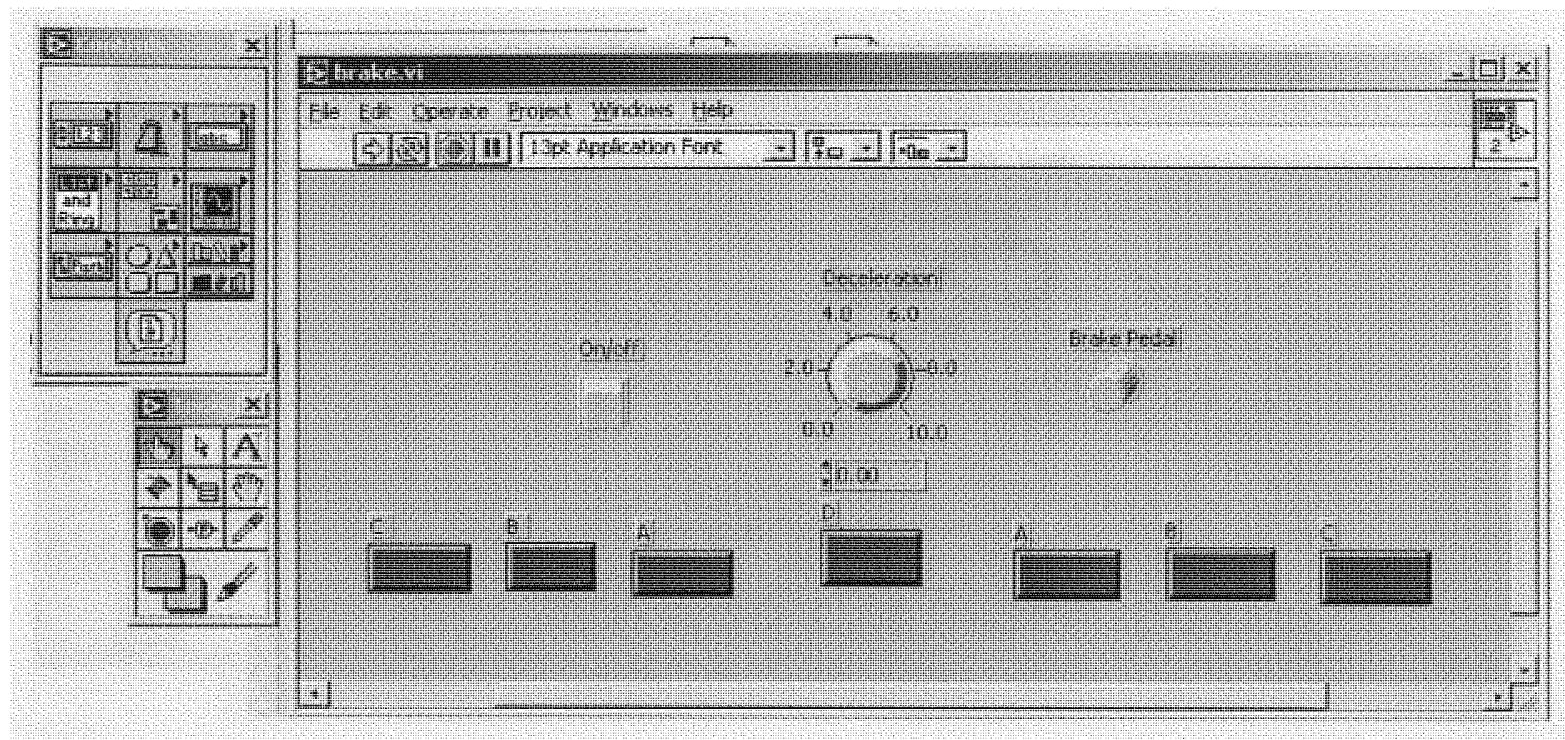

Figure 5-8. Front Panel when Deceleration is Zero

The design of this controller uses simple if/then controller logic. The system monitors the car's change in speed over time and compares that to the values given above. When these values are reached, the corresponding brake light is illuminated. Since this method is not tested on an actual vehicle, a dial control in LabVIEW environment is used to generate possible decelerations. This controller also uses a Boolean button to simulate the brake pedal actuation. Figure 5-11 shows the wiring diagram for this controller while Figure 5-9 shows the front panel for the controller. Figure 5-10 illustrates the front panel when Deceleration is Maximum. 


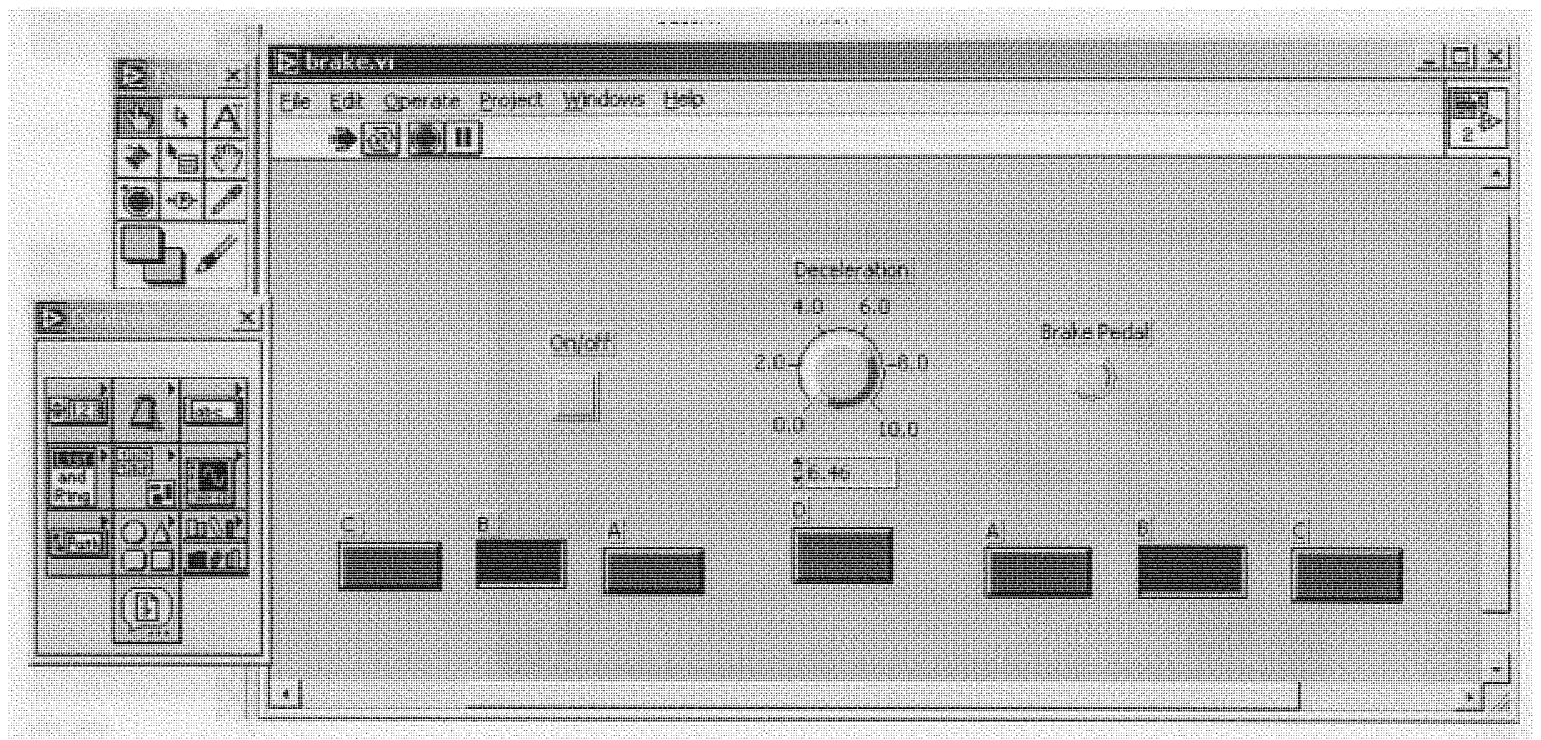

Figure 5-9. Front Panel when Deceleration is at $6.46 \mathrm{ft} / \mathrm{s}^{2}$

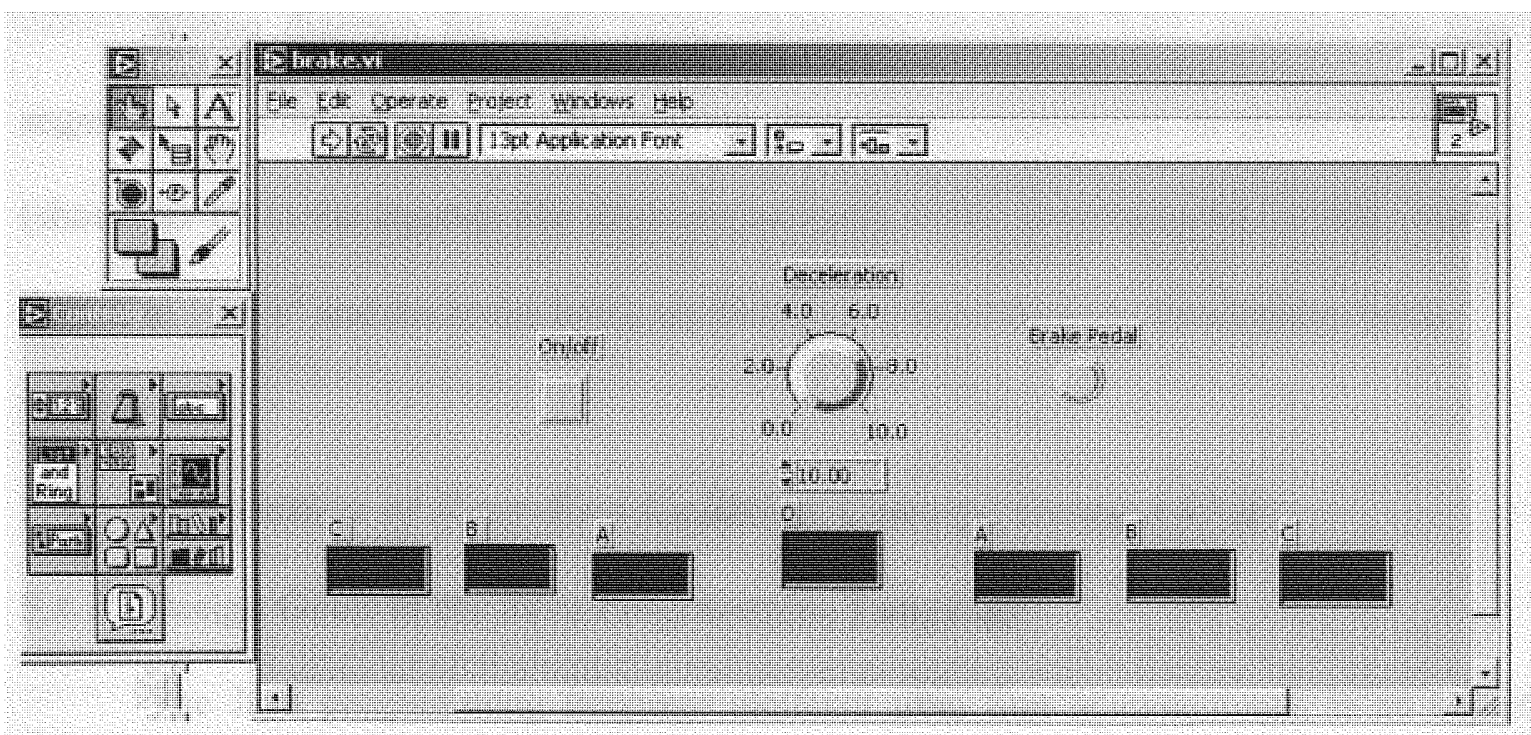

Figure 5-10. Front Panel when Deceleration is Maximum 


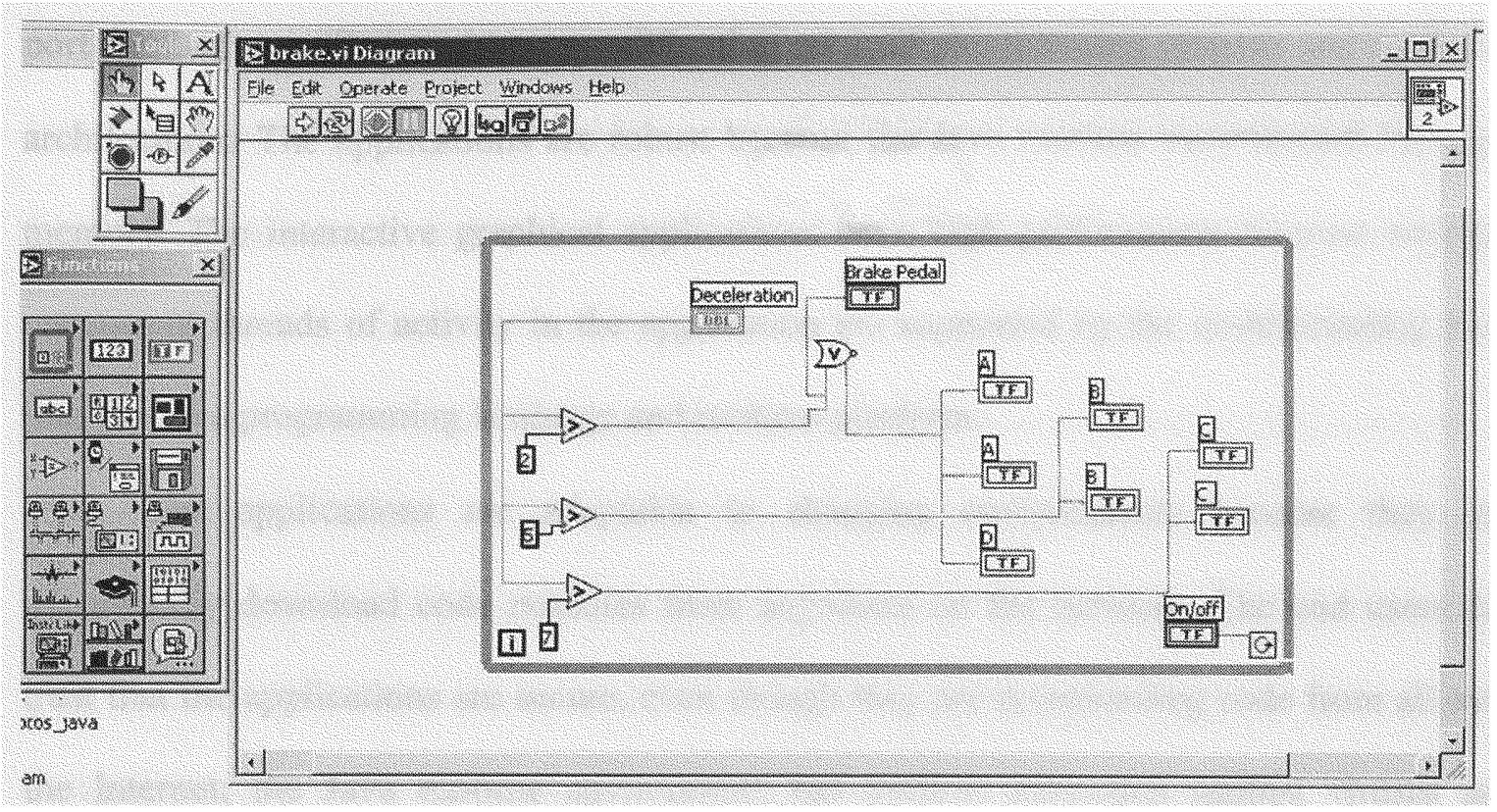

Figure 5-11. Wiring Diagram for Brake Lights

Wiring diagram for brake lights, illustrated in Figure 5-11, contains the four segments of wire, which are connected to four lights represented as $\mathrm{A}, \mathrm{B}, \mathrm{C}$, and D (shown as TF in the figure). The deceleration knob, which is represented as DBL, varies from 0 to $10 \mathrm{ft} / \mathrm{s}^{2}$ and the brake lights are illuminated according the deceleration value.

\subsection{Simulation of Rear-End Collision Concept Using JAVA}

\subsubsection{Design Goals of the Java Programming Language}

The Java programming language platform from Sun Microsystems, is an objectoriented programming language. The development cycle is much faster because the Java technology is interpreted. This new approach makes the compile-link-load-test-crash-debug cycle obsolete and simplifies it to just compile and run. Most applications are portable across multiple platforms. The applications are developed once, and the user never needs to 
port them--they will run without modification on multiple operating systems and hardware architectures. The applications are robust because the Java runtime environment manages memory. The interactive graphical applications have high performance because multiple concurrent threads of activity in the application are supported by the multithreading built into the Java programming language and runtime platform.

The applications are adaptable to changing environments because they can dynamically download code modules from anywhere on the network. The end users can trust that the applications are secure, even though they are downloading code from all over the Internet; the Java runtime environment has built-in protection against viruses and tampering. The Java programming language platform provides a portable, interpreted, highperformance, simple, object-oriented programming language and supporting run-time environment. The Hot Java Browser is an innovative World Wide Web browser, and the first major application written using the Java platform. It is the first browser to dynamically download and execute Java code fragments from anywhere on the Internet and do so in a secure manner.

The design requirements of the Java programming language are driven by the nature of the computing environments in which software must be deployed. The massive growth of the Internet and the World Wide Web leads us to a completely new way of looking at development and distribution of software. To live in the world of electronic commerce and distribution, Java technology must enable the development of secure, high performance, and highly robust applications on multiple platforms in heterogeneous, distributed networks. Operating on multiple platforms in heterogeneous networks 
invalidates the traditional schemes of binary distribution, release, upgrade, patch, and so on. To survive in this rapidly changing environment, the Java programming language must be architecture neutral, portable, and dynamically adaptable. The system that emerged to meet these needs is simple, so it can be easily programmed by most developers; familiar, so that current developers can easily learn the Java programming language; object oriented, to take advantage of modern software development methodologies and to fit into distributed client-server applications; multithreaded, for high performance in applications that need to perform multiple concurrent activities, such as multimedia; and interpreted, for maximum portability and dynamic capabilities.

\subsubsection{Simple, Object Oriented, and Familiar Environment}

Primary characteristics of the Java programming language include a simple language that can be programmed without extensive programmer training while being attuned to current software practices. The fundamental concepts of Java technology are grasped quickly; programmers can be productive from the very beginning. The Java programming language is designed to be object oriented from the ground up. Object technology has finally found its way into the programming mainstream after a gestation period of thirty years. The needs of distributed, client-server-based systems coincide with the encapsulated, message-passing paradigms of object-based software. To function within increasingly complex, network-based environments, programming systems must adopt object-oriented concepts. 
Java technology provides a clean and efficient object-based development platform. The Java programming language can access existing libraries of tested objects that provide functionality ranging from basic data types through $\mathrm{I} / \mathrm{O}$ and network interfaces to graphical user interface toolkits. These libraries are extended to provide new behavior. Even though $\mathrm{C}++$ was rejected as an implementation language, keeping the Java programming language looking like $\mathrm{C}++$ as far as possible results in it being a familiar language, while removing the unnecessary complexities of $\mathrm{C}++$. Having the Java programming language retain many of the object-oriented features and the "look and feel" of $\mathrm{C}++$ means that programmers will migrate easily to the Java platform and be productive quickly [86].

\subsubsection{Robust and Secure Platform}

The Java programming language is designed for creating highly reliable software. It provides extensive compile-time checking, followed by a second level of run-time checking. Language features guide programmers towards reliable programming habits. The memory management model is extremely simple: objects are created with a new operator. There are no explicit programmer-defined pointer data types, no pointer arithmetic, and automatic garbage collection. This simple memory management model eliminates entire classes of programming errors that bedevil $\mathrm{C}$ and $\mathrm{C}++$ programmers. One can develop Java code with confidence that the system will find many errors quickly and that major problems will not lay dormant until after the production code has shipped. Java technology is designed to operate in distributed environments, which means that security is of paramount importance. With security features designed into the language and run-time system, Java technology lets the programmer construct applications that 
cannot be invaded from outside. In the network environment, applications written in the Java programming language are secure from intrusion by unauthorized code attempting to get behind the scenes and create viruses or invade file systems [86].

\subsubsection{Neutral Architecture and Portable Features}

Java technology is designed to support applications that will be deployed into heterogeneous network environments. In such environments, applications must be capable of executing on a variety of hardware architectures. Within this variety of hardware platforms, applications must execute atop a variety of operating systems and interoperate with multiple programming language interfaces. To accommodate the diversity of operating environments, the Java Compiler product generates byte codes--an architectureneutral intermediate format designed to transport code efficiently to multiple hardware and software platforms. The interpreted nature of Java technology solves both the binary distribution problem and the version problem; the same Java programming language byte code runs on any platform. Architecture neutrality is just one part of a truly portable system. Java technology takes portability a stage further by being strict in its definition of the basic language. Java technology puts a stake in the ground and specifies the sizes of its basic data types and the behavior of its arithmetic operators. Again all Java programs are the same on every platform--there are no data type incompatibilities across hardware and software architectures.

The architecture-neutral and portable language platform of Java technology is known as the Java virtual machine. It is the specification of an abstract machine for which Java programming language compilers can generate code. Specific implementations of the 
Java virtual machine for specific hardware and software platforms then provide the concrete realization of the virtual machine. The Java virtual machine is based primarily on the posix interface specification--an industry-standard definition of a portable system interface. Implementing the Java virtual machine on new architectures is a relatively straightforward task as long as the target platform meets basic requirements such as support for multithreading.

\subsubsection{High Performance}

Performance is always an important consideration in computer technology. The Java platform achieves superior performance by adopting a scheme by which the interpreter can run at full speed without needing to check the run-time environment. The automatic garbage collector runs as a low-priority background thread, ensuring a high probability that memory is available when required, leading to better performance. Applications requiring large amounts of computer power can be designed such that compute-intensive sections can be rewritten in native machine code as required and interfaced with the Java platform. In general, users perceive that interactive applications respond quickly even though they are interpreted.

\subsubsection{Interpreted, Threaded, and Dynamic Interpreter}

The Java interpreter executes Java byte codes directly on any machine to which the interpreter and run-time system have been ported. In an interpreted platform such as the Java technology-based system, the link phase of a program is simple, incremental, and lightweight. The programmer benefits from much faster development cycles--prototyping, 
experimentation, and rapid development are the normal case, versus the traditional heavyweight compile, link, and test cycles.

Modern network-based applications, such as the Hot Java Browser for the World Wide Web, typically need to do several things at the same time. A user working with the Hot Java Browser runs several animations concurrently while downloading an image and scrolling the page. Java technology's multithreading capability provides the means to build applications with many concurrent threads of activity. Multithreading thus results in a high degree of interactivity for the end user.

The Java platform supports multithreading at the language level with the addition of sophisticated synchronization primitives: the language library provides the thread class, and the run-time system provides monitor and condition lock primitives. At the library level, moreover, Java technology's high-level system libraries have been written to be thread safe: the functionality provided by the libraries is available without conflict to multiple concurrent threads of execution.

While the Java compiler is strict in its compile-time static checking, the language and run-time system are dynamic in their linking stages. Classes are linked only as needed. New code modules can be linked in on demand from a variety of sources, even from sources across a network. In the case of the Hot Java Browser and similar applications, interactive executable code can be loaded from anywhere, which enables transparent updating of applications. The result is on-line services that constantly evolve; they can remain innovative and fresh, draw more customers, and spur the growth of electronic commerce on the Internet. 


\subsubsection{The Java Platform: A New Approach to Distributed Computing}

Taken individually, the characteristics discussed above are found in a variety of software development platforms. What is completely new is the manner in which Java technology and its runtime environment have combined them to produce a flexible and powerful programming system.

Developing the applications using the Java programming language results in software that is portable across multiple machine architectures, operating systems, and graphical user interfaces, it is secure, and offers high performance. With Java technology, the user's job as a software developer is much easier--focus their full attention on the end goal of shipping innovative products on time, based on the solid foundation of the Java platform.

\subsubsection{Object Oriented Feature of Java}

To stay abreast of modern software development practices, Java is object oriented from the ground up. The point of designing an object-oriented language is not simply to jump on the latest programming fad. The object-oriented paradigm meshes well with the needs of client-server and distributed software. Benefits of object technology are rapidly becoming realized as more organizations move their applications to the distributed clientserver model.

\subsubsection{Object Oriented Programming in Java}

To be truly considered "object oriented," a programming language should support at a minimum four characteristics: 
- Encapsulation--implements information hiding and modularity (abstraction)

- Polymorphism--the same message sent to different objects results in behavior that is dependent on the nature of the object receiving the message,

- Inheritance--defines new classes and behavior based on existing classes to obtain code re-use and code organization

- Dynamic binding--objects could come from anywhere, possibly across the network. The programmer need to be able to send messages to objects without having to know their specific type at the time the programmer's write the code. Dynamic binding provides maximum flexibility while a program is executing.

Java meets these requirements nicely, and adds considerable run-time support to make the software development much easier than relative to the conventional.

\subsubsection{Programming Using Object Oriented Technology in Java}

One of the principal advantages of object-oriented programming techniques over procedural programming techniques is that they enable programmers to create modules that do not need to be changed when a new type of object is added. A programmer simply creates a new object that inherits many of its features from existing objects. This makes object-oriented programs easier to modify. The two most important concepts in objectoriented programming are the classes and the objects. In the broadest term, an object is a thing, both tangible and intangible. A program written in object-oriented style will consist of interacting objects. For a program to maintain bank accounts for a bank, one can have 
many Accounts, Customers, Transactions, and ATM objects. An object is comprised of data and operations that manipulate these data. For example, an Account object may consist of data such as account number, owner, date opened, initial balance, and current balance and operations such as deposit, transfer, and withdrawal. The diagram shown in Figure 5-12 represents an object.

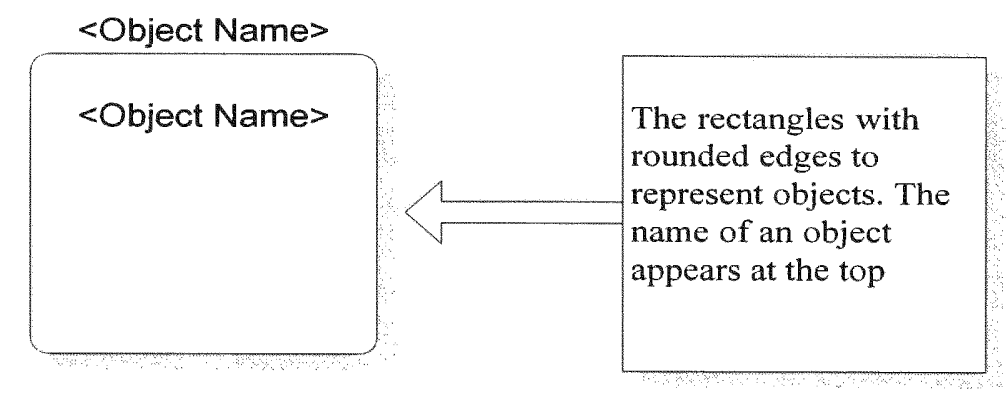

\section{Example}

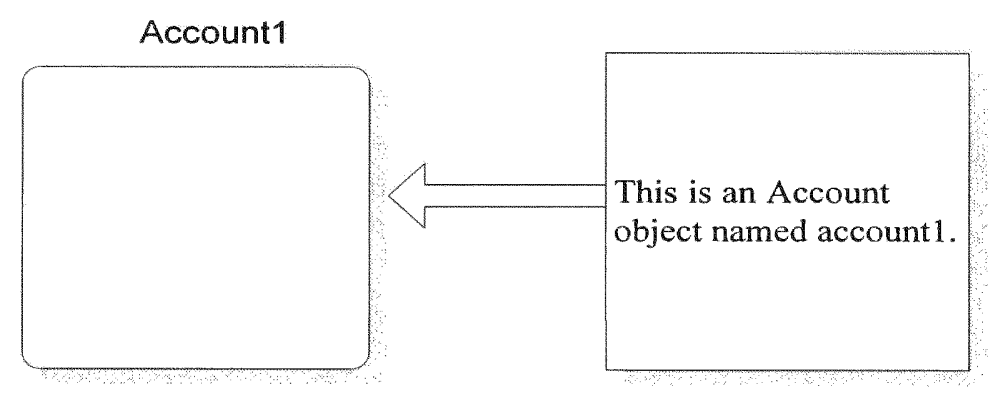

Figure 5-12. A graphical representation of an object

Inside a program the programmer must write instructions to create objects. An object is defined via its class, which determines everything about an object. Objects are individual instances of a class. A class is a kind of mold or template that the computer uses to create objects. An object is called an instance of a class. An object is an instance 
of exactly one class. An instance of a class belongs to the class. A class must be defined before the programmer can write create an instance (object) of the class.

\subsubsection{Java Programming Basics}

The first example Java application program given below displays HELLO WORLD on the screen.

/*

The HelloWorldApp class implements an application that simply displays "Hello World!" to the standard output.

*/

class HelloWorldApp \{ public static void main(String[] args) \{

System.out.println ("Hello World!"); //Display the string. \} \}

\subsubsection{Comments in Java Code}

The "Hello World" application has two blocks of comments. The first block, at the top of the program, uses $/^{*}$ and $* /$ delimiters. Later, a line of code is explained with a comment that is marked by // characters. The Java language supports a third kind of comment, as well -- the familiar C-style comment, which is delimited with $/ *$ and $* /$.

\subsubsection{Defining a Class}

In the Java language, each method (function) and variable exists within a class or an object (an instance of a class). The Java language does not support global functions or variables. Thus, the skeleton of any Java program is a class definition. 


\subsubsection{Main Method}

The entry point of every Java application is its main method. When the programmer runs an application with the Java interpreter, one should specify the name of the class to run. The interpreter invokes the main method defined within that class. The main method controls the flow of the program, allocates whatever resources are needed, and runs any other methods that provide the functionality for the application.

\subsubsection{Using Classes and Objects}

The other components of a Java application are the supporting objects, classes, methods, and Java language statements that write to implement the application. Using Classes and Objects introduces these components. The Java applet is a program that adheres to a set of conventions that allows it to run within a Java-compatible browser.

Here is the code for the "Hello World" applet:

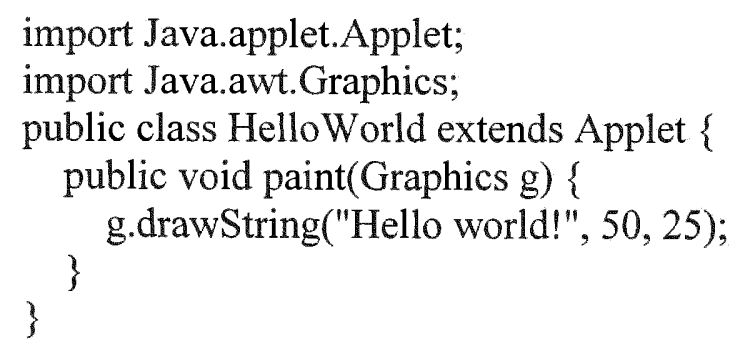

\subsubsection{Importing Classes and Packages}

The code above starts off with two import statements. By importing packages, a class can easily refer to predefined classes in those packages. In the 
Java language, packages are used to group classes, similar to the way libraries are used to group $\mathrm{C}$ functions.

\subsubsection{Defining an Applet Subclass}

Every applet must define a subclass of the applet class. In the "Hello World" applet, this subclass is called Hello World. Applets inherit a great deal of functionality from the applet class, ranging from communication with the browser to the ability to present a graphical user interface (GUI).

\subsubsection{Implementing Applet Methods}

The Hello World applet implements just one method, the paint method. Every applet must implement at least one of the following methods: init(), start(), or paint(Graphics g):

- Init $($ ) is called when the applet is loaded into memory

- Start() is called when the applet's HTML document is displayed

- Paint(Graphics g) is called when the applet's display area is exposed or when repaint $($ ) is called

Unlike Java applications, applets do not need to implement a main method.

\subsubsection{Running an Applet}

Applets are meant to be included in HTML pages. Using the <APPLET> tag, the user specifies (at a minimum) the location of the applet subclass and the 
dimensions of the applet is onscreen display area. When a Java-capable browser encounters an $<$ APPLET $>$ tag, it reserves onscreen space for the applet, loads the applet subclass onto the computer the browser is executing on, and creates an instance of the applet subclass.

The bold lines of the following listing comprise the $<$ APPLET $>$ tag that includes the "Hello World" applet in an HTML page.

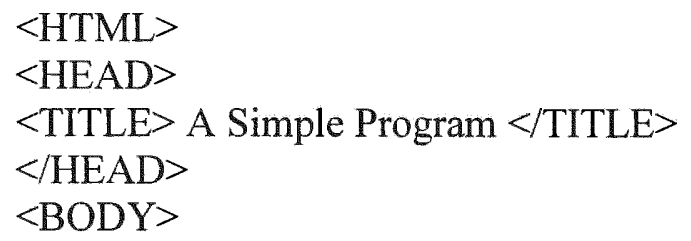

The above $<$ APPLET $>$ tag specifies that the browser should load the class whose compiled code is in the file named HelloWorld.class. The browser looks for this file in the same directory as the HTML document that contains the tag.

When the browser finds the class file, it loads it over the network, if necessary, onto the computer the browser is running on. The browser then creates an instance of the class. If the programmer includes an applet twice in one page, the browser loads the class file once and creates two instances of the class.

The WIDTH and HEIGHT attributes are like the same attributes in an $<\mathrm{IMG}>$ tag: They specify the size in pixels of the applet's display area. Most browsers do not let the applet resize itself to be larger or smaller than this display area. For example, every 
bit of drawing that the "Hello World" applet does in its paint method occurs within the 150x25-pixel display area that the above $<$ APPLET $>$ tag reserves for it.

\subsection{Development of Simulations}

Computer-based simulations are very important in the critical conditions where tasks need to be operated under adverse conditions without error. The goal of the development of simulation software for a Rear-End Collision Avoidance System is for different angles of the sensors to scan the preceding vehicle without missing a single car while lane changing, in the front and the blind spot car is to be detected. The software developed is in Java so that it is accessible on the World Wide Web to access to all the users who are developing RCAS. It demonstrates that it is capable of accepting the sensor angle and depth of the sensor, as shown in Figure 5-13.

\section{Simulation of Rear-End Collision Avoidance System \\ Robotics and Automation Laboratory \\ Forida Intemational University, Miam, Forida.}

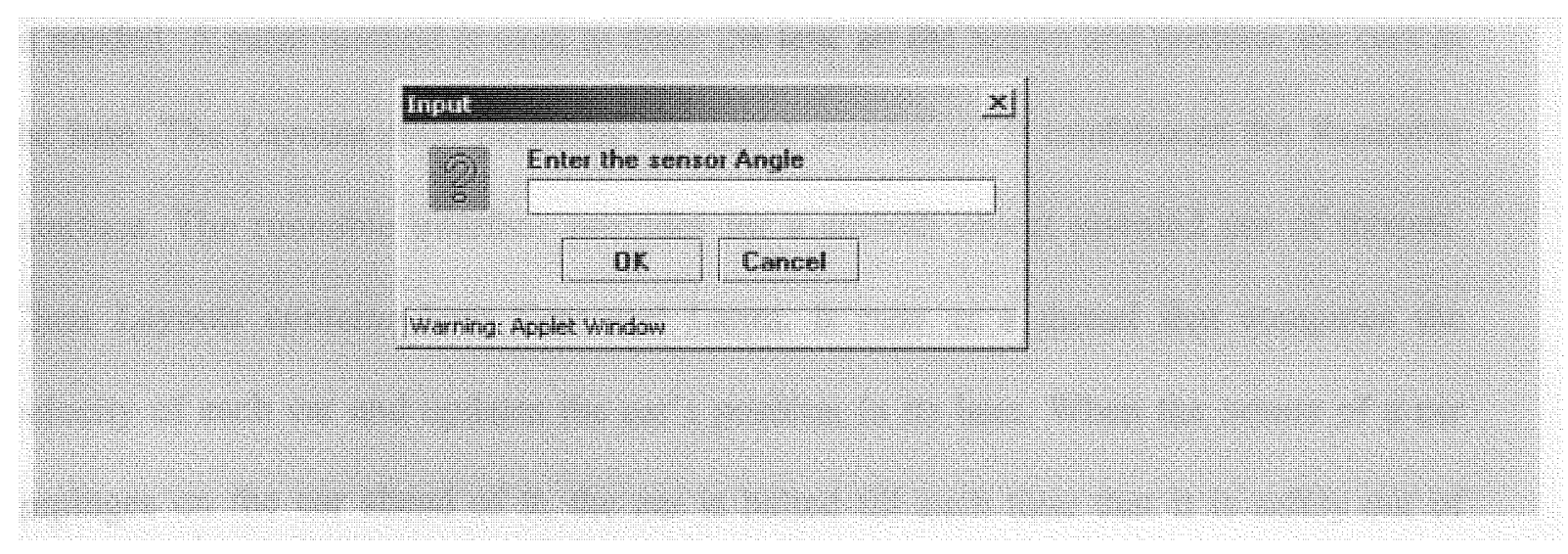

Figure 5-13. Simulation for Input of Sensor Angle 
This allows the user to easily test for different angles of the sensors. Thus, the package can be used for any sensor to detect the cars.

\subsubsection{Java Simulation Program Explanation}

The program is completely written in Java. The output is shown in Figures 5-135-15. The program import statements like import-predefined Java packages. There are three classes used in the simulation. Each of the classes is a subclass of the applet class. The event package is used to implement threads and timers to synchronize the running of the threads. The swing package is used to provide a quick and easy interface for user input. Class Car defines the object car. The length and width, position, lane and the angle of the sensor on the car are the main properties of the object car. The methods used are constructors, methods to set the position and lane as well as a method to paint the car on the screen. Class Lane defines the object lane. The properties of the lane are its width and the number of cars on it. A lane can contain several car objects. The methods that the class uses are methods to set cars in specific lanes and to update their position in the lanes as needed. A paint method is used to draw the lane on the screen and position the cars in the lane. The Layouts class performs the actual simulation. It implements the Runnable interface. The runnable interface provides for a smooth object oriented use of threads. Class Layouts contains both Cars and Lanes. It runs as a thread that computes the velocity of each car and updates the car's position in its lane. When the sensor of a car impinges on the car ahead of it, the car is halted till such time that it is safely out of collision range of the car in front. In the program the speed of each car is randomly assigned and adjusted later by RECAS as needed to avoid the collisions. 
As illustrated in Figure 5-14, the sensors scan the cars; these sensors are mounted in the front. The system concentrates on objects in front of the vehicle. The sensor mounted in the front of the car continuously scans the objects in the front and when an unsafe distance is detected then it automatically activates the auto braking or issues a warning to the driver to slow down the car, as shown in Figure 5-15.

\section{Simulation of Rear-End Collision Avoidance System \\ Robotics and Automation Laboratory \\ Florida International University, Mami, Florida.}

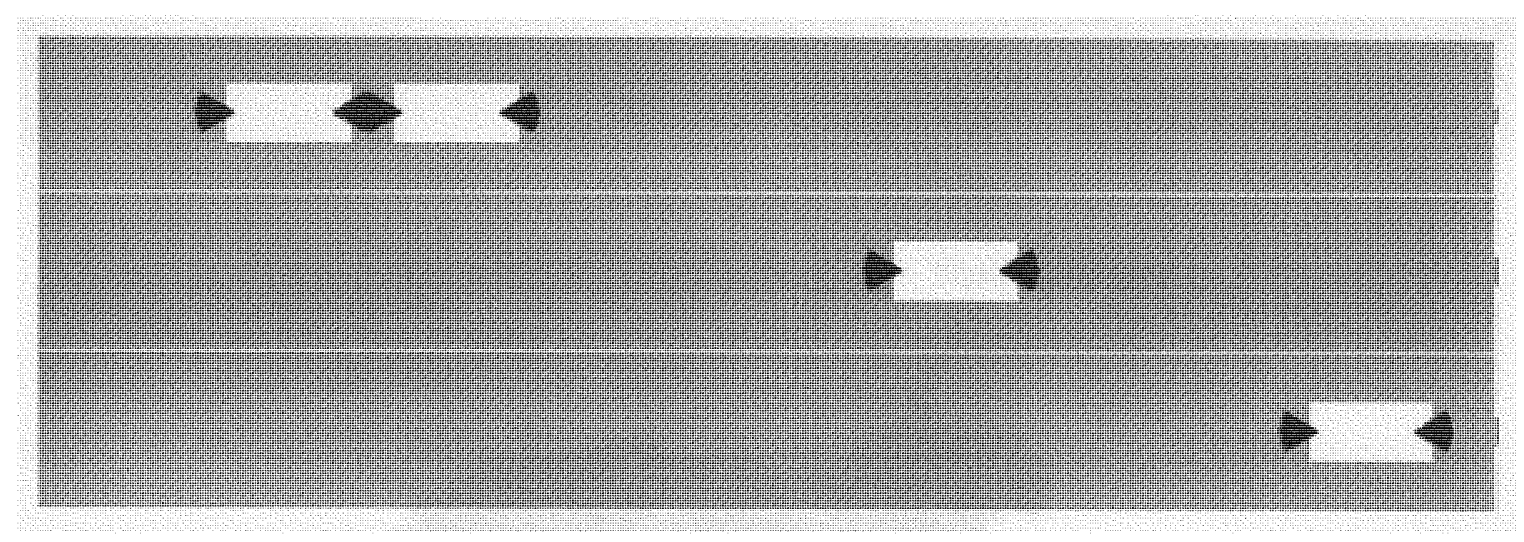

Figure 5-14. Sensor Scans the Preceding Vehicle

When the unit measures an unsafe following distance or an unsafe change in relative velocity a warning is issued. In an emergency situation the system automatically reduces the speed of the vehicle. The application of the different sensors is shown Figure $5-15$. 


\section{Simulation of Rear-End Collision Avoidance System}

Robotics and Automation Laboratory

Florida Intematonal University, Miamu, Flarida

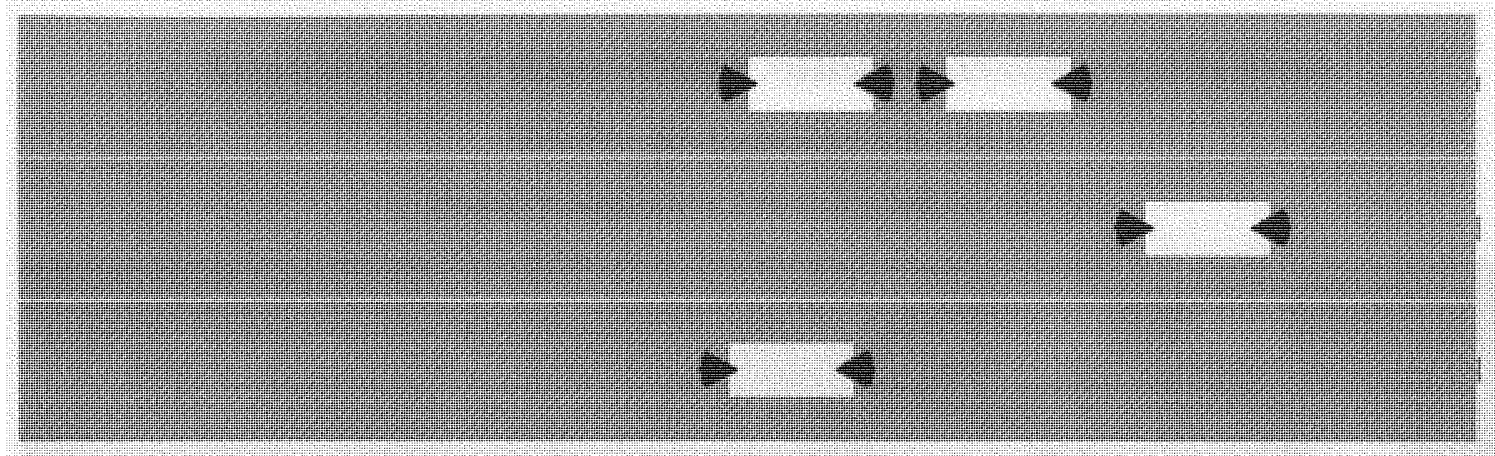

Figure 5-15. Demonstration of the Auto Braking System

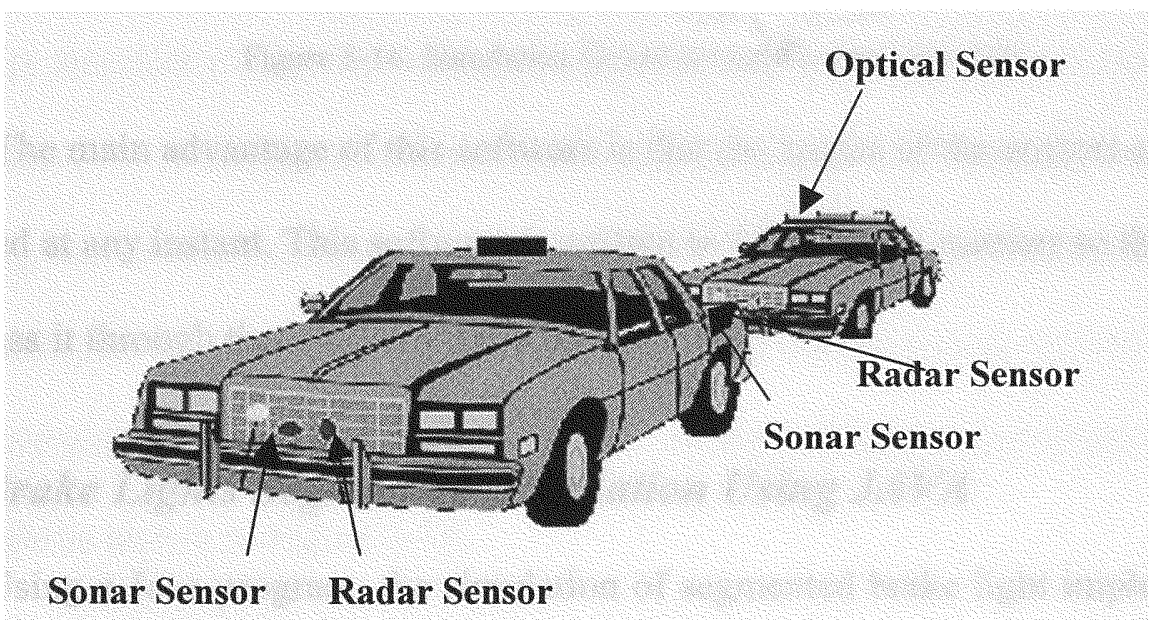

Figure 5-15. Practical Application Different Sensors Mounted on the Cars [68]

The sensors with different angles, which were discussed in detail in Chapter 4, are implemented in the software before implementation on the real cars. For scanning angles of 180 degrees refer to Figure 5-16. The field coverage for these sensors is higher than the 
field coverage for scanning angles of 90 degrees as in shown in Figure 5-14. The higher the field coverage the more the number of vehicles detected.

\section{Simulation of Rear-End Collision Avoidance System}

Robotics and Automation Laboratory

Florida International University, Miami, Florida.

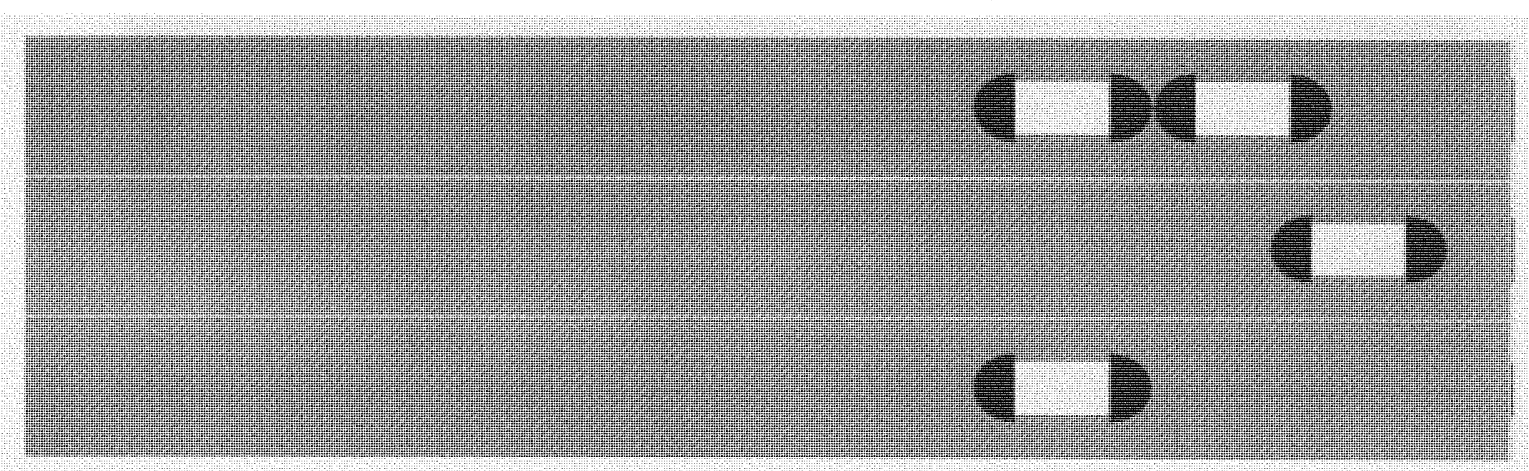

Figure 5-16. Simulation Demonstrates for the Angle 180

The main advantage of this software is that the angles of the sensors can be compared at any instant. This software is written in the simplest manner so that all users can access it through the World Wide Web.

\subsection{Brake Lights Segmented Simulation Using JAVA}

Using a Java program, the simulation of segmented brake light implementation is also demonstrated. This simulation shows the communication between the two vehicles. The communication is accomplished through the use of segmented brake lights. 


\section{Simulation of Rear-End Collision Avoidance System \\ Robotics and Automation Laboratory \\ Florida International University, Miami, Florida.}

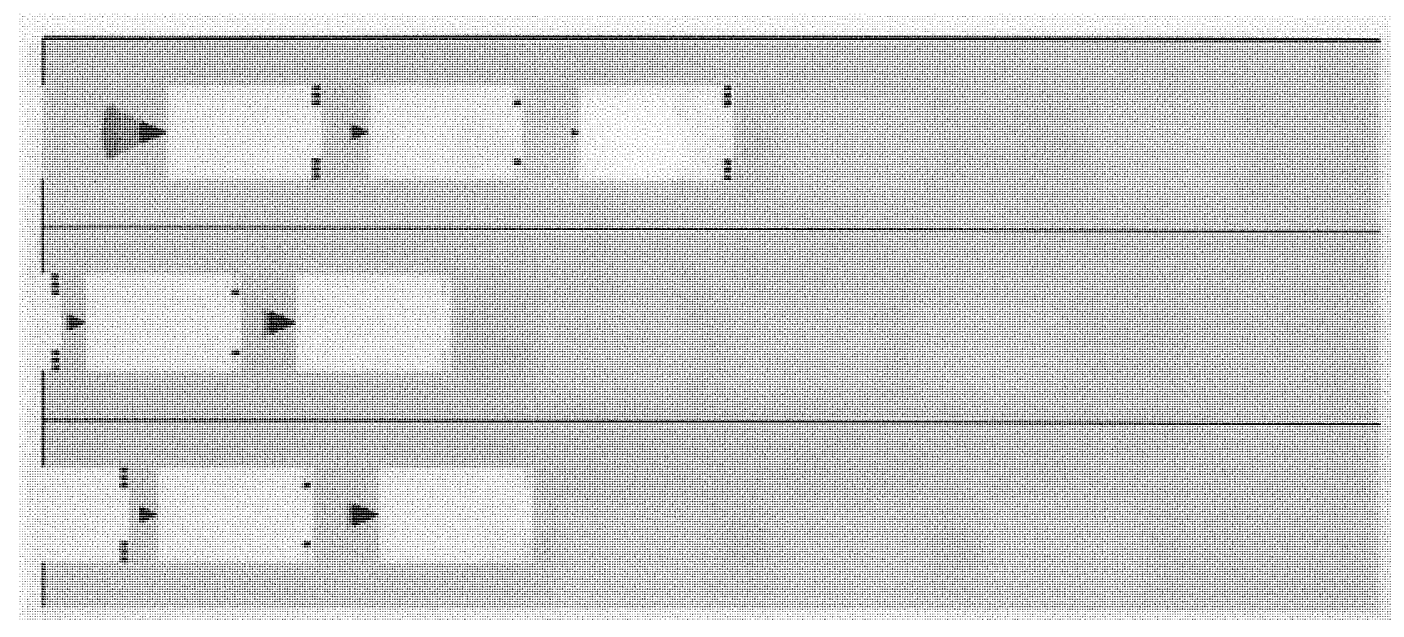

Figure 5-17. Simulation of Segmented Brake Lights

This simulation is purely a communications tool rather than intervening on behalf of the driver. It is designed to warn following drivers of the stopping intensity of the preceding car. In these simulations, it has three levels of warning systems are utilized as shown in Figure 5-17. The sensors have three intensity levels: green, yellow, and red. The first (inner most) segment and third brake light on the car is activated when it touches the green light as shown in Figure 5-18. 


\section{Simulation of Rear-End Collision Avoidance System \\ Robotics and Automation Laboratory \\ Florida International University, Miami, Florida.}

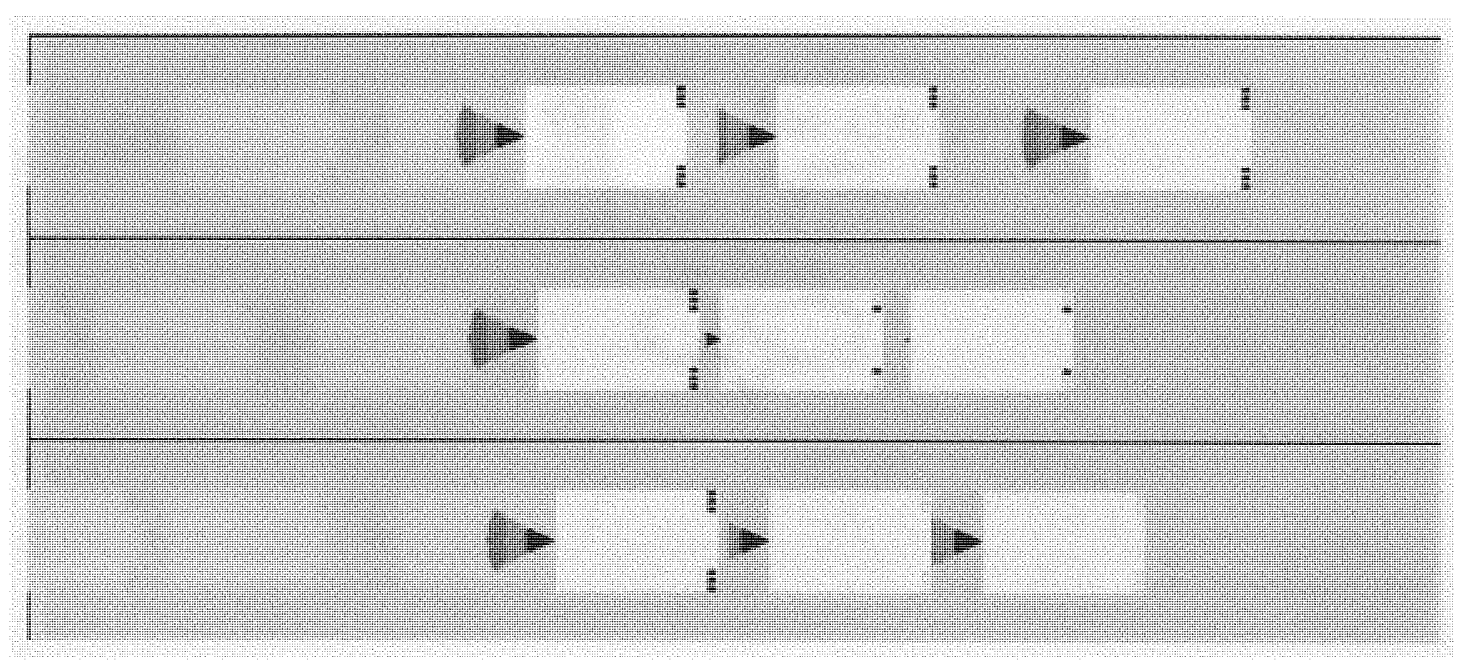

Figure 5-18. Intensity Level of Stopping the Vehicle

The outer two light segments are activated when the preceding vehicle is the orange sensor range. All the lights are activated when the preceding vehicle is the red sensor range. The intensity of the brake lights is directly proportional to distance between the two cars as shown in Figure 5-19. The complete Java program code is presented in Appendix B. 


\section{Simulation of Rear-End Collision Avoidance System}

Robotics and Automation Laboratory

Florida International Uniyersity, Miam, Fonida.

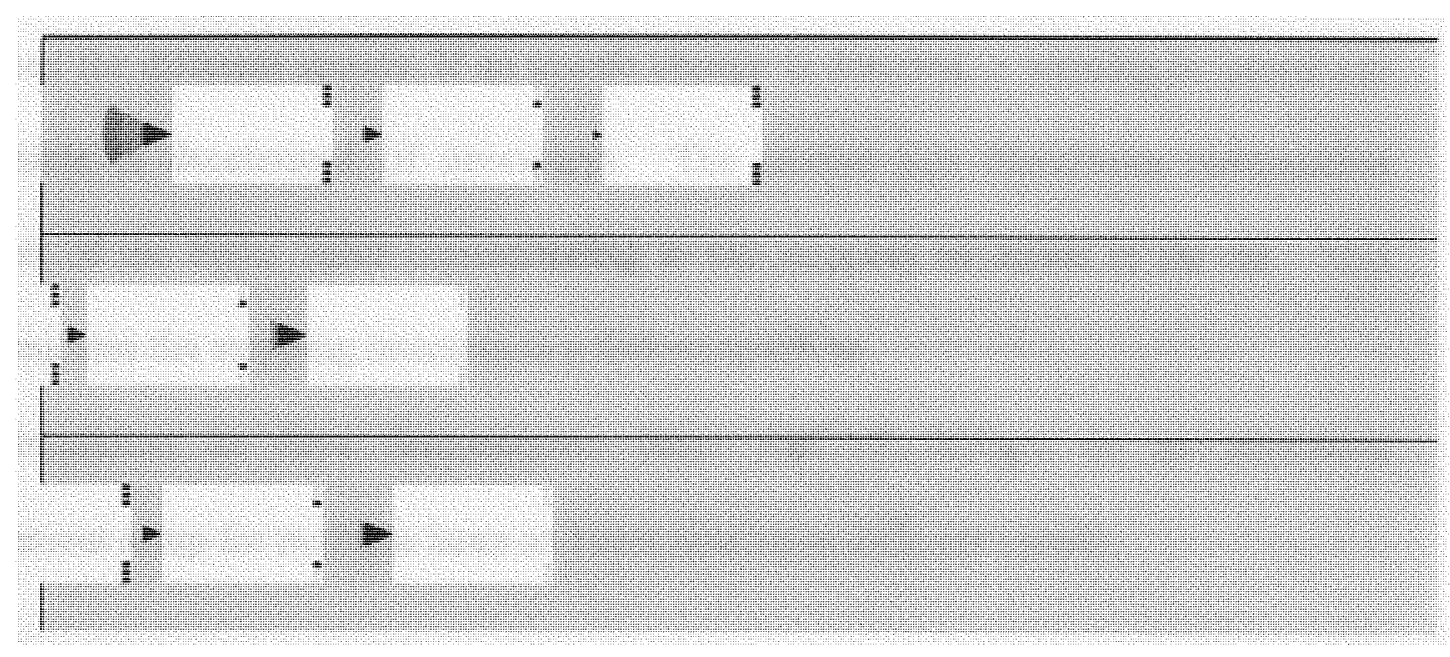

Figure 5-18. When the Preceding Vehicle is Orange and Red sensor Range

\subsubsection{Java Simulation Program Explanation}

Java program enhances the previous simulation program. The output of the programs is shown in Figures 5-16 through 5-18. In this program, four classes are used. All the classes subclass the applet class. The event, graphics, swings package, and applet packages is used in the program. When the sensors of a car impinges on the car ahead of it, the car's speed is reduced until such time that it is safely out of collision range of the car in front. The program illustrates the implementation of RECAS on multiple lanes and multiple cars avoiding possible collisions.

\subsection{Summary}

In this chapter, two features are proposed, the RECAS are simulated using Java program which is also provides access through the World Wide Web. The system is 
designed to enhance driver communication and awareness using LabVIEW (Graphical programming Language). The first part monitors the distance and speed of the car ahead, and the brake pressure required to activate the auto braking system of the vehicle is computed for different speeds. If an unsafe change is detected, a warning is issued and the vehicle is decelerated (if necessary). The second part illuminates independent segments of the brake lights corresponding to the stopping condition of the car. This communicates the stopping intention to a following driver.

Simulation in Java demonstrates these RECAS features in an animation environment setup for multiple lanes and cars running at different speeds. 


\section{CHAPTER 6}

\section{CONCLUSIONS, RECOMMENDATIONS,}

\section{AND FUTURE WORK}

The development of Rear-End Collision Avoidance Systems is motivated by their potential for increased vehicle safety. Once achieved, this will not only save lives, but result in a considerable amount of financial gains as well. In order to develop the Rearend Collision Avoidance System it is stated that the most important difference from the old practice is the fact that new design approach attempts to completely avoid collision instead of minimizing the damage by over-designing cars. The system should perform well in a variety of driving conditions. The objective of the research is to incorporate advanced capabilities, user acceptance, and benefits of Rear-End Collision Avoidance Systems to the automobile designs. Also includes the technical performance of the systems and its components: sensors, processors, and driver interface or controls. The primary are reductions in the number of collisions and their associated injuries and costs.

\subsection{Conclusions}

In the RECAS development effort, the systems must be accepted by drivers, they must be useful and simultaneously, the cost of the vehicles should not increase. Chapter 2 
has reviewed some of the previous designs of the Rear-End Collision Avoidance Systems and the system outline of RECAS. Also, the international approach to this problem has been discussed.

In chapter 3 various types of Rear-End Crashes, behavioral and perceptual aspects of Rear-End Crashes (REC) such as driver attention, driver perception/decision/reaction time, display factors in REC Systems, and various conditions effecting RECAS for instance weather, gender etc. are reviewed. Systems that enhance driver performance essentially cut across the various crash types, and provide alternative approaches for reducing accident rates. Contributing factors in accidents are usually listed as reduced visibility, e.g., at night or in degraded weather conditions, and/or driver drowsiness.

In chapter 4, sensor technologies of Rear-End Collision Avoidance Systems are identified based on a literature search about the available products, prototypes, and experimental systems. Rear-End Collision Avoidance sensor technologies encompass microwave, millimeter-wave and near-infrared radars; ultrasonic transducers, chargecoupled device cameras operating in near-infrared and visible bands; passive infrared detectors; millimeter-wave imaging radar; and near-infrared communications. Vision at night and during inclement weather conditions is enhanced by systems that sense images that the driver does not normally perceive and converts them into visible forms for detection by the driver. Overall, these products sense objects in the near-field around the vehicle, process information with the aid of artificial intelligence, communicate with other vehicles and roadside devices, and deliver assistance to the driver through visual, audio, and tactile presentations, and through supplementary control. When a crash does 
occur, emergency help can be summoned to the site of the crash through a (manual or automated) collision notification transmission. Systems that incorporate collision detectors, Global Positioning System (GPS) position location receivers, and communications systems that provide increased safety.

In Chapter 5, the Rear-End Collision Avoidance System is simulated using Java program. The RECAS is designed to enhance driver communication and awareness using LabVIEW (Graphical programming Language). The first part monitors the distance and speed of the car ahead. And the required brake pressure is calculated required for different speeds. If an unsafe change is detected a warning is issued and the vehicle is decelerated if needed. The second part activates independent segments of brake lights corresponding to the stopping condition of the car. This communicates the stopping intention to the following driver.

In order to illustrate this system, a Java program was developed to simulate the response of the proposed RECAS in a multi-lane, multi-car highway environment. The Java simulation is an applet, which is easily accessed through the World Wide Web and also can be tested for different angles of the sensor. Sensor technologies of RECAS are identified based on a literature survey search about available products, prototypes, and experimental systems. The characteristics and capabilites of alternative sensor technologies are also describesd.

\subsection{Recommendations}

Although the goal of this work has been achieved, looking back at the work conducted, we can always identify areas where further improvement can be introduced. 
In the simulation should be enhanced more in the following areas:

- Number of lanes and cars can selected by the user

- Developing the simulation for curved roads

- Designing the auto-braking system

- Communication Systems

- Adaptive Cruise Control

- Construction of Prototype

Number of cars and lanes can be increased by the user: By increasing the number of cars and lanes, different traffic conditions can be generated so as to test RECAS effectively. Developing the simulation for curved roads: The simulation of RECAS for curved roads provides the help to test for different complex turning conditions on the road can be examined.

Designing the auto-braking system: The purpose of the automatic braking system would be to safely stop an automobile that was approaching an obstruction in an emergency conditions.

Communication Systems: An effective communication system should be designed without disturbing the driver attention.

Adaptive Cruise Control: An effect Adaptive Cruise Control Systems should be used so that sensor information to monitor vehicles ahead, and change cruise speed accordingly. 


\subsection{Future Work}

As for the future work, the problem with curved roads is that sensors can mistake a car running in the opposite direction, for a hazard on the lane where the RECAS equipped vehicle is. Completely simulating RECAS using Java for curved roads. In order to cope with the issues raised previously, more work is required in the eventual development of Rear End Collision Avoidance technology, which includes three major elements:

- Development Collision Avoidance Knowledge Database

- Development of vital research tools, including the National Advanced Driving Simulator (NADS)

- Examination of key human factors and system design issues Collision Avoidance Knowledge Base: The NHTSA research program has developed a safety-related database, which continues to be updated and enhanced. This database comprises the collective knowledge developed by the NHTSA collision avoidance research program. A substantial effort has to be accomplished in the research (statistical analysis and case studies) of the major causes of crashes and in the understanding of precrash factors, which contribute to the crash. This knowledge base provides the (causal analysis) background to identify crash mitigation approaches as well as the statistical basis for focusing NHTSA's program activities. The knowledge base also includes initial performance specifications, benefit estimates, and development and test guidelines for crash avoidance concepts and/or products. The NHTSA research program has also developed a base of knowledge of the human factors that affect traffic safety. This 
database comprises the collective knowledge obtained by agency research to date, and continues to be updated and enhanced.

National Advanced Driving Simulator (NADS): Simulators are considered essential to the efforts for understanding driver behavior and for testing of various situational, display, and control conditions rapidly without endangering the experimental subject. NHTSA is focusing on the development of a high fidelity, moving base simulator, to replicate the highway-driving scenario. This will be a national research facility for human-in-the-loop, real-time vehicle driving simulation. With this facility, researchers will be able to present the antecedent events of a likely crash situation and then study the responses of research subjects (drivers) as well as the vehicle. Within the simulator these events can be presented in a precise and repeatable manner, efficiently, while providing complete safety to the human subjects.

Examination of Key Human Factors and System Design Issues: Driver/human factors that can will likely impact a detailed rear-end crash prediction model. In order to develop a performance specification, which provides parameter requirements for collision intervention systems that affect driver/system reaction, a number of "unknown" issues must be addressed. Since it has been shown that driver attention is the leading causal factor in rear-end crashes, it is imperative that any type of collision intervention system orient the driver's attention to the forward vehicle. Furthermore, since following too closely is also a causal factor, it is important to increase the drivers situation awareness of the leading vehicle. 


\section{Future Research Projects on Collision Avoidance Systems (CAS)}

The development of a broad understanding of how advanced technology systems can be used to help avoid collisions on the nations highways. The approach to implementing this focus is to arrange projects by problem area. Each of the projects in the program provide specific input to improving the overall knowledge base and understanding, of systems that address one or more problem areas. The problem areas that are being addressed in the program are as listed below:

- Intersection Collision Avoidance

- Road Departure Avoidance

- Lane Change/Merge

- Heavy Vehicle Stability

- Drowsy Driver

- Driver Vision Enhancement

- Visibility Program Area

Intersection Collision Avoidance: This project requires a thorough analysis of intersection collision problem size and causal factor analysis. Based upon the results of the causal analysis activity, simulation routines should be utilized to evaluate the effectiveness of conceptual collision avoidance systems. Both in-vehicle systems, infrastructure-based systems, and hybrid vehicle/infrastructure systems are to be examined. Further efforts will involve the development of an intersection collision avoidance system test bed and the refinement of system specification, prior to development of prototype systems for test and evaluation. 
Road Departure Collision Avoidance Program Area: The performance specifications for road departure countermeasure systems have to be thoroughly examined. In addition, the project have to be developed into two prototype systems and a test bed vehicle for system test and evaluation. Sensor technologies to support detection of roadway or lane boundaries are to be examined while investigating potential approaches for prediction of imminent road departure.

Lane Change/Merge Collision Avoidance Program Area: This project needs to investigate the feasibility of equipping motor vehicles with countermeasure systems to assist drivers in safely carrying out lane change, merging, and backing maneuvers. The study should consider the effectiveness, reliability, costs, and implementation practicability of such systems. A preliminary performance specification as well as methodologies for estimating benefits of potential countermeasure systems has to be developed.

Heavy Vehicle Stability Enhancement System: Two countermeasures are identified by NHTSA to help reduce the incidence of heavy vehicle rollovers. The first is a Roll Stability Advisory System (RSA) that measures the rollover stability properties of a typical tractor-semitrailer as it is operated on the roadway and provides the driver with a graphical depiction of the vehicle's loading condition relative to it's rollover propensity.

The RSA is intended to assist drivers in maintaining safe speeds on curves. The second countermeasure is a Rearward Amplification Suppression System (RAMS) that employee an active brake control system coupled with Electronic Brake System (EBS) technology. This system can selectively apply brakes to wheels to stabilize the vehicle and thus 
reduce the incidence of rear trailer rollover in double- and triple-trailer combination vehicles during crash avoidance steering maneuvers [56].

Drowsy Driver: This project area is on the commercial trucking segment for four key reasons:

- The extensive night driving in commercial operations

- The need to minimize fatigue-related accidents among paid drivers

- The high cost of commercial vehicle accidents

- The relative affordability of such systems for high-value heavy trucks

Ultimately, drowsy driver monitor systems should be deployable at a lower cost in all passenger vehicles. Systems currently rely on sensing of two features of driver performance. One feature is lane-tracking maintenance, i.e., how well the vehicle stays within lane demarcations. The other is eye and eyelid movements. Additional indicators of driver performance include steering wheel motions, head movement, and lateral acceleration. The drowsy driver program should be oriented toward identifying effective combinations of detection devices, development of drowsiness detection algorithms, and selection of the best detection devices for implementation.

Driver Vision Enhancement: Driver vision enhancement systems help drivers when visibility is low by providing an augmented view of the forward scene. These systems fall into two broad categories:

- That depend upon natural or infrastructure-based illumination

- That depend on additional illumination from the vehicle 
Infrastructure-based systems use reflective materials on pavement marking, road signs, and other fixed roadside objects to provide an enhanced view of the driving environment. On the other hand, vehicle-based systems use a suite of sensors and equipment to improve the view of the driving scene through an in-vehicle display. Prototypes of driver vision enhancement systems exist and are currently being used to support a wide range of engineering tests and product development activities. Fundamental questions about the causal relationship between visibility and safety have not yet been answered. Moreover, key performance requirements and user acceptability of in-vehicle vision enhancement systems are not yet understood.

Visibility Program Area: Convex and multi-radius rearview mirrors provide drivers a wider field of view as compared to flat mirrors. However, the driver may experience greater difficulty judging the distance and approaching speed of vehicles due to the reduced image size. The objective of this research is to measure the relative differences in driver performance when using the standard (planar) driver-side rear-view mirror and selected non-planar mirror types. Studies include the use of laboratory driving simulators and data collection of drivers experiences in Europe where these mirrors have been used.

After the development of the above projects, standardization should be made due to the large degree of machine-driver interaction; several operational characteristics of CAS will need to be standardized across manufacturers. These characteristics include, for example, warning thresholds, sensor effective range, and area of coverage, type of warning, and type and strength of steering or braking intervention. 


\section{REFERENCES}

[1] P. Batsomboon, and S. Tosunoglu, "A review of teleoperation and telesensation systems," 1996 Florida Conference on Recent Advances in Robotics, Florida Atlantic University, Boca Raton, Florida, pp. 281-285, April 11-12, 1996.

[2] U. Dravidam and S. Tosunoglu, "A survey on automobile collision avoidance system," 1999 Florida Conference on Recent Advances in Robotics, Gainesville.

[3] A. Martin, H. Marini, and S. Tosunoglu, "Intelligent vehicle / highway system survey and practical application- part 1," 1999 Florida Conference on Recent Advances in Robotics, Gainesville.

[4] A. Martin, H. Marini, and S. Tosunoglu, "Intelligent vehicle / highway system survey and practical application- part 2," 1999 Florida Conference on Recent Advances in Robotics, Gainesville.

[5] R. L. French, "From Chinese Chariots to Smart Cars: 2000 Years of Vehicular Navigation," R. L French \& Associates, Fort Worth, Texas, Found in Navigation, Vol. 42, No. 1, pp. 235-258, Spring 1995.

[6] M Stanney, R. S. Kennedy, and W. Yurcik, University of Pittsburgh, "Computer and Telecommunications in the Year 2000 Virtual Environments Intelligent Transport Systems, "Proceedings of the Human Factors and Ergonomics Society," Volume 1, Human Factors and Ergonomics Society, Inc., Santa Monica, CA, USA. pp. 298-302, 1996. 
[7] M. R. Jackson, M. D. Galer-Flyte, and A.J. Grafton, "The Smart Seat Approach," Sensor Review, Vol. 16, No. 4, pp. 25-30,1996.

[8] R. Huston, W. B. Spillman, Jr., R. O. Claus, D. V. Ayra, and N. Zabaronick, "Vehicle classification by pattern matching gage sensors," Proceedings of SPIE - The International Society for Optical Engineering, pp. 239-250, 1996.

[9] H. M. Kim, and B. Ksko,"Fuzzy control for platoons of smart cars," IEEE International Conference on Fuzzy Systems, Vol. 3, IEEE, Piscataway, New Jersey, pp. 1632-1637, 1994.

[10] A. Puri, and P. Varaiya, "Driving safely in smart cars," Proceedings of the American Control Conference, Vol. 5, pp. 3597-3599, 1995.

[11] R. E. Munson, "Conformal antennas for smart cars," Proceedings of the IEEE Aerospace Applications Conference, IEEE Computer Society Press, Los Alamitos, California, pp. 325-332, 1994.

[12] H. J. Huijsing, "Sensors and Actuators Integrated Smart Sensors," Vol. 30, pp. 167174, 1-2 Jan, 1992.

[13] P. Nelson and P. Palacharla, "A neural network model for data fusion in ADVANCE (Advanced Driver and Vehicle Advisory Navigation Concept)," Proceedings of the ASCE International Conference on Applications of Advanced Technologies in Transportation Engineering, ASCE, New York, New York, pp. 237-293, 1993.

[14] V. Bianchi, R. D. Acqua, M. Marelli, and F. Rancis, "The role of sensors in future automotive applications," Vehicle Electronics in the 90's: Proceedings of the 
InternationalCongress on Transportation Electronics, IEEE, Dearborn, MI, USA, pp. $131-142,1990$.

[15] M. Fischetti, "Smart Cars and Smart Highways," Photonics Spectra Vol. 28, pp. 8, November 11, 1994.

[16] "Smart Cars Take the High-tech Road," Laser Focus World, Vol. 32 No. 6, pp. 5, June $6,1996$.

[17] "RFID Tags Connect Smart Cars to Smart Highways," EDN Vol. 39, No. 26, pp. 3336, December 22, 1994.

[18] "Network Vehicle Developed by IBM," Delco, Netscape, Sun Microsystems, IBM Website, 1998.

[19] S. Murata, "Effect of on board information display on driving," Toward An Intelligent Transport System, Proceedings of the First World Congress on Applications of Transport Telematics and Intelligent Vehicle Highway Systems, Vol. 4, November 30December 3, 1994.

[20] I. Catling, R. Harris, F. Ziderhand, P. Robinson, T. Biding and G. Riegelhuth, "The Socrates Projects: An overview of progress in the ATT Program," Toward An Intelligent Transport System Proceedings of the First World Congress on Applications of Transport Telematics and Intelligent Vehicle Highway Systems, Vol. 5, November 30-December 3, 1994.

[21] M. Schmidt, "Centrally determined route guidance (CDRG) goes commercial," Toward An Intelligent Transport System Proceedings of the First World Congress on 
Applications of Transport Telematics and Intelligent Vehicle Highway Systems, Vol. 5, November 30-December 3, 1994.

[22] S. Khardi, and M. Vallet, "Driver Vigilance - analysis of difference in vigilance states assessment by physiological and mechanical indicators," Toward an Intelligent Transport System Proceedings of the First World Congress on Applications of Transport Telematics and Intelligent Vehicle Highway Systems, Vol. 6, November 30December 3, 1994.

[23] S. Becker, M. Bork, H. P. Dorben, G. Geduld, O. Hofmann, K. Naab, G. Nocker, P. Rieth, and J. Sonaag, "Summary of experience with autonomous intelligent cruise control (AICC): Part I, Study Objectives and Methods," Toward an Intelligent Transport System Proceedings of the First World Congress on Applications of Transport Telematics and Intelligent Vehicle Highway Systems, Vol. 4, pp. 18281835, November 30-December 3, 1994.

[24] C. Lemarchand, and F. Coffin, "Conception method of man machine interface for an automotive vehicle transversal driving assistance system," Toward an Intelligent Transport System Proceedings of the First World Congress on Applications of Transport Telematics and Intelligent Vehicle Highway Systems,Vol. 4, pp. 1820-1819, November 30-December 3, 1994.

[25] A. Smiley, M. Vernet, G. Labiale, and A. Pavzie, "Navigation and Guidance Displays Impact on Driver Performance," Toward An Intelligent Transport System Proceedings of the First World Congress on Applications of Transport Telematics and Intelligent vehicle Highway Systems, Vol. 4, pp. 1852-1859, November 30-December 3, 1994. 
[26] “Crash Avoidance Research," NHTSA Research and Development Website, 1998.

[27] "Report to Congress on the National Highway Traffic Safety Administration ITS Program: Progress During 1992-1996 and Strategic Plan for 1997-2002," US Department of Transportation, January 1997.

[28] "Strategic Plan for Intelligent Vehicle-Highway Systems in the United States," Prepared by IVHS America, May 1992.

[29] "Implementation of the National Intelligent Transportation Systems," US Department of Transportation, Federal Highway Administration, Report to Congress Joint Program, Office for Intelligent Transportation Systems, May 1996.

[30] T. Agee, D. G. Smedley, and A. Sri, "Braking Analysis for Collision Avoidance Autonomous Braking System Performance Modeling and Benefits Analysis," National Highway Traffic Safety Administration, Office of Crash Avoidance Research, Washington, D.C., October 1995.

[31] S. Ashley, "Smart Cars and Automated Highways," Mechanical Engineering Magazine, pp. 58-62, May 1998.

[32] "Longitudinal Collision Avoidance Learning from the Evaluation and Analysis of Performance," Website, 1998.

[33] J. Gondak, "Vision Enhancement for Crash Avoidance," Published on the World Wide Web, (http://traffic.ce.gatech.edu/ce8103/userserv/user26.htm), 1999.

[34] Woll, Jerry D., "VORAD Collision Warning Radar," 1995 IEEE International Radar conference. 
[35] E. Lissel and H. Rohling, "77 GHz Sensor for Car Application," 1995 IEEE International Radar Conference.

[36] L. Erikson and B. Ås, "A High Performance Automotive Radar for Automatic AICC," 1995 IEEE Radar Conference.

[37] E. Lissel, Andreas, R. Bergholz and R. Holze, "Automatic Distance Regulation (ADR) - a New System for Driver Assistance in Future VW Vehicles," 1996 ImechE International Conference.

[38] E. Stewart, and L. Lauren, Bowler, "Road Testing of Wheel Slip Control Systems in the Laboratory," 1969 International Automotive Engineer Congress and Exposition.

[39] C. Drane, C. Rizos, "Positioning Systems in Intelligent Transportation Systems," Artech House, 1998.

[40] S. Elliott, "Wireless Communications for Intelligent Transportation Systems," Artech House, 1995.

[41] ERTICO, Editor, "Toward an Intelligent Transport System," Proceeding of the First World Congress on Applications of Transport Telematics and Intelligent VehicleHighway Systems, Vol. 1-6, Paris, France, December 1994.

[42] F. Fariborz, (Editor) "Intelligent Cars and Automated Highways System (AHS)," Proceeding of the First World Congress on Applications of Transport Telematics and Intelligent Vehicle-Highway Systems, Vol. 1-6, Paris, France, December 1994.

[43] U.S. Dept. of Transportation, National Highway Traffic Safety Administration, "Examination of Reduced Visibility Crashes and Potential IVHS Countermeasures Microform," pp. 663-678,1995. 
[44] R. Whelan, "Smart Highways, Smart Cars," Artech House, Boston-London 1995.

[45] U.S. Department of Transportation, National Highway Traffic Safety Administration, Saving People, "IVHS Countermeasures for Rear-End Collisions," Task (http://www.nhtsa.dot.gov), DOT HS 808 561, Interim Report, February, 1994, Volume I: Summary

[46] U.S. Department of Transportation, National Highway Traffic Safety Administration, "IVHS Countermeasures for Rear-End Collisions Task 1 Volume VI: Human Factors Studies," DOT HS 808565 Interim Report, February 1994.

[47] U.S. Department of Transportation, National Highway Traffic Safety Administration, "IVHS Countermeasures for Rear-End Collisions," Task 1, Volume IV: 1992 NASS CDS Case Analysis, DOT HS 808 564, Interim Report, February 1994.

[48] U.S. Department of Transportation, National Highway Traffic Safety Administration, "IVHS Countermeasures for Rear-End Collisions," Task 1, Volume VI, DOT HS 808 565, Interim Report, February 1994.

[49] U.S. Department of Transportation, National Highway Traffic Safety Administration, "IVHS Countermeasures for Rear-End Collisions," Task 1, Volume II: Statistical Analysis, DOT HS 808 582, Interim Report, February 1994.

[50] U.S. Department of Transportation, National Highway Traffic Safety Administration, "IVHS Countermeasures for Rear-End Collisions," Task 2-Functional Goals, DOT HS 808 513, Interim Report, May 1996. 
[51] U.S. Department of Transportation, National Highway Traffic Safety Administration, "IVHS Countermeasures for Rear-End Collisions," Task 3-Test Results, DOT HS 808 514, Interim Report, October 1996.

[52] R. Knipling, D. Hendricks, J. Koziol, J. Allan, L. Tijerinal, C. Wilson, "A front-end analysis of rear-end crashes," NHTSA, October 1991.

[53] H. Araki, K. Yamada, Y. Hiroshima, Toshio Ito Electronics Engineering Div. Daihatsu Motor Co., Ltd., "Development of Rear-end Collision Avoidance System," 1-1 Daihatsu-cho, Ikeda-city Osaka 563 Japan, October 1996.

[54] COMSIS, (in press, 1993). Preliminary Human Factors Guidelines for Crash Avoidance Warning Devices. NHTSA Project No, DTNH22-91-C-07004.

[55] G. Davis, N. Schweitzer,A Parosh, D.G Liebermann,Y.Aptor, "Measurement of the Minimum Reaction Time for Braking of Vehicles," Wingate Institute Technical Report. Israel, May 1990.

[56] T. Dingus, J.Antin, M. Hulse, "Some human factors design issues and recommendations for automobile navigation information systems," Transportation Research, October 1993.

[57] T. Dingus, J.Antin, M. Hulse, and W. Wierwille, "Attentional demand requirements of an automotive moving map navigation system," Transportation Research, December 1989.

[58] L.Evans, and R.Rothery, "Experimental Measurements of Perceptual Thresholds in Car-Following," Highway Research Board Meeting, January 1973. 
[59] E.R Hoffmann, "Note on Detection of Vehicle Velocity Changes," Human Factors, April, 139-141, 1966.

[60] R.G Mortimer, "Weber's Law and Rear-End Collisions," The Michigan Academician, pp. $99-105,1992$.

[61] C.J.Taylor, K.Jana, B.Robert, M.Jitendra, L.Hayes, "A Comparative Study of VisionBased Lateral Control Strategies for Autonomous Highway Driving,” The International Journal of robotics research, 442-453,1999.

[62] G.Theodore "Radar Sensors for Automotive Collision Warning and Avoidance," Synthetic Vision for Vehicle Guidance and Control, pp. 239-247, April 1995.

[63] N.Shinichi, C.Ka C, Y.J.William, Z.Wel, P.Levine, "Traffic Monitor Using Two Multiple-Beam Laser Radars," IEEE Conference on Intelligent Transportation Systems, pp. 342-365, November 1997.

[64] A.Madhu, G.Philip, M.Lawrence, "Laser Vibration Sensor," Applied Laser Radar Technology II, April 1995.

[65] S.Ron "Miniaturized, Multi-Beam, Solid-State Scanning Laser Radar in Automobile Collision Avoidance Sensors Systems," Applied Laser Radar Technology II, April 1995.

[66] M.Tistarelli, F.Guarnotta, D.Rizzieri, F.Tarocchi, "Application of Optical Flow for Automated Overtaking Control," IEEE Workshop on Applications of Computer Vision, pp. 105-112, December 1994.

[67] H.Roe and G.S. Hobson, "Improved Discrimination of Microwave Vehicle Profiles," IEEE MIT-S International Microwave Symposium, pp.75-81, November 1992. 
[68] Peter Seiler,Bongsob Song and J.Karl Hedrick, "Development of a Collision Avoidance System," In the Proceedings at Society of Automotive Engineers, pp. 98-104,December 1997.

[69] Ron Sargent, "Miniaturized, "Multi-Beam, Solid-State Scanning Laser Radar in Automobiles Collision Avoidance System," Proceedings of SPIE--the International Society for Optical Engineering, pp. 105-110, April 1995.

[70] P.Cremona, M.Kunert, F.castanie, "Parametric Spectrum Analysis for Target Charcterization," Proceedings of the Intelligent vehicles '94 Symposium, pp. 149-154, October 24-26,1994.

[71] R.A.Keith and O.Umit, "The Ohio State University Automated Highway System Demonstration Vehicle," SAE International Congress \& Exposition, pp. 117-125, December 1998.

[72] Z.Dinghai, Y.Shenghua and W.Chunche, "Structured-lighting Surface Sensor and its Calibration," Optical Engineering: The Journal of the Society Photo-Optical Instrumentation Engineers," pp. 3040-3043, Vol 10, California, November 1995.

[73] F.Jahard, D.A. Fish, A.A.Rio and C.P.Thomson, "Far/Near Infrared Adapted PyramidBased Fusion for Automotive Night Vision," Institution of Electrical Engineers, pp. 886-890,January 1997.

[74] T.Shoichi, A.masahira, B.William, "Development of a Scan Laser Radar," Intelligent transportation systems, pp.27-32, November 1997. 
[75] P.W.Kenneth, J.L Jones and W.F.Thomas "Solid State Sensing Techniques for Automotive Aftermarket Emissions Analysis," Intelligent transportation systems, pp. 221-231, November 1997.

[76] D.B. Maciuca, J.C. Gerdes, J.K. Hedrick, "Automatic Braking Control for IVHS," Proceedings of the International Symposium on Advanced Vehicle Control (AVEC 1994), Tsukuba, Japan, 1994.

[77] N.G.Wassim, "Comparaison of Alternative Crash Avoidance Sensor Technologies," Proceedings of SPIE- the international Society for optical Engineering, V.2344, pp.6271, November 1994.

[78] W.B.Terry, B.Walker, M.V.Dan, and D.A.Tom, "Forward-Looking Collision Warning System Performance Guidelines," Intelligent transportation systems, pp 119-143, 1997.

[79] L.Hamm, F.de.Charaentenay, B.Hoffliner and D.Reister, "Improved Driver Information and Driver Assistanceby Prometheus Systems," The promise of new technology in the automotive industry, Torino, Italy, pp. 485-495, May 1990

[80] A.G Stove, "80GHz Car Obstacle Detection Radar," Institution of Electrical Engineers, pp. 6-10, April 1996.

[81] Olson, P.L., and Sivak, M., (1986), "Perception-Response Time to Unexpected Roadway Hazards," Human Factors, Vol 28(1), 91-96.

[82] Olson, P., Wachsler, P., and Bauer, H., (1961), "Driver Judgment of Relative Car Velocity," Journal of Applied Psychology, 45, No. 3, 16 1- 164.

[82] Olsen, P.L. (1989), "Driver Perception Response Time," SAE Report No. 890731. 
[83] Lister, R.D, "The Reaction Time of Drivers in Moving and Stationary Vehicles," Road Research Laboratory, Great Britain, RN/1324/RDL, 1950.

[84] Davis, J., and Schmandt, C. (1989), "The back seat driver: Real-time spoken driving instructions," In Vehicle Navigation and Information Systems Conference Proceedings.

[85] Evans, L., (1992), "Traffic Safety and the Driver," Intelligent transportation systems, July 1998.

[86] Laura L, Rogers C, "SAMS Teach Yourself Java 2 in 21 Days," Edition July 1998.

[87] Daniel J. Berg, J. Steven Fritzinger, "Advanced Techniques for Java Developers," Published 1998. 


\section{APPENDIX}

- SIMULATION COMPUTER PROGRAM IN JAVA

- BRAKE LIGHTS SEGMENTED SIMULATION COMPUTER PROGRAM IN JAVA 


\section{APPENDIX A:}

\section{SIMULATION COMPUTER PROGRAM IN JAVA}

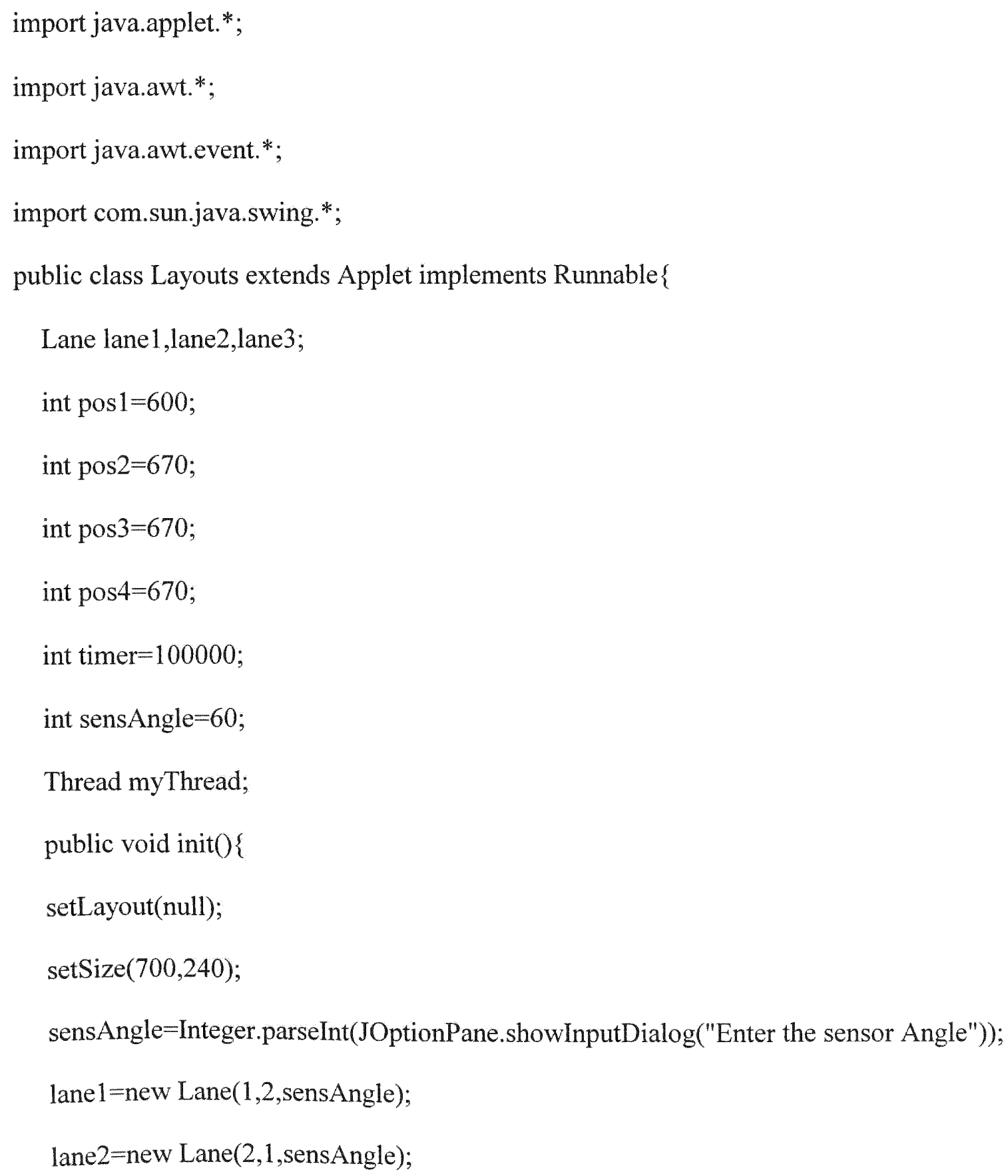


lane3=new Lane $(3,1$,sensAngle);

lane1.setCarPos(pos1,1);

lane1.setCarPos(pos4,2);

lane2.setCarPos(pos2);

lane3.setCarPos(pos3);

myThread=new Thread(this);

myThread.start();

\}

public void run()

while $($ timer $>0)\{$

try \{

Thread.sleep(500);

$$
\begin{aligned}
& \operatorname{pos} 1=20 \\
& \operatorname{pos} 2=10 \\
& \operatorname{pos} 3=30 \\
& \operatorname{pos} 4-=25 ; \\
& \text { timer }=500
\end{aligned}
$$

if $(\operatorname{pos} 1<0) \operatorname{pos} 1=670$;

if $(\operatorname{pos} 2<0) \operatorname{pos} 2=670$;

if $(\operatorname{pos} 3<0) \operatorname{pos} 3=670$;

if $(\operatorname{pos} 4<0) \operatorname{pos} 4=670$;

lane1.setCarPos(pos1); 


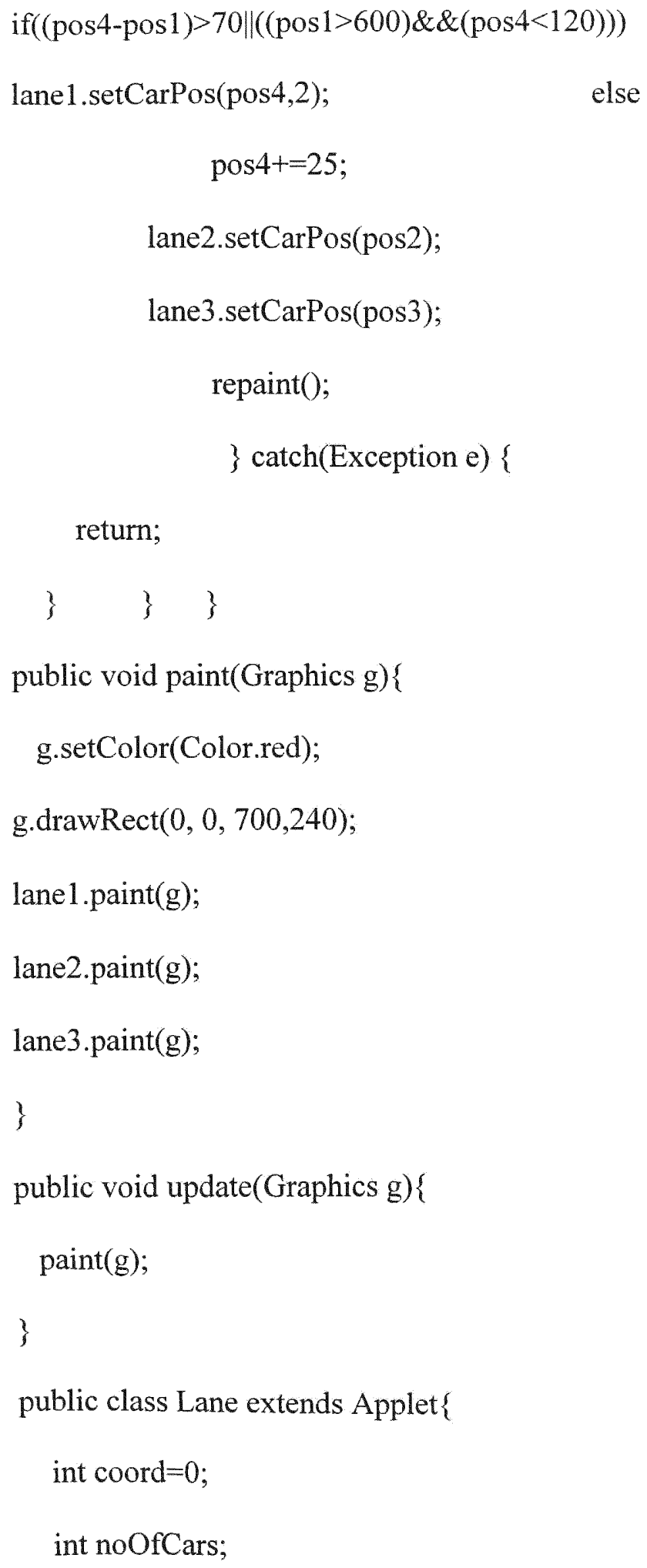


int sensAngle $=60$;

Car car[];

public Lane(int 1) \{

noOfCars $=1$;

coord $=(1-1) * 12+1$

car= new Car[noOfCars];

initCars(car,noOfCars,coord,sensAngle);

\}

public Lane(int l,int cars,int s) \{

noOfCars $=$ cars;

sensAngle=s;

coord $=(1-1) * 80+1$

car $=$ new $\operatorname{Car}[$ noOfCars $]$;

initCars(car,noOfCars,coord,sensAngle);

\}

void initCars(Car cars[],int noCars, int c,int s) \{

for (int $\mathrm{z}=0 ; \mathrm{z}<$ noCars $\left.; \mathrm{z}^{++}\right)\{$

$\operatorname{car}[\mathrm{z}]=$ new $\operatorname{Car}(30,60, \mathrm{~s})$;

$\operatorname{car}[\mathrm{z}] \cdot \operatorname{setLane}(\mathrm{c}+25)$;

\} $\}$

void setCarPos(int pos) \{

$\operatorname{car}[0] \cdot \operatorname{setPos}(\operatorname{pos}) ; \quad$ \} 


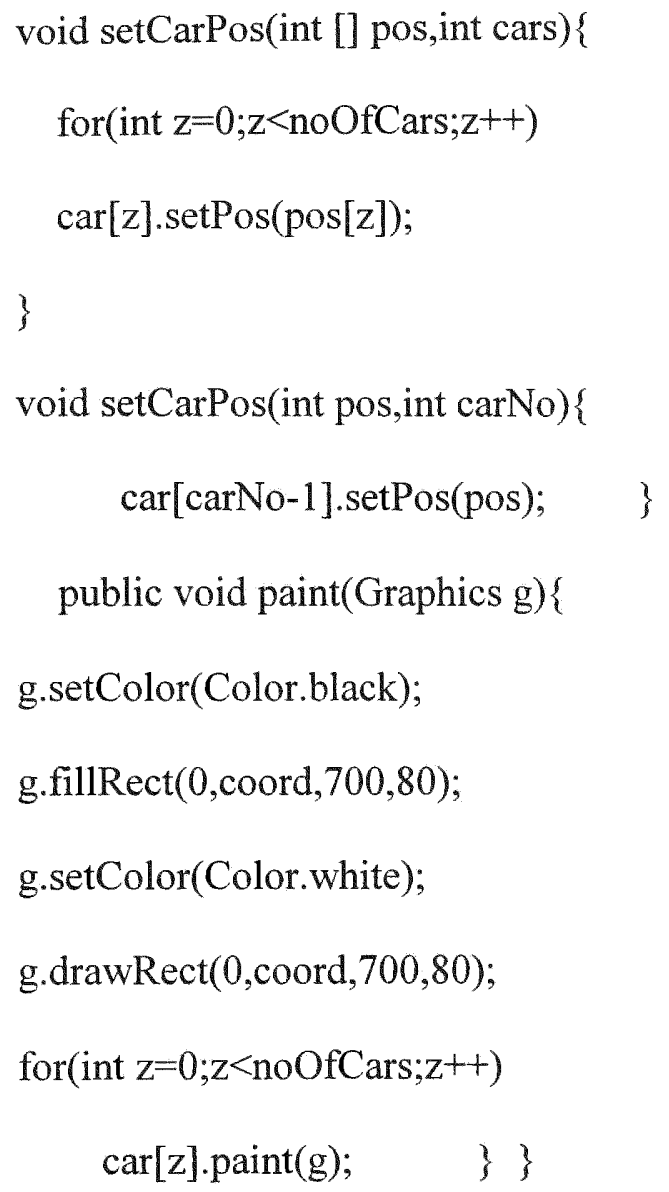

public class Car extends Applet\{

int carw,carl;

int fcarw,fcarl;

int position,lane;

int sensorAngle $=60$;

public CarO\}

carw $=6$; $\operatorname{carl}=12$;

fcarw $=8 ;$ farl $=24$;

position $=0$; 


$$
\begin{aligned}
& \text { lane }=0 ; \\
& \text { public Car(int w, int } 1, \text { int } \mathrm{s})\{ \\
& \text { carw }=\mathrm{w} ; \text { carl = } ; \\
& \text { fcarw }=8 ; \text { fcarl = 24; } \\
& \text { lane }=0 ; \\
& \text { position=0; } \\
& \text { sensorAngle }=\mathrm{s} ;
\end{aligned}
$$

void setPos(int $p)\{$

position=p; $\}$

void setLane(int 1) \{

$$
\text { lane=l; } \quad\}
$$

public void paint(Graphics g)\{

$$
\text { g.setColor(Color.red); }
$$

g.fillRect(position,lane,carl,carw);

g.setColor(Color.white);

g.fillArc(position-15,lane-5,40,40,180-sensorAngle/2, sensorAngle);

g.fillArc(position+30,lane-5,40,40,0-sensorAngle/2,sensorAngle);

\} \} \} 


\section{APPENDIX B:}

\section{BRAKE LIGHTS SEGMENTED SIMULATION \\ COMPUTER PROGRAM IN JAVA}

import java.applet.*;

import java.awt.*;

import java.awt.event.*;

import com.sun.java.swing.*;

public class Layouts extends Applet implements Runnable \{

Lane lane1,lane2,lane3;

int timer $=100000$;

int sensAngle $=60$;

Thread myThread;

public void init ()\{

String s=JOptionPane.showInputDialog("Enter the sensor Angle");

if (s!=null)sensAngle=Integer.parseInt(s);

lane1=new Lane( 1,3 ,sensAngle);

lane2=new Lane $(2,3$, sensAngle $) ;$

lane3=new Lane( 3,3 ,sensAngle);

lane1.setVelocity $(15,1)$; 
lane1.setVelocity (25,2);

lane1.setVelocity $(35,3)$;

lane2.setVelocity $(3,1)$;

lane2.setVelocity (11,2);

lane2.setVelocity( 19,3);

lane3.setVelocity $(5,1)$;

lane3.setVelocity( 18,2);

lane3.setVelocity( 27,3);

myThread=new Thread(this);

myThread.start();

$/ /\{\{$ INIT_CONTROLS

setLayout(null);

setSize(700,300);

$1 /\}\}\}$

public void run()

while $($ timer $>0)\{$

try \{

Thread.sleep(100);

lane1.velCarPos(1,1);

lane1.velCarPos $(1,2)$;

lane1.velCarPos(1,3);

lane2.velCarPos(1,1); 


$$
\begin{aligned}
& \text { lane2.velCarPos }(1,2) ; \\
& \text { lane2.velCarPos }(1,3) ; \\
& \text { lane3.velCarPos }(1,1) ; \\
& \text { lane3.velCarPos }(1,2) ; \\
& \text { lane3.velCarPos(1,3); } \\
& \text { lane1.setCloseness }() ; \\
& \text { lane2.setCloseness }() ; \\
& \text { lane3.setCloseness }() ;
\end{aligned}
$$

$$
\begin{aligned}
& \text { repaint }() ; \\
& \text { (catch(Exception e) }
\end{aligned}
$$

return;

$$
\text { \} \} }
$$

public void paint(Graphics g)\{

g.setColor(Color.red);

g.drawRect $(0,0,700,300)$;

lane1.paint(g);

lane2.paint(g);

lane3.paint(g);

$$
\text { \} }
$$

public void update(Graphics g)\{

lane1.update(g); 


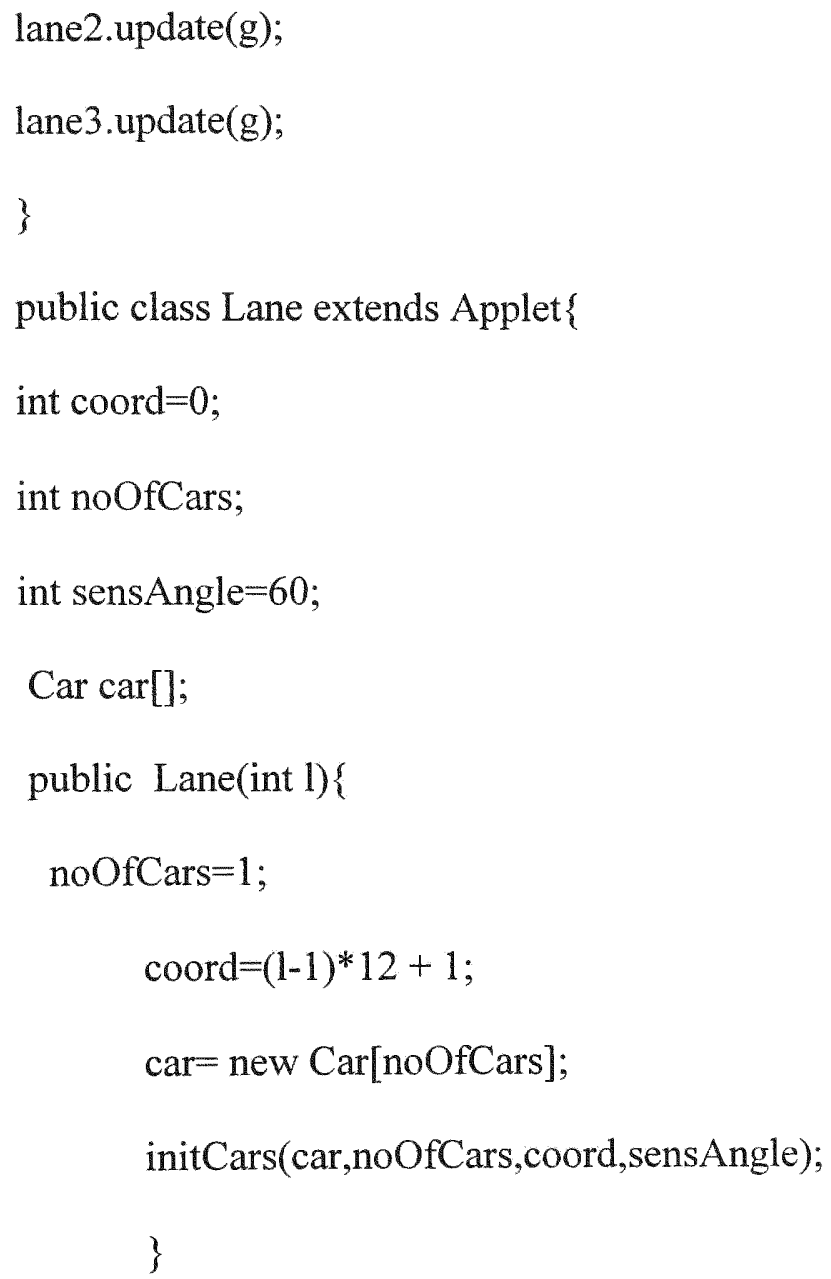




$$
\begin{aligned}
& \text { for }(\text { int } z=0 ; z<\text { noCars; } z++)\{ \\
& \operatorname{car}[z]=\text { new } \operatorname{Car}(50,80, s) ; \\
& \operatorname{car}[z] . \operatorname{setLane}(c+25) ; \\
& \operatorname{car}[z] . \operatorname{set} \operatorname{Pos}(620+z * 250) ;
\end{aligned}
$$

\})

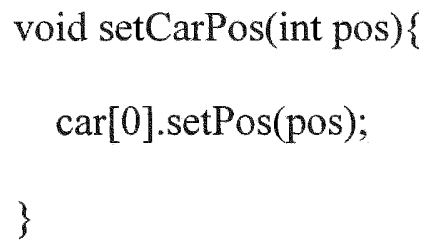


if (index[i]>105) $\operatorname{car}[\mathrm{i}] \cdot \operatorname{setClose}(0)$;

else if(index $[\mathrm{i}]<=105 \& \&$ index $[\mathrm{i}]>100) \operatorname{car}[\mathrm{i}] \cdot \operatorname{setClose}(1)$;

else if(index $[\mathrm{i}]<=100 \& \&$ index $[\mathrm{i}]>90) \operatorname{car}[\mathrm{i}] \cdot \operatorname{setClose}(2)$;

else if(index $[\mathrm{i}]<=90 \& \&$ index $[\mathrm{i}]>0) \operatorname{car}[\mathrm{i}] . \operatorname{setClose}(3)$;

else car[i].setClose $(0)$;

\} \}

void velCarPos(int time,int carNo)\{

int prevpos $=\operatorname{car}[\operatorname{carNo}-1]$.position;

int pos=prevpos $-\operatorname{car}[\mathrm{carNo}-1]$.velocity*time;

$\operatorname{car}[\operatorname{carNo}-1] . \operatorname{setPos}(\mathrm{pos})$;

if $($ car[carNo-1].position $<(-80))\{$

$\operatorname{car}[$ carNo-1].position $=620+($ carNo-1 $) * 250$;

3\}

public void paint(Graphics g)\{

g.setColor(Color.lightGray);

g.fillRect $(0$, coord, 700,100$)$;

g.setColor(Color.black);

g.drawRect $(0$, coord, 700,100$)$;

for (int $\mathrm{z}=0 ; \mathrm{z}<$ noOfCars; $\mathrm{z}++)$

$\operatorname{car}[\mathrm{z}] \cdot \operatorname{paint}(\mathrm{g})$;

\}

public void update(Graphics g) \{ 
for(int $z=0 ; z<$ noOfCars $;+++$ )

car[noOfCars-z-1].update(g);

\}\}

public class Car extends Applet\{

int carw,carl;

int position $=640$, prevpos, lane, close $=0$, velocity $=15$;

int sensorAngle $=60$;

public $\operatorname{Car}()\{$

$\operatorname{carw}=6 ; \operatorname{carl}=12$;

lane $=0$;

\}

public Car(int w, int 1 ,int s) \{

$\operatorname{carw}=\mathrm{w} ; \operatorname{carl}=1$;

lane $=0$;

sensorAngle=s;

\}

void setPos(int $\mathrm{p})\{$

prevpos=position;

position=p;

\} void setLane(int 1$)\{\quad$ lane=l; $\quad\}$

void setVelocity(int v)\{ velocity=v; \}

void setClose $($ int $\mathrm{c})\{\quad$ close $=\mathrm{c} ; \quad$ if $($ close $==3)$ position $=$ prevpos; $\}$ 
public void paint(Graphics g)\{ g.setColor(Color.white);

g.fillRect(position,lane,carl,carw);

g.setColor(Color.green);

g.fillArc(position-35, lane-5,50,60,180-sensorAngle/2, sensorAngle);

g.setColor(Color.orange);

g.fillArc(position-25, lane-5,40,60,180-(sensorAngle-20)/2,sensorAngle-

20);

g.setColor(Color.red);

g.fillArc(position-15,lane-5,30,60,180-(sensorAngle-40)/2, sensorAngle-

40);

if $($ close $==1)\{$ g.fillRect(position+carl-5, lane $+8,4,3)$;

g.fillRect(position+carl-5,lane+carw-11,4,3);

g.setColor(Color.yellow);

g.fillRect(position+carl-5, lane $+4,4,3$ );

g.fillRect(position+carl-5,lane+carw-7,4,3);

g.setColor(Color.yellow);

g.fillRect(position+carl-5,lane,4,3);

g.fillRect(position+carl-5,lane+carw-3,4,3);

\} else if $($ close $==2)\{$ g.fillRect $($ position + carl-5, lane $+8,4,3)$;

g.fillRect(position+carl-5,lane+carw-11,4,3);

g.setColor(Color.yellow);

g.fillRect(position+carl-5, lane $+4,4,3$ ); 
g.fillRect(position+carl-5, lane+carw-7,4,3);

g.fillRect(position+carl-5,lane,4,3);

g.fillRect(position+carl-5, lane+carw-3,4,3);

\} else if $($ close $==3)\{\quad$ g.setColor(Color.yellow);

g.fillRect(position+carl-5,lane,4,3);

g.fillRect(position+carl-5, lane+carw-3,4,3);

g.fillRect(position+carl-5,lane $+4,4,3$ );

g.fillRect(position+carl-5, lane+carw-7,4,3);

g.fillRect(position+carl-5, lane $+8,4,3$ );

g. fillRect(position+carl-5, lane+carw-11,4,3);

\} else \{ g.fillRect(position+carl-5,lane,4,3);

g.fillRect(position+carl-5, lane+carw-3,4,3);

g.fillRect(position+carl-5, lane $+4,4,3$ );

g.fillRect(position+carl-5,lane+carw-7,4,3);

g.fillRect(position+carl-5, lane $+8,4,3$ );

g.fillRect(position+carl-5,lane+carw-11,4,3); \}\}

public void update(Graphics g)\{

g.setColor(Color.lightGray);

g.fillRect(prevpos-35,lane,carl+35,carw);

paint $(\mathrm{g}) ; \quad\} \quad\} \quad / /\{$ DECLARE_CONTROLS $/ /\}\}\}$ 